\title{
YAEC-97
}

PROGRESS REPORTS

\section{QUARTERLY PROGRESS REPORT FOR THE PERIOD JULY 1 TO SEPTEMBER 30, 1958}

\author{
By \\ R. W. Garbe \\ H. E. Walchli
}

November 14,1958

Atomic Power Department

Westinghouse Electric Corporation

Pittsburgh, Pennsylvania

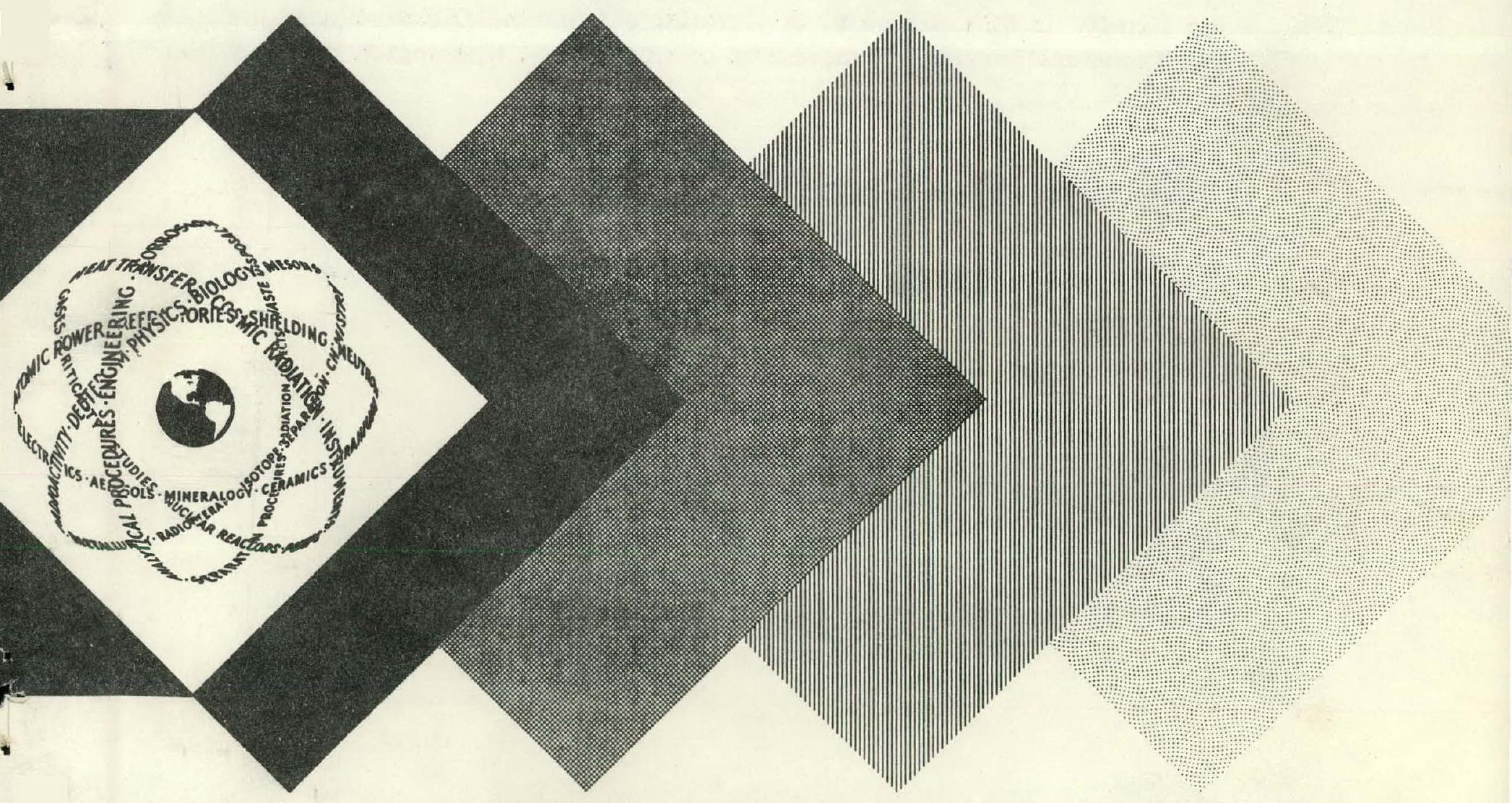

UNITED STATES ATOMIC ENERGY COMMISSION

Technical Information Service Extension, Oak Ridge, Tennessee 


\section{DISCLAIMER}

This report was prepared as an account of work sponsored by an agency of the United States Government. Neither the United States Government nor any agency Thereof, nor any of their employees, makes any warranty, express or implied, or assumes any legal liability or responsibility for the accuracy, completeness, or usefulness of any information, apparatus, product, or process disclosed, or represents that its use would not infringe privately owned rights. Reference herein to any specific commercial product, process, or service by trade name, trademark, manufacturer, or otherwise does not necessarily constitute or imply its endorsement, recommendation, or favoring by the United States Government or any agency thereof. The views and opinions of authors expressed herein do not necessarily state or reflect those of the United States Government or any agency thereof. 


\section{DISCLAIMER}

Portions of this document may be illegible in electronic image products. Images are produced from the best available original document. 


\section{LEGAL NOTICE}

This report was prepared as an account of Government sponsored work. Neither the United States, nor the Commission, nor any person acting on behalf of the Commission:

A. Makes any warranty or representation, express or implied, with respect to the accuracy, completeness, or usefulness of the information contained in this report, or that the use of any information, apparatus, method, or process disclosed in this report may not infringe privately owned rights; or

B. Assumes any liabilities with respect to the use of, or for damages resulting from the use of any information, apparatus, method, or process disclosed in this report.

As used in the above, "person acting on behalf of the Commission" includes any employee or contractor of the Commission to the extent that such employee or contractor prepares, handles or distributes, or provides access to, any information pursuant to his employment or contract with the Commission.

This report has been reproduced directly from the best available copy.

Printed in USA. Price \$2.50. Available from the Office of Technical Services, Department of Commerce, Washington 25, D. C.

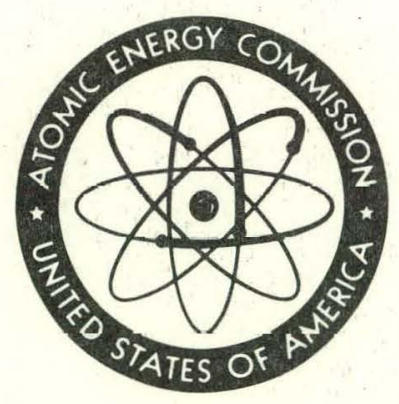


Yankèe Atomic Electric Company

\title{
Research And Development Program
}

\author{
QUARTERLY PROGRESS REPORT \\ for the period \\ July 1 to September 30, 1958 \\ by
}

R. W. Garbe

H. E. Walchli

Large Plant Engineering

For The Yankee Atomic Electric Company

Under Research and Development Subcontract.

No. 1 of USAEC-YAEC Contract AT(30-3)-222

November 14,1958

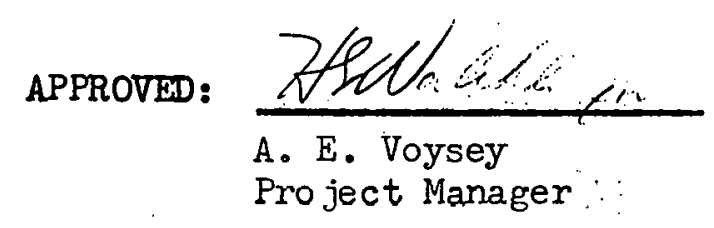




\section{PAGES 2 to 4 WERE INTENTIONALLY LEFT BLANK}


TABLE OF CONTENTS

PAGE

Abstract .. . . . . . . . . . . . . . . . . . . 7

Introduction .......................... 9

RESEARCH AND DEVELOPMENT PROJECTS

\subsection{FUEL ELEMENT DEVELOPMENT}

1.1 Uranium Dioxide Fuel Material Preparation . . . . . . . II

1.3.1 End Closure of Fuel Rods . . . . . . . . . . 24

1.3.2 Joining Fuel Bundles Into Assemblies .......... . 24

1.4 Fabrication and Analysis of Fuel Elements for Critical

Assembly and Irradiation Tests . . . . . . . . 32

2.0 NUCLEAR DESIGN AND REACTOR PHYSICS

2.I Core Design Optimization . . . . . . . . . . 36

2.2 Core Steady State Analysis . . . . . . . . . . . 36

2.3 Core Kinetic Analysis . . . . . . . . . . . . . . 41

2.4 Control Rod and Chemical Poison Aralysis . . . . . . 4 44

2.5 Critical Experiment Planning and Analysis ......... 47

2.6 Irradiation Experiment Design and Analysis . . . . . . . 51

2.7 Shielding Analysis ............... . . 52

2.8 Startup Experiment Assistance . . . . . . . . . 52

\subsection{CHEMISTRY}

3.1 Properties and Removal of Chemical Neutron Absorbers . . 53

3.3 Corrosion of Materials of Construction . . . . . . . . 55

3.4 Interactions Between Chemical Absorbers, Corrosion Products and Fission Products ...................... 63

3.5 Decontamination and Waste Disposal Studies ....... 64

3.6 Crud Inhibition, Suspension and Removal ......... 68

4.0 MECHANICAL DESIGN'

4.1 Fuel Assemblies and Control Rod Design . . . . . . . 70

4.2 Control Rod Drive Mechanisms . . . . . . . . . . . 73

4.3 Design of Core Support Structure and Fuel Handling Tools . 73

4.4 Dosign of Critical Experiment and Irradiation Tests . . . 74 
5.0 THERMAL AND HYDRAULIC DESIGN

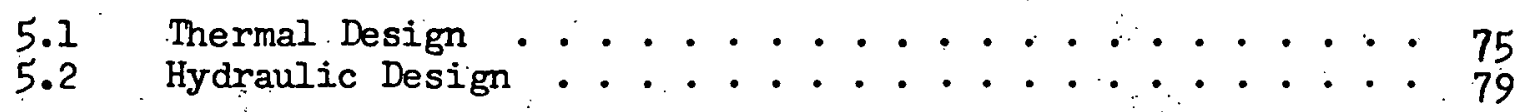

6.0 CONTROL ROD DEVELOPMENT

7.0 INSTRUMENTATION AND CONTROL

8.0 PLANT SYSTEMS DEVELOPMENT

8.5 Chemical Handling and Cóntrol Systems . . . . . . 82

8.11 Reactor Handling Tools and Plant Shielding Analysis . . . 82

9.0 PLANT SAFETY ANALYSIS . . . . . . . . . . . . . . 83 .

10.0 CRITICALITY EXPERIMENTS . . . . . . . . . . . . . . 83

11.0 RADIATION DAMAGE EXPERIMENTS

11.I Design and Fabrication of In-Pile Test Loop . . . . . . 96

11.2 Performance of Radiation Damage Experiments . . . . . . 100

APPENDIX

Section A

First Core Design Data . . . . . . . . . . . . . . . . . . . .

Section $\mathrm{B}$

Information Availability . . . . . . . . . . . . . 106

Section C

Abstracts of Trip Reports . . . . . . . . . . . . . 109 


\section{ABSTRACT}

This report contains a technical description of the research and development work accomplished and the progress made during the period from July 1 to September 30, 1958 (under the Research and Development Program as presented in YAEC Development Program Report YAEC-61 Revision-1 for the second half of 1958.) An evaluation and the resulting conclusions of work performed are given for each project in which definitive progress has been made.

The principle progress during the third quarter of 1958 consisted of:

1. Obtaining promising fuel fabrication results from production scale investigations of simplified. UO preparations methods, presintering operation elimination; increasing pellet densities and reductions of $\mathrm{UO}_{2}$ losses.

2. Successfully brazlng a ninety-five inch long experimental fuel subassembly in which all joints, including outside ferrules and control rod rubbing strips, had brazed filiets.

3. Completing the fabrication of the last group of MTR process water irradiation samples and all of the in-pile test loop samples except for the specimens containing $27 \%$ enriched pellets.

4. Performing a nuclear analysis of various fuel assembly designs as part of an overail evaluation of fuel assembly bowing in the Yankee reactor.

5. Completing corrosion studies of primary plant materials in static autoclaves to aid in the selection of a $\mathrm{pH}$ control agent.

6. Developing a "Compromise Design" for the fuel assembly which incorporates a series of small design changes to eliminate the possibility of restricting control rod motion by interference due to a superposition of bowing of the fuel assembly and an adverse accumulation of mechanical tolerances.

7. Completing the calculation of the following first core kinetic parameters: moderator temperature coefficient, the Doppler temperature coefficient, the vold coefficient, neutron lifetime and delayed neutron fraction.

8. Obtaining flux profiles, flux peaking, flux spectrum, peripheral fuel rod worth, void coefficient, temperature coefficient and control rod worth data from the Critical Reactor Experiments with a 3:I water-to-uranium metal ratio core at the Westinghouse Reactor Evaluation Center.

9. Continuing instrumentation and individual component operational testing of the in-pile test loop.

10. Analyzing the results of the post-irradiation examination of the second group of process water samples and delivery of the last group of samples to the MITR. 
Section-A of the Appendix contains the latest nuclear, mechanical and thermal design data for the first core. The studies and calculations performed under Projects 2.0, 4.0, and 5.0 during the third quarter of 1958 were responsible for the changes made in these data from the data presented in Quarterly Progress Report) YAEC-87 covering the second quarter of 1958.

Section-B, "Information Availability"; reviews the accessibility to the Westinghouse Atomic Power Department and the Yankee Atomic Electric Company of documents and reports pertaining to nuclear power reactors. The quantities. and types of reports and microfilms received by Westinghouse APD and YAEC during the third quarter of 1958 are also given in this section.

Section-C contains abstracts of trip reports written as a result of visits made by Westinghouse APD and YAEC personnel during the third quarter of 1958 to nuclear testing facilities, vendors' locations and installations of AEC contractors. 


\section{INTRODUCTION}

The Yankee Atomic Electric Company has contracted with the Westinghouse Atomic Power Department under Yankee Contract No. 1 of Contract AT(30-3)-222 between the U. S. Atomic Energy Comission and the Yankee Atomic Electric Company to perform the research and development work required to build a $134 \mathrm{MW}$ (net electrical output) pressurized light water nuclear reactor power plant using slightly enriched uranium dioxide ( $\left.\mathrm{JO}_{2}\right)$ fuel pellets contained in stainless steel tubes.

YAEC Development Program Report, YAEC-61, Revision 1, outlines the Research and Development Program for the period from July 1 to December 31, 1958. Quarterly Progress Reports, YAEC-7, YAEC-13 (Revision 1), YAEC-20, YAEC-35, YAEC-44, YAEC-52, YAEC-65 and YAEC-87 describe and evaluate the work accomplished from the beginning of the program, June 6, 1956 to June 30, 1958.

The basic objectives of the YAEC Research and Development Program are:

1. The carry out the development of stainless steel $\mathrm{UO}_{2}$ fuel rods to a point where successful operation of experimental elements in a test reactor has been demonstrated.

2. To improve the process of manufacturing sintered $\mathrm{UO}_{2}$ fuel pellets for the rod elements and, to reduce fuel preparation costs.

3. To select a proven material or to demonstrate the feasibility of a material suitable for use in control rods for a long-lifetime pressurized water reactor core.

4. To obtain through analysis and experiments a thorough understanding of the nuclear physics aspects of the proposed stainless steel $\mathrm{UO}_{2}$ pressurized water reactor.

5. To obtain an optimized preliminary design for a nuclear reactor and associated auxiliaries for a turbine electric power plant based upon the use of a stainless steel clad long-life core.

6. To determine the proper primary system materials, the required efficiency of the water purficiation system, the selection and use of a soluble neutron absorber and the minimizing of crud deposition through water chemistry analyses.

"Information Availability Report", YAEC-30 for the period from June 6, 1956 to September 30, 1957, and Quarterly Progress Reports, YAEC-44, YAEC-52, YAEC-65 and YAEC-87 for the third and fourth quarters of 1957 and the first and second quarters of 1958, covered the availability of information to, and the difficulties encountered by the Westinghouse Atomic Power Department and the Yankee Atomic Electric Company in their efforts to obtain documents and reports to further the success of the YAEC Research and Development Program. The five reports also included a section containing abstracts of trip reports made under the YAEC Research and Development Program.

A cut-away drawing of the positive engagement type control rod drive mechanism being procured under subproject 4.2 is shown on the following page. 


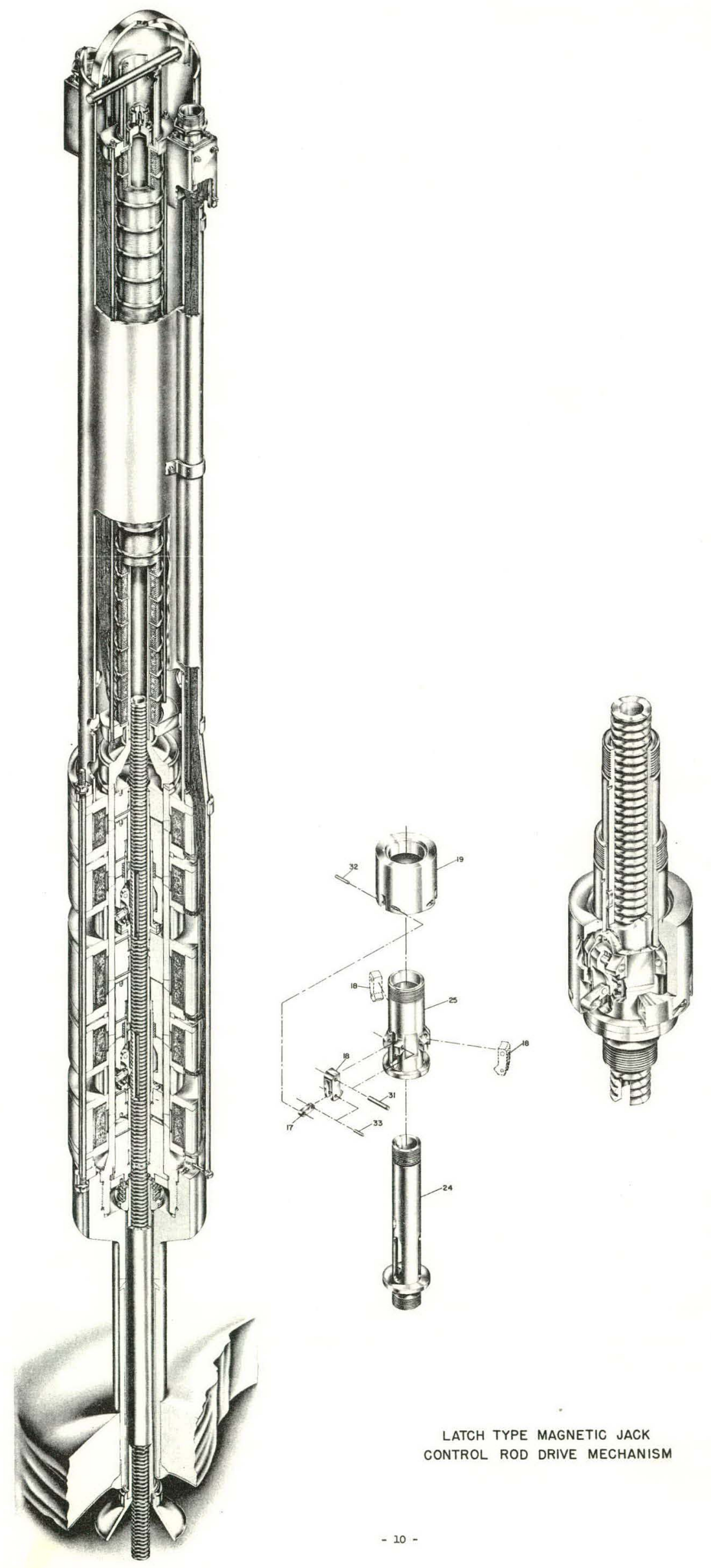




\subsection{FUEL ELEMENT DEVELOPMENT}

Chemistry and Ceramics Section:

Metallurgical section:
R. F. Sterling, Manager

R. K. McGeary, Manager

The work under this project is directed toward the development of a satisfactory stainless steel clad $\mathrm{UO}_{2}$ fuel element.

\subsection{Uranium Dioxide Fuel Material Preparation}

R. Winchell

Simplified Fuel Fabrication Procedures

The subcontract to investigate the following fabrication procedures on a production scale with production equipment at the Westinghouse Materials Manufacturing Department is approximately half completed. These fabrication procedures were first found practicable at (W) APD on a laboratory scale:

1. The simplification of $\mathrm{UO}_{2}$ preparation for pelletization

2. The elimination of the siow and costly presintering operation

3. The increasing of pellet densities to improve dimensional contrul

4. The reduction of $\mathrm{UO}_{2}$ losses through improved dimensional control

Results reported by the (W) MMD on the subcontract thus far include:

1. The development of a simpler, less expensive, method for preparing $\mathrm{UO}_{2}$ for pressing.

Formerly the $\mathrm{UO}_{2}$ powder required all of the operations listed in Column A in its ${ }^{2}$ preparation for pressing. On the two materials (i.e., two different samples of $\mathrm{UO}_{2}$ ) tried so far, every trlal by the procedure indicated in Colum $B$ produced satisfactory pellets.

\section{A (이)}

1. Ball mill 2 hrs., wet

2. Dry

3. Granulate

4. Mix in PVA

5. In another mixer, add $\mathrm{H}_{2} \mathrm{O}$

6. Dry partially

7. Granulate to - 8Mesh

8. Dry thoroughly

9. Granulate to - 20Mesh

10. Add Iubricant

\section{B}

(new)

1. Ball mill 2 hrs., wet, with l\% PVA $+2 \%$ Carbowax

2. Dry

3. Granulate to $=20 \mathrm{Mesh}$ 
2. Promising indications that the presintering operation can be eliminated.

On the two types of $\mathrm{UO}_{2}$ utilized on this subcontract thus far, elimination of presintering had no deleterious effect - in fact; hour glassing was less in non-presintered pellets. Larger. scale trials on pellets produced from the shorter material preparation procedure above - are to be conducted.

3. Data confirming that high sintering temperatures are much more effective than long sintering times in increasing pellet density.

Comparison of Figure-1 with Figure-2 shows that increasing the sintering temperature is.more effective in increasing pellet density than is increasing the time at temperature. Note that the reduced rate of change of density with time after about three hours implies that long hold times will reduce pellet density variations - the major cause of dimensional control problems. Note further that each powder has, for practical purposes, a maximum density it will achieve at each specific temperature - suggesting that density (and, therefore, dimensional) control can be achieved by employing the sintering temperature at which the specific powder supplied will be asymptotic within the density range specified for pellets.

Investigation indicates that the pellet density specification could be increased above $93 \pm 1.5 \%$ of the theoretical density, if only fresh $\mathrm{UO}_{2}$ were employed. However, economical recovery of scrap pellets requires their oxidation to. $\mathrm{U}_{3} \mathrm{O}_{2}$ powder and subsequent reduction to UO powder, a procedure which ${ }^{3}$ thus far does not yield powders which próduce high density pellets.

4. Powder differences from lot-to-lot manifest themselves in shrinkage variations which have prevented attempts to improve dimensional control, and thereby reduce $\mathrm{UO}_{2}$ losses.

The problem of UO powder variability is being investigated as described under Process Improvement Studies.

The remainder of the subcontract will concentrate on confirming the promising indications that raw material preparation and pellet sintering can be greatly simplified.

\section{Process Improvement Studies}

1. Non-Uniformity of $\mathrm{UO}_{2}$ Powder

Powder variations from vendor to vendor and even lot-to-lot in a single series from a single vendor have impeded development; as each lot must be pilot run to determine whether previously established fabrication parameters apply. 


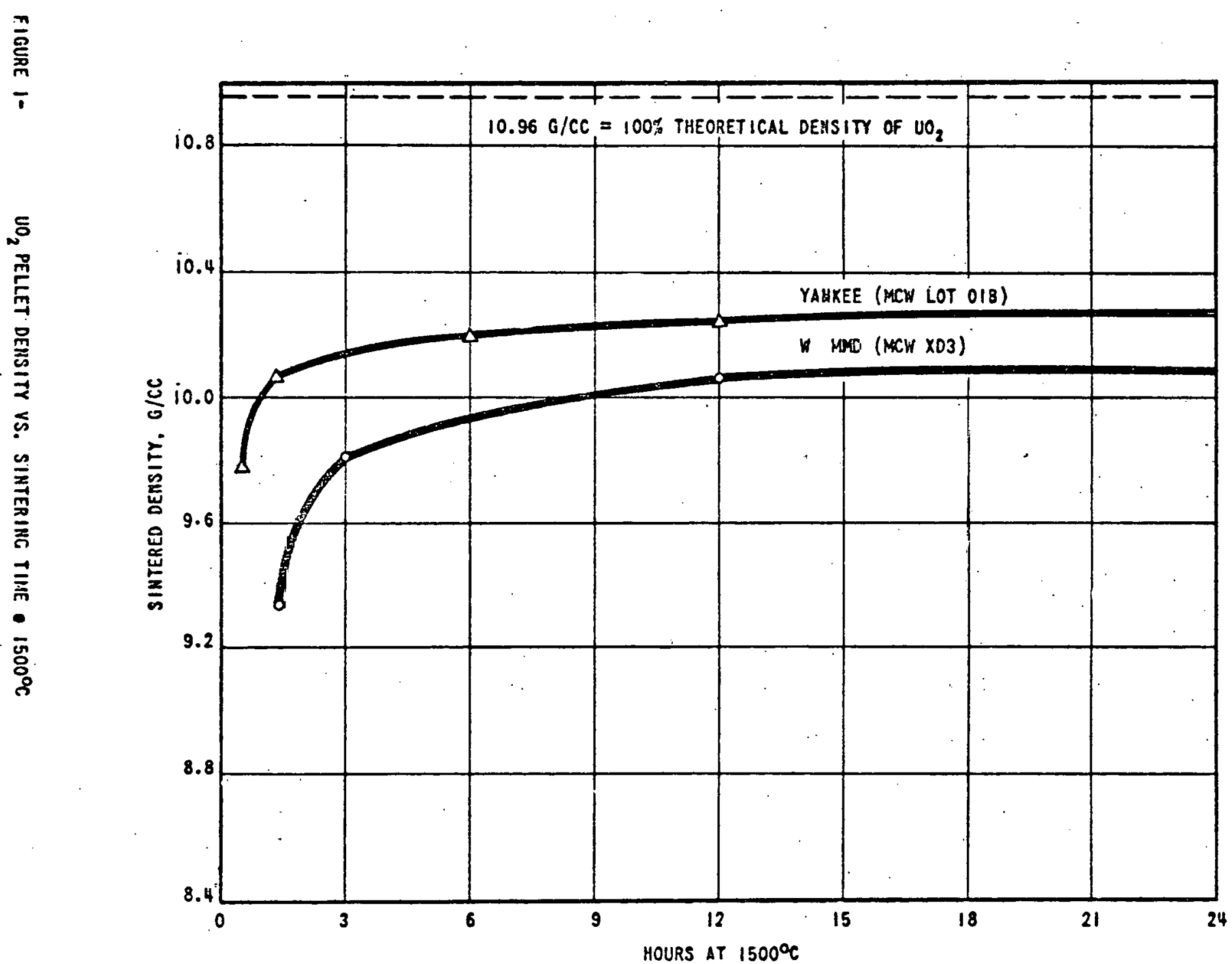




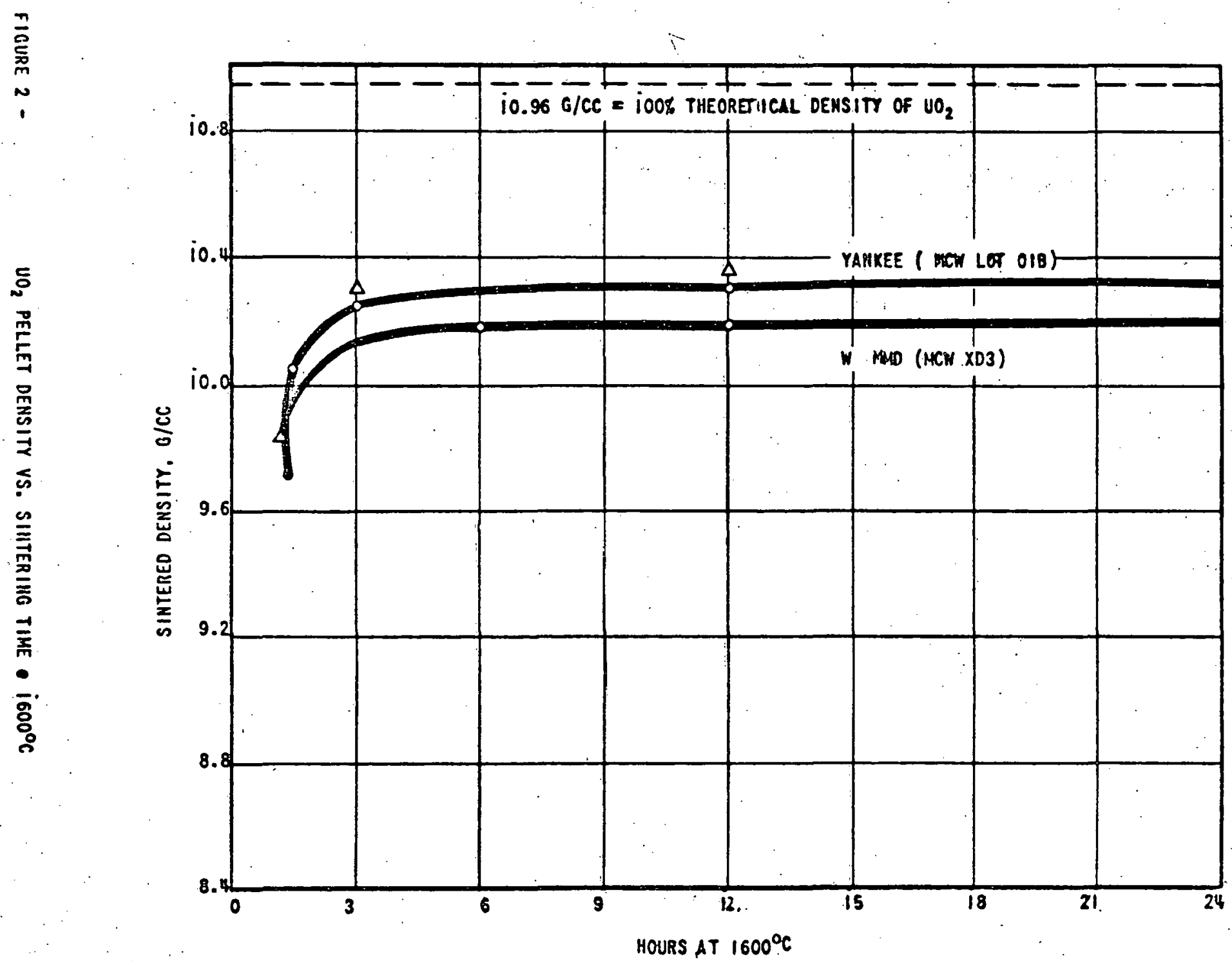


The presently existing powder specification is being refined and negotiations are in progress with powder suppliers to persuade them to guarantee reasonable uniformity by means of a performance requirement. Each supplier is asked to agree that his powder will always press to the green density the supplier stipulates (pressure may be varied), when prepared in some standard manner, and that these pellets when sintered under agreed upon conditions will always fall within a certain range of densities. Each supplier may choose his own conditions, but must meet those conditions with every lot, to assure the pelletizer of uniform raw material. In general, the suppliers are agreeable, but the specific values and procedures have not been developed.

2. Atmospheres and Additives to Enhance UO 2 Pellet Densification

In efforts to reduce sintering costs and improve density and dimensional control by lowering sintering temperatures, work was begun on steam sintering (replacing the normal furnace atmosphere of $\mathrm{H}_{2}$ with steam, above $1200 \mathrm{C}$. and the use of minor additives in improving densification. Steam sintering shows promise, but results are erratic, being not duplicable and sometimes showing decreased density with increased time or temperature. Similarly, the results with additives are inconsistent, and the pellets show a tendency to crack and to hourglass to an unusual degree. At present, it has not been determined whether the cracking and hour-glassing are mechanical (a result of material preparation or pressing) or compositional (related to the additives). The Spencer Chemical Company has supplied samples which are guaranteed to be duplicable and to sinter to $10.2 \mathrm{~g} / \mathrm{cc}$ (about $93 \%$ T.D.) at only $1250^{\circ} \mathrm{C}$. in 3 hours in hydrogen. Since the work with atmospheres and additives cannot be completed in time to reduce pellet cost's for the Yankee First Core, and the Spencer $\mathrm{UO}_{2}$ may accomplish the purpose, the work will be discontinued for this project, except for the testing of Spencer $\mathrm{UO}_{2}$ powders.

\section{a. Steam Sintering}

Typical results of steam sintering are shown in Table I and Figure 3. The reduction of powder batch HLOI density when sintering time is increased from two to three hours is attributed to experimental error.

\section{b. Additives}

Four different $\mathrm{UO}_{2}$ powders were ball-milled, each with an addition of $0.179 \% \mathrm{TiO}$, and $0.321 \% \mathrm{CaO}$, pelletized, and sintered, with the results shown in Table II.

3. "Hour-Glassing" Studies

An important reason for centerless grinding of pellets is the occurrence of "hour-glassing" (smaller diameter at the middle of the cylinder than at the ends) in unground pellets. To the unaided eye, 


\section{TABLE I}

\section{RESULTS OF STEAM SINTERING UO PELJETS}

Powder OLB

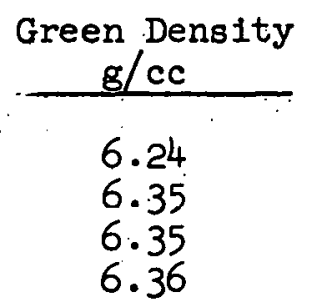

6.35

Powder HLOI

\begin{tabular}{|c|c|}
\hline $\begin{array}{c}\text { Green Density } \\
\mathrm{g} / \mathrm{cc} \\
\end{array}$ & $\begin{array}{c}\text { Tempèrature } \\
\mathrm{C} .\end{array}$ \\
\hline $\begin{array}{l}6.65 \\
6.62 \\
6.68 \\
6.65 \\
6.67\end{array}$ & $\begin{array}{l}1200 \\
1250 \\
1300 \\
1350 \\
1400\end{array}$ \\
\hline 6.65 & 1700 \\
\hline
\end{tabular}

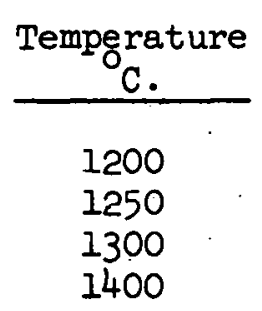

1500

1700

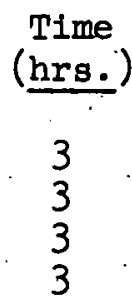

4

$\begin{array}{ccc}\begin{array}{c}\text { Time } \\ \text { (hrs:) }\end{array} & \begin{array}{c}\text { Steam Sintered } \\ \text { g/cc }\end{array} & \begin{array}{c}\text { Density } \\ \text { of T.D. }\end{array} \\ 3 & 8.29 & 75.7 \\ 3 & 8.56 & 78.2 \\ 3 & 8.89 * & 90.3^{*} \\ 3 & 9.48 * * & 86.6 * * \\ 3 & 9.55 & 87.2\end{array}$

Hydrogen Sintered Density

88.3

92.2

96.0

96.0

91.5

Hydrogen Sintered Density

3

9.65

88.1 


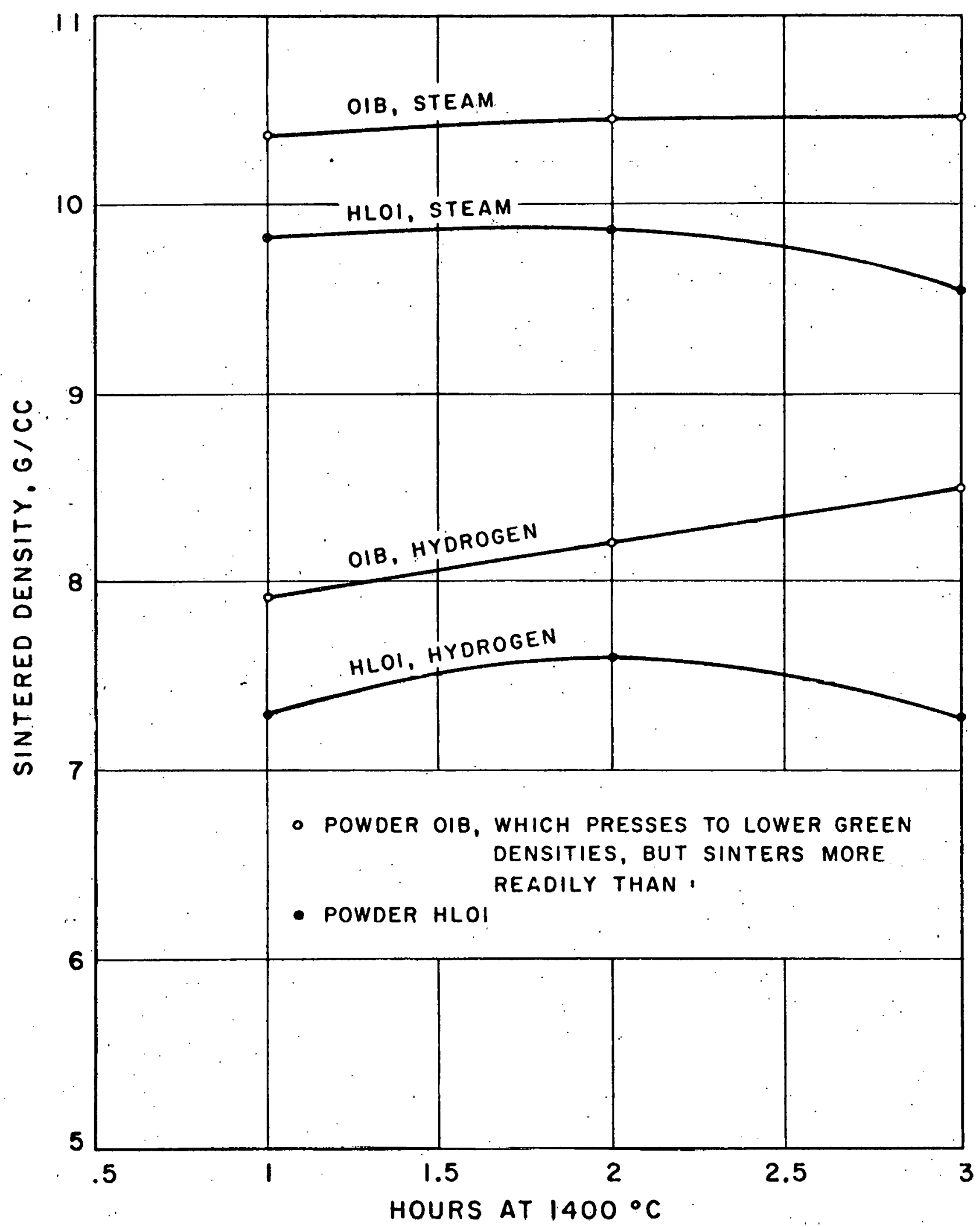

Figure 3 Effect of Furnace Atmosphere Upon $\mathrm{UO}_{2}$ Pellet Densification 


\section{TABLE II}

\section{RESULTS OF SINTERED DENSITY WITH AND WITHOUT ADDITIVES}

\begin{tabular}{|c|c|c|c|c|c|}
\hline Powder & $\begin{array}{c}\text { Green Density } \\
\mathrm{g} / \mathrm{cc} \\
\end{array}$ & $\begin{array}{l}\text { Temp. } \\
\text { C. } \\
\end{array}$ & $\begin{array}{l}\text { Time } \\
\text { hrs. }\end{array}$ & $\begin{array}{l}\text { Sintered Der } \\
\text { With Additive }\end{array}$ & $\begin{array}{l}\text { nsity, } \mathrm{g} / \mathrm{cc} \\
\text { Without Additive }\end{array}$ \\
\hline $\begin{array}{c}\mathrm{O} 2 \mathrm{~B} \\
\quad \therefore\end{array}$ & $\begin{array}{l}6.63 \\
6.63\end{array}$ & $\begin{array}{l}1500 \\
1400\end{array}$ & $\begin{array}{l}4 \\
4\end{array}$ & $\begin{array}{l}10.22-10.31_{A}^{A} \\
10.12-10.17^{A}\end{array}$ & $\begin{array}{c}10 \cdot 35^{\mathrm{B}} \\
\mathrm{E}\end{array}$ \\
\hline$O \perp B$ & $6.56^{\circ}$ & 1500 & 4 & $9.95-10.27^{\mathrm{B}}$ & $10.21^{B}$ \\
\hline RXO5 & $\begin{array}{l}6.59 \\
6.59\end{array}$ & $\begin{array}{l}1500 \\
1400\end{array}$ & $\begin{array}{l}4 \\
4\end{array}$ & $\begin{array}{r}10.37-10.36^{\mathrm{B}} \\
9.30-9.37^{\mathrm{B}}\end{array}$ & $\frac{9.8^{B}}{E}$ \\
\hline SG06B & $\begin{array}{l}6.52 \\
6.27 \\
6.59\end{array}$ & $\begin{array}{l}1500 \\
1400 \\
1400\end{array}$ & $\begin{array}{l}4 \\
4 \\
4\end{array}$ & $\begin{array}{c}10.23-18.25^{\mathrm{C}} \\
10.01^{\mathrm{D}} \\
9.43^{\mathrm{D}}\end{array}$ & $\begin{array}{l}8 \cdot 3^{F} \\
E \\
E\end{array}$ \\
\hline
\end{tabular}

A. Pellets cracked. Density determined by. water immersion

B. Good pellets. Density determined by measuring and weighing

C. Pellets evidenced slight lamination. Density, determined by measuring and weighing, is probably higher

D. One pellet

E. No data yet

F. : Extrapolated 
many hour-glassed pellets appear to be generally straight, except for a short length of narrower "waist". Figure-4 shows the true shape of hour-glassing in a $\mathrm{UO}_{2}$ pellet.

Pellets of two different types of $\mathrm{UO}_{2}$ powder were produced with $\mathrm{L} / \mathrm{D}$ ratios of $1,1.5$ and 2 (Tables III, IV, and V) at forming pressures of $20,40,61$, and 81 TSI, with $0.2 \%, 0.6 \%$, and $1.0 \%$ Sterotex $\mathrm{Z}$, using the unabbreviated $\mathrm{UO}$ preparation process, to determine the effects of various factors so that hour-glassing may be eliminated or minimized.

1. As expected, hour-glassing increases as the $\mathrm{L} / \mathrm{D}$ ratio increases, and differs from powder to powder.

\begin{tabular}{lccc} 
Powder & \multicolumn{3}{c}{ Average Mils of Hour-Glassing for L/D Ratios of } \\
\cline { 2 - 2 } & $\underline{1}$ & $\underline{1.5}$ & $\underline{2}$ \\
HLO1 & 1.0 & 1.9 & 2.5 \\
BYOIB & 0.7 & 0.9 & 1.0
\end{tabular}

2. In general, hour-glassing is reduced by increasing the amount of lubricant - this effect being much more definite and consistent with the HLOI powder than with the BYOIB powder.

\begin{tabular}{lccc} 
Powder & \multicolumn{3}{l}{$\begin{array}{l}\text { Average Mils of Hour-Glassing in } 36 \text { Pellets } \\
\text { with Sterotex Z Percentages of }\end{array}$} \\
\cline { 2 - 4 } & $\underline{0.2}$ & $\underline{0.6}$ & $\underline{1.0}$ \\
HLOI & 2.4 & 1.9 & 1.2 \\
BYOIB & 1.0 & 0.8 & 0.8
\end{tabular}

3. Increased time of application of forming pressure appeared to increase hour-glassing of the HLOl powder and to be inconsistent with the hour-glassing of the BYOLB powder (even the minimum time employed in these trials is longer than the maximum time in production pressing.

4. Hour-glassing appears to be less for both powders when pressed to an intermediate pressure, i.e. 40 TSI, rather than at higher or lower pressures.

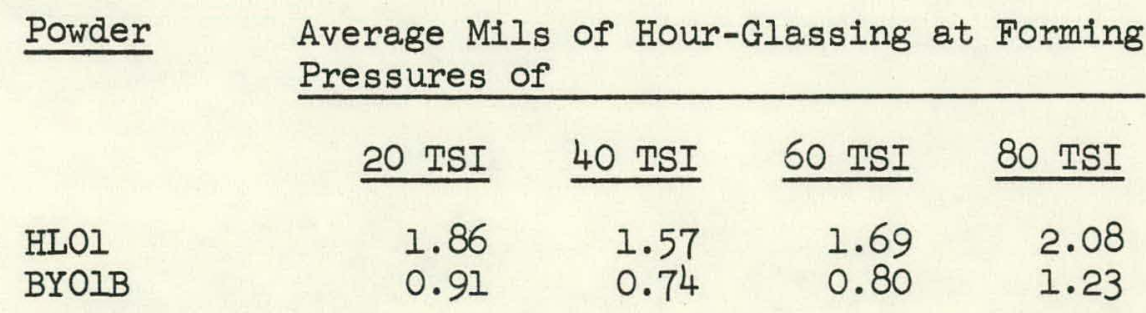

The final draft of topical report YAEC-84 "Progress in the Development of a Process for Producting $\mathrm{UO}_{2}$ Pellets" is being prepared covering the progress made under this subproject as of July $1,1958$. 


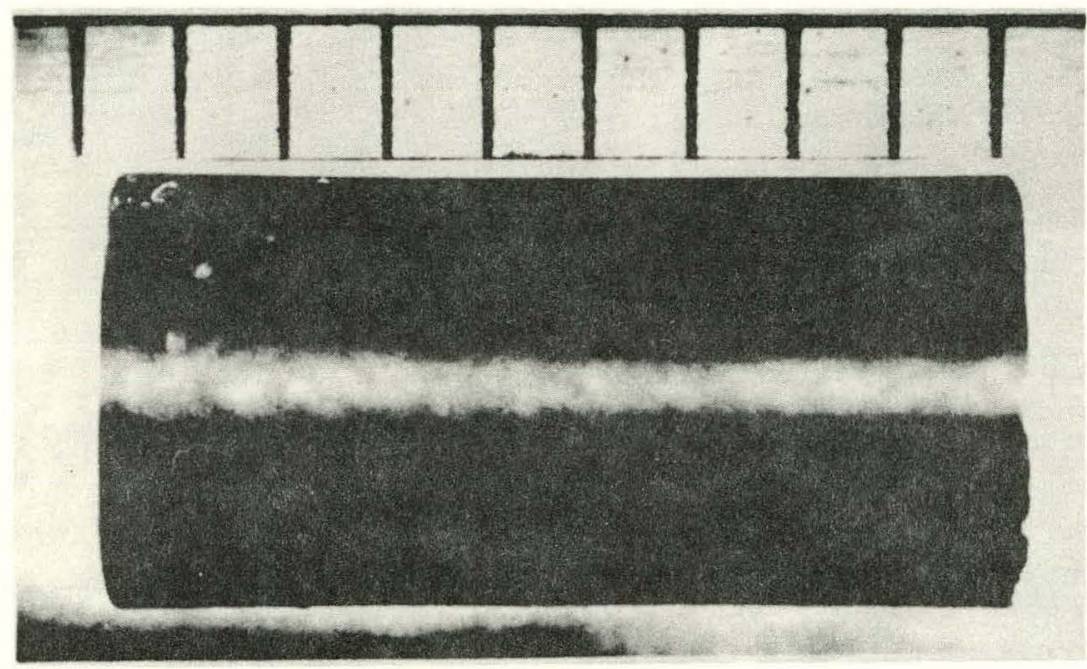

Pellet A Powder: BYOZB (MCW)

Pressed at 10.4 tsi, to $5.2 \mathrm{~g} / \mathrm{cc}$

Sintered at $1750^{\circ} \mathrm{c} . / 4 \mathrm{hrs}$. to $10.32 \mathrm{~g} / \mathrm{cc}$

Figure 4 Hour Glassing of $\mathrm{UO}_{2}$ Pellet 
TABLE III

MILS OF HOUR-GLASSING*** L/D $=1.0$

\begin{tabular}{|c|c|c|c|c|c|c|}
\hline \multirow[b]{2}{*}{ Powder } & Pressing & \multicolumn{4}{|c|}{ Pressure (TSI) } & \multirow[b]{2}{*}{ Additive } \\
\hline & Time (Seconds) & $\underline{20}$ & $\underline{40}$ & 60 & 81 & \\
\hline $\mathrm{HLOI}$ & 1 & 1.8 & 0.9 & 1.1 & 1.3 & $0.2 \%$ stero-tex \\
\hline$"$ & 7 & 1.6 & 1.0 & 1.0 & 1.4 & $"$ \\
\hline$"$ & 20 & 1.8 & 1.5 & 1.2 & 1.8 & $"$ \\
\hline$"$ & 1 & 1.7 & 0.5 & 0.7 & 0.5 & $0.6 \%$ stero-tex \\
\hline$"$ & 7 & 0.7 & 0.7 & 1.2 & 0.8 & $"$ \\
\hline$"$ & 20 & 2.0 & 1.6 & 1.3 & 1.1 & $"$ \\
\hline BYOLB & 1 & 1.1 & 0.5 & 0.5 & 0.7 & $0.2 \%$ stero-tex \\
\hline$"$ & 7 & 0.4 & 0.3 & 0.2 & 0.6 & $"$ \\
\hline$" 1$ & 20 & 0.3 & 0.2 & 0.2 & 0.6 & $"$ \\
\hline " & 1 & 2.0 & 1.5 & 0.5 & * & $0.6 \%$ stero-tex \\
\hline$"$ & 7 & 0.5 & 0.6 & 1.6 & * & $"$ \\
\hline " & 20 & 0.4 & 0.6 & 0.5 & * & $"$ \\
\hline$"$ & 1 & 1.3 & 0.7 & 1.1 & * & 1.0\% stero-tex \\
\hline$"$ & 7 & 1.2 & 0.5 & 0.7 & * & " \\
\hline 11. & 20 & 0.7 & 0.6 & 0.5 & * & $"$ \\
\hline
\end{tabular}

* Could not press - laminated

* Difference in mils between maximum diameter found on end measurements minus minimum diameter found from center measurement. 


\section{TABLE IV}

MILS OF HOUR-GLASSING $-I / D=1.5$

\begin{tabular}{|c|c|c|c|c|c|c|}
\hline \multirow[b]{2}{*}{ Powder } & Pressing & \multicolumn{4}{|c|}{ Pressure (TSI) } & \multirow[b]{2}{*}{ Additive } \\
\hline & Time (Seconds) & 20 & $\underline{40}$ & 61 & 81. & \\
\hline $\begin{array}{l}\text { HLOI } \\
"\end{array}$ & $\begin{array}{r}1 \\
7 \\
20\end{array}$ & $\begin{array}{l}2.6 \\
2.4 \\
1.9\end{array}$ & $\begin{array}{l}1.9 \\
2.1 \\
2.2\end{array}$ & $\begin{array}{l}2.3 \\
2.8 \\
2.6\end{array}$ & $\begin{array}{l}3.0 \\
3.3 \\
3.8\end{array}$ & $\begin{array}{c}0.2 \% \text { Stero-tex } \\
" \\
"\end{array}$ \\
\hline $\begin{array}{l}" \\
" 1\end{array}$ & $\begin{array}{r}7 \\
7 \\
20\end{array}$ & $\begin{array}{l}2.4 \\
2.2 \\
2.1\end{array}$ & $\begin{array}{l}1.2 \\
1.3 \\
2.1\end{array}$ & $\begin{array}{l}1.7 \\
1.5 \\
2.2\end{array}$ & $\begin{array}{l}2.0 \\
2.6 \\
2.7\end{array}$ & $\begin{array}{c}0.6 \% \text { stero-tex } \\
" 1\end{array}$ \\
\hline $\begin{array}{l}" \\
" 1\end{array}$ & $\begin{array}{r}1 \\
7 \\
20\end{array}$ & $\begin{array}{l}1.2 \\
1.4 \\
1.5\end{array}$ & $\begin{array}{l}1.3 \\
1.1 \\
1.0\end{array}$ & $\begin{array}{l}1.3 \\
0.9 \\
1.0\end{array}$ & $\begin{array}{l}1.4 \\
1.3 \\
1.4\end{array}$ & $\begin{array}{c}1.0 \% \text { Stero-tex } \\
" ~\end{array}$ \\
\hline $\begin{array}{c}\text { BYOLB } \\
" 1 \\
"\end{array}$ & $\begin{array}{r}1 \\
7 \\
20\end{array}$ & $\begin{array}{l}0.3 \\
0.8 \\
1.2\end{array}$ & $\begin{array}{l}0.4 \\
0.1 \\
0.8\end{array}$ & $\begin{array}{l}1.2 \\
1.0 \\
1.4\end{array}$ & $\begin{array}{l}2.0 \\
0.7 \\
0.9\end{array}$ & $\begin{array}{c}0.2 \% \text { stero-tex } \\
" \\
"\end{array}$ \\
\hline $\begin{array}{l}" 1 \\
" 1\end{array}$ & $\begin{array}{r}1 \\
7 \\
20\end{array}$ & $\begin{array}{l}1.2 \\
0.4 \\
0.8\end{array}$ & $\begin{array}{l}0.8 \\
0.9 \\
0.6\end{array}$ & $\begin{array}{l}1.0 \\
0.8 \\
0.7\end{array}$ & $\begin{array}{l}* \\
* \\
*\end{array}$ & $\begin{array}{c}0.6 \% \text { Stero-tex } \\
" 1\end{array}$ \\
\hline $\begin{array}{l}" \\
" 1\end{array}$ & $\begin{array}{r}1 \\
7 \\
20\end{array}$ & $\begin{array}{l}1.1 \\
1.1 \\
1.8\end{array}$ & $\begin{array}{l}1.5 \\
0.7 \\
0.5\end{array}$ & $\begin{array}{l}0.5 \\
0.4 \\
0.2\end{array}$ & $\begin{array}{l}* \\
* \\
*\end{array}$ & $\begin{array}{c}1.0 \% \text { stero-tex } \\
" \\
"\end{array}$ \\
\hline
\end{tabular}

* Coula not press - laminated 


\section{TABLE V}

\section{MILS OF HOUR-GLASSING: L/D -2.0}

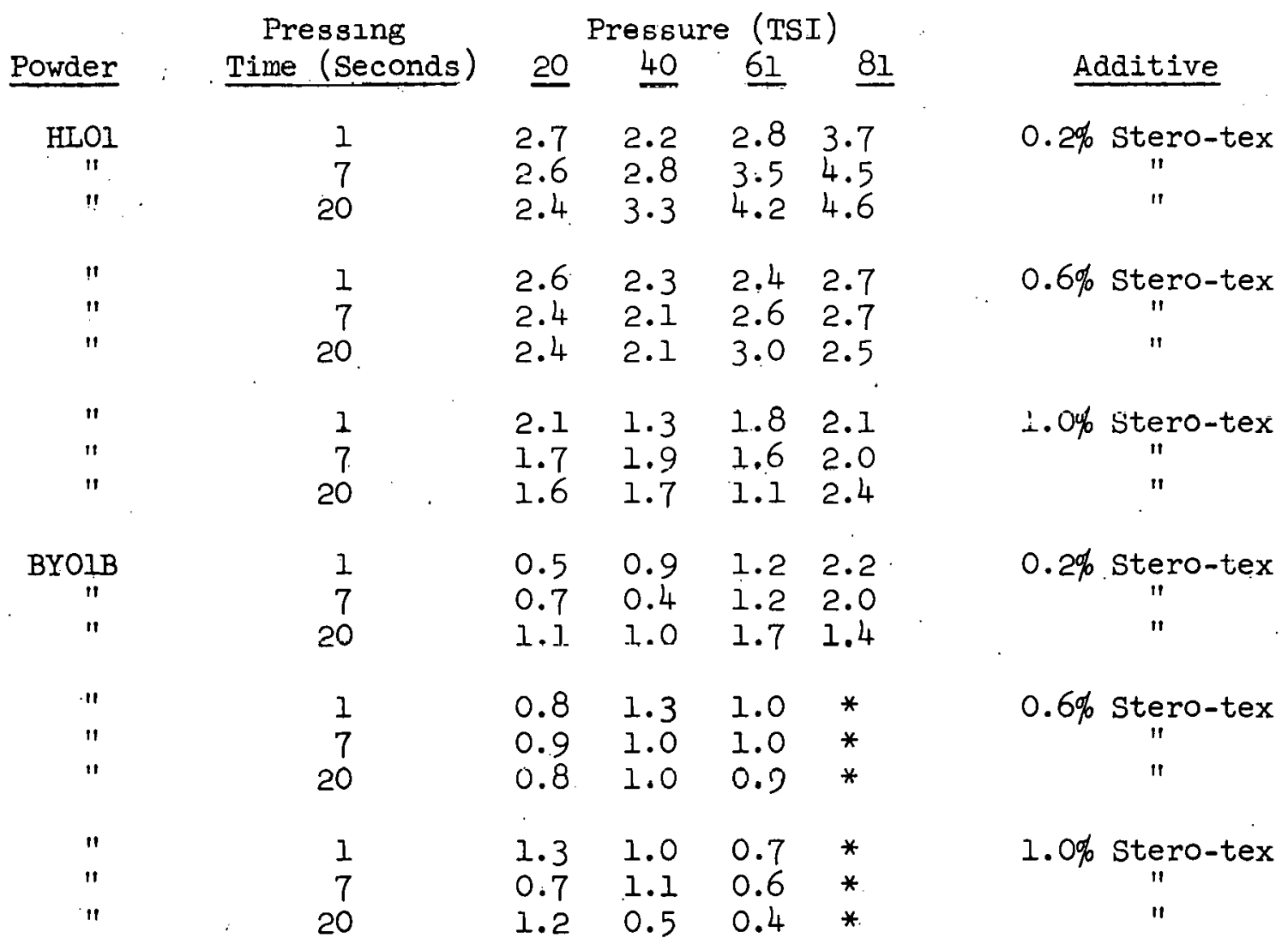

* Could not press - laminated 


\subsubsection{End Closure of Fuel Rods}

G. G. Lessmann

Over 100 welds were made in checking parameters and consistency of welding with the AIRCO automatic welding head. Excellent metallographic results that have been consistently obtained are attributed primarily to the control of welding voltage permitted through use of the automatic head. Fit-up of the end plug to the tube is not as critical a problem with the new head because close control of arc voltage permits welding even through open plug-tube interfaces. Numerous samples considered to have poor fit-up have. been successfully welded without discs brazed in place near the end plugs. Considerable difficulty, however, was encountered as a result of high air pressure build-up in the end plugdisc compartment. During welding, the pressure in the small volume becomes heated because it is confined, forcing air out through the molten weld causing blowholes to form. Blowholes, due to this preseure build-up, have been practically eliminated by a multiple end plug pressing-repressing operation which limits the interference fit enough to eliminate the pressure build-up.

1.3.2 Joining Fuel Bundles Into Assemblies
P.P. King
J. R. Dazen
M. D'Amore

Brazed'Joint Studies

A 95 inch experimental Yankee type subassembly was successfully brazed at $1890+10 \mathrm{~F}$. for three hours, then furnace cooled. The maximum bow along the length was $0.034 "$ "and the maximum spread in cross section was $0.014 "$ " All of the joints, outside ferrules, and control rod rubbing strips showed brazed fillets. An overall view of the subassembly is shown in Figure-5. A close-up view of the external bumper ferrules and the rubbing strips is shown in Figure-6. Table VI shows a compilation of data for 14 brazed bundles made to date. These data indicate for. the last several bundles a close control of dimensions and practically no unbrazed joints. Jigging and fixturing methods are still being altered for each run in order to improve fit-up of parts which has been found to be the major factor determining final dimensions and integrity brazed jointo.

Dimensional surveys and joint-strength studies indicate that two brazing techniques appear feasible for subassemblies. One technique is chemically plating 0.0005 inch of $\mathrm{Ni}-\mathrm{P}$ on the ferrules backed up with Nicrobraz 50 slurry and the other technique involves plating 0.001 inch of $\mathrm{Ni}-\mathrm{P}$ on the ferrules. Bundles $\mathrm{X}-4$ and $\mathrm{X}-5$ using each technique with variations in ferrule arrays have been inspected and tested with results shown in Table VII. 


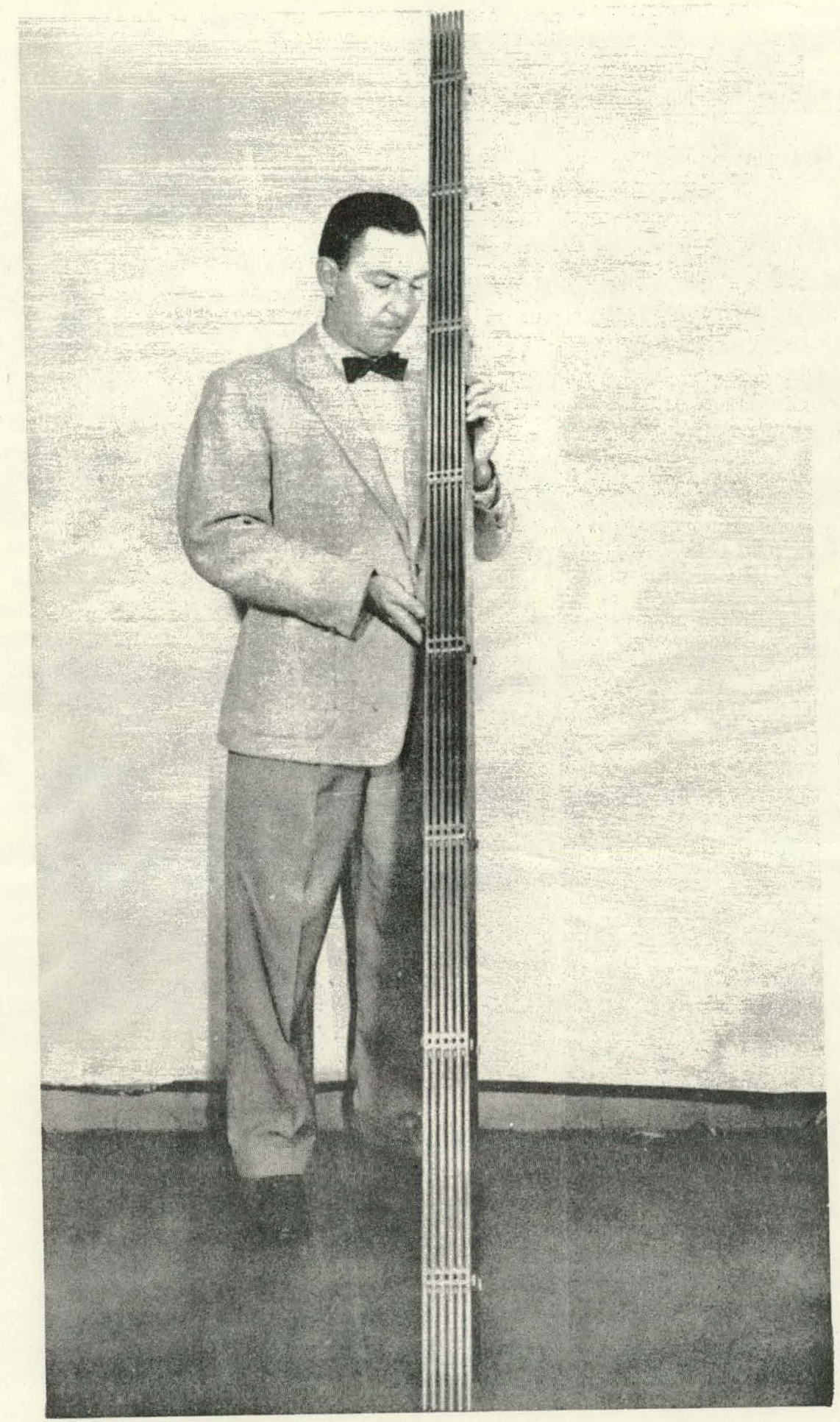

Figure 5 Yankee Fuel Element Sub-Assembly (95") Showing Rubbing Straps and Outside Fermules 


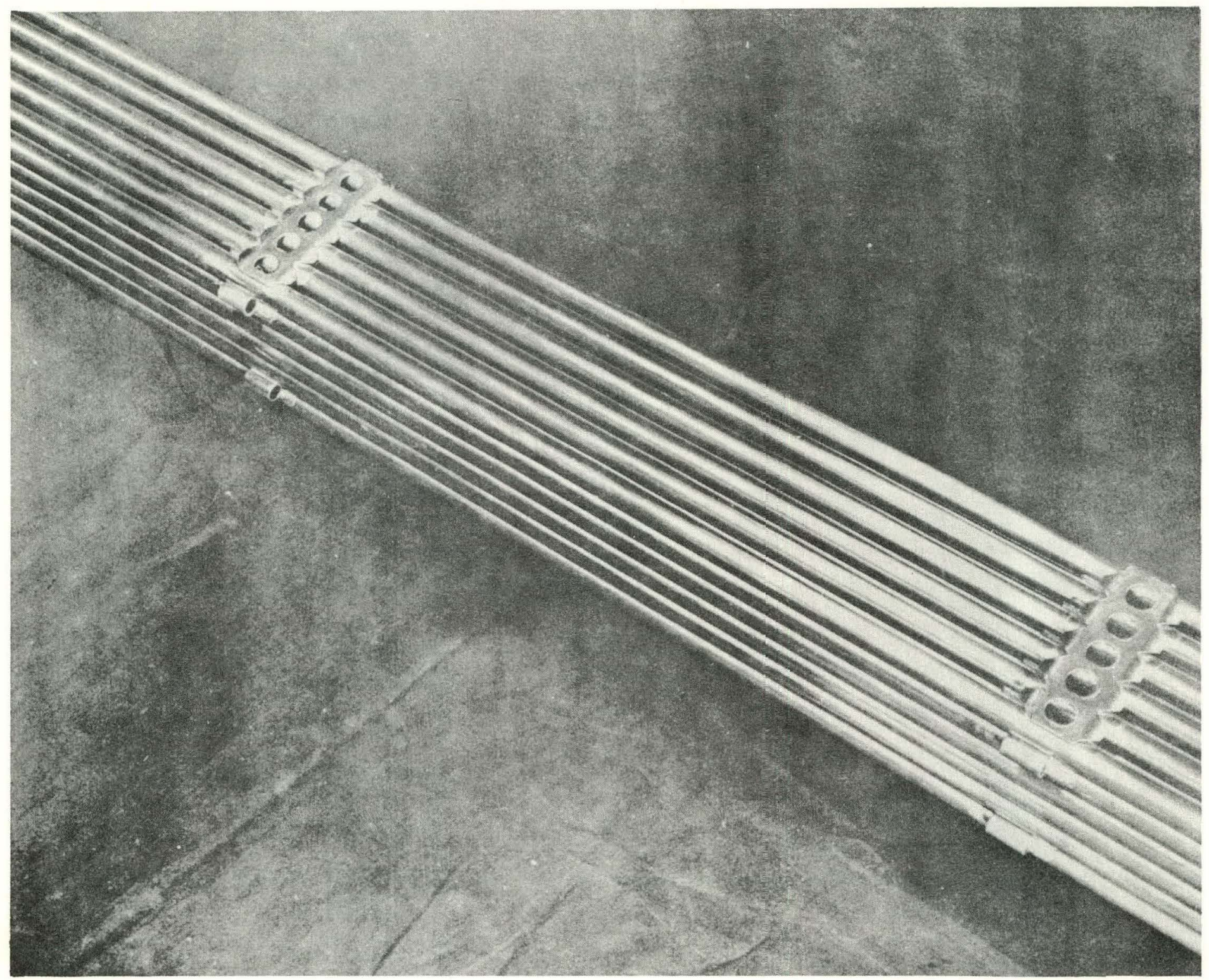

Figure 6 Close-up View of Yankee Fuel Element Sub-Assembly 
TABLE VI

QUAIIIY SURVEY OF ERAZED FUEL GUBASSEMBLTES

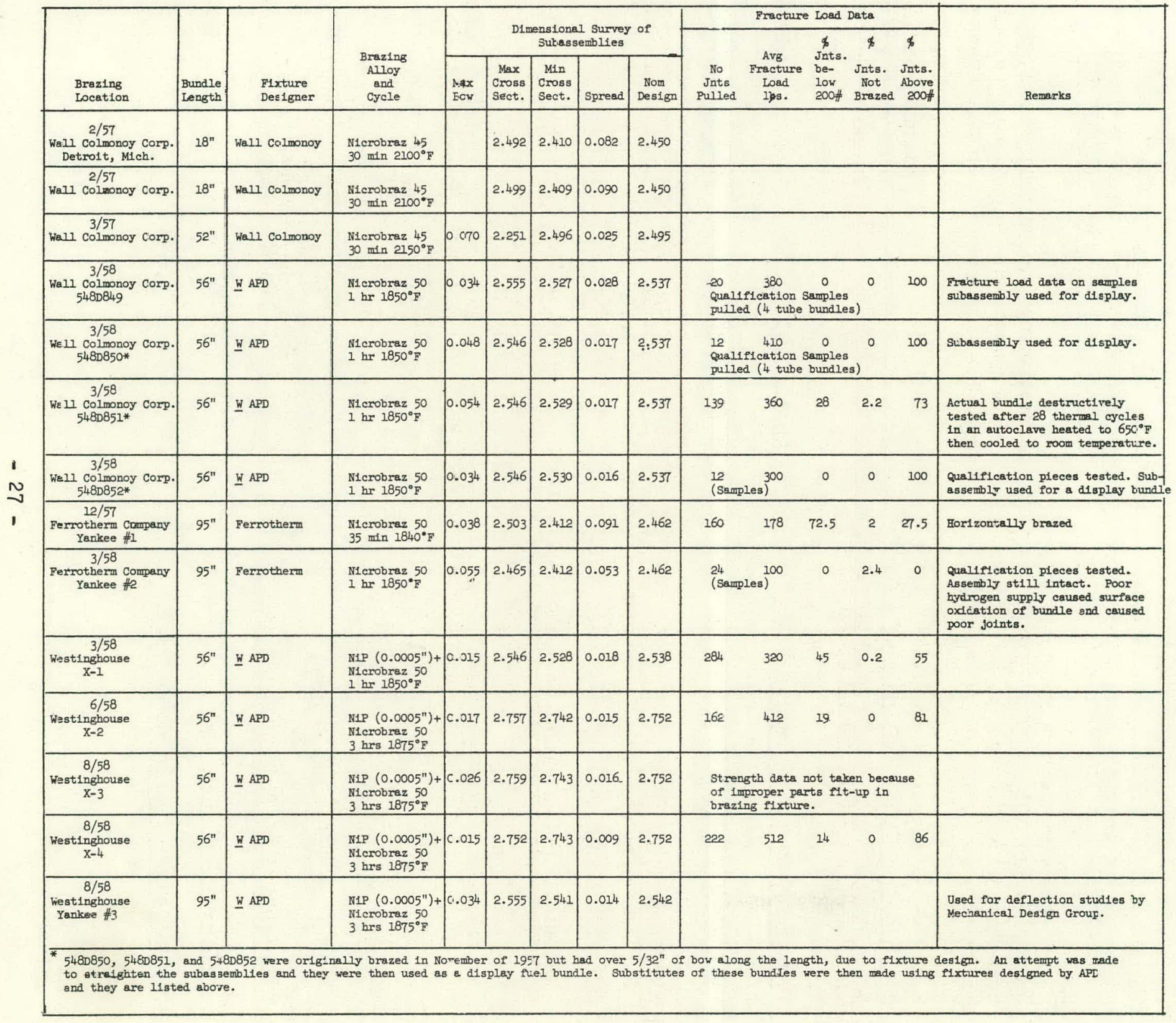


Both brazed at $1875^{\circ} \mathrm{F}$ for 3 hours

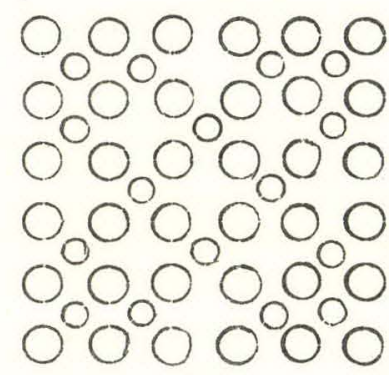

A

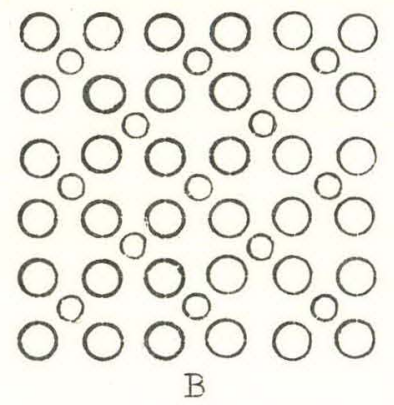

Maximum bow along length

Design Size

Maximum Size

Minimum Size

Spread

Design Spacings, Tube-to-Tube

Maximum Spacing

Minimum Spacing

Spread

Spread on Layers, 1, 2, $3(\mathrm{X}-5)$

Number of Unbrazed Joints

Percentage of Joints below $200 \mathrm{lbs}$

Average Fracture Load

Percentage of Zero Load Joints \begin{tabular}{cc}
$\mathrm{X}-4$ & $\mathrm{X}-5$ \\
$0.0005^{\prime \prime} \mathrm{NiP}+\mathrm{NB} 50$ & $0.001^{11} \mathrm{NiP}$ \\
\hline
\end{tabular}

Alternating layers Layers 1, 2, of arrangements $\quad 3$ with ferrules $A$ and $B$. in all spaces. Layers 4 \& 6 per arrangement $A$; Layers 5 \& 7 per arrangement $B$.

Approx. 0.013" Approx.0.014"

$2.752 \times 2.752 \quad 2.752 \times 2.752$

2.752

2.743

0.009

2.742

0.015

0.136

0.136

0.154

0.117

0.147

0.127

0.037

0.020

--

0.010

0

0

$16.9 \%$

$14 \%$

485 lbs 360 Ibs

$3.95 \%$ 
Although the Ni-P + Nicrobraz 50 joints gave a higher average fracture load, the plated ferrule joints gave a higher percentage of joints with fracture loads above 200 pounds. In addition, the plated ferrule bundles were cleaner, less subject to base metal erosion, and free of brazing to fixture members because of run-off of excess braze material. Plated ferrules required about one-half the assembly time compared to the slurry method. None of the:ferrules slipped out of position significantly when vertically brazed.

Conclusions drawn from the brazed joint studies are as follows:

1. Longitudinal bowing and cross-sectional dimensions are not affected by the brazing technique.

2. Tube-to-tube spacing variations can be cut in half if ferrules are placed between each fuel tube.

3. Joints brazed with 0.0005 inch of plated $\mathrm{Ni}-\mathrm{P}$ and Nicrobraz 50 gave an average fracture load 125 pounds higher than with the 0.001 inch plated ferrule technique although the latter can probably be increased by increased time at temperature.

4. Cleaner, more consistent fuel elements can be made faster by using 0.001 inch of $\mathrm{Ni}-\mathrm{P}$.

5. Corrosion studies indicate that the corrosion resistance of Ni-P is equivalent to Nicrobraz 50 and AISI-304 stainless steel.

Stretch Forming Studies

Experimental loading studies were continued with the use of eight full length Yankee-type fuel tubes. It was found that vacuum drawing of the pellets into the tube was required since a column of pellets longer than 5 to 6 feet produced excessive friction. Pellet chipping tendencies and Inaring friction have been reduced by the use of the vacuum technique in the loading operation. Planning has been directed toward incorporating the loading operation in the same machine that will stretch the tubes.

Much of the detailed statistical data obtained for the Belgian Thermal Reactor stretch-forming operation have been analyzed and found to be applicable to the Yankee fuel element. From these data, Tables VIII and IX have been obtained showing a tentative stretching procedure for 15 and 21 mil wall tubing depending on the cold tube-pellet gap and axi.a.l clearance desired.

\section{Corrosion Coupons}

A total of 175 stainless steel AISI-304 corrosion coupons ( $2-1 / 8^{\prime \prime} \times 3 / 4 "$ $\left.\mathrm{x} 1 / 8^{\prime \prime}\right)$ were prepared. Of these, 133 coupons were given the following heat treatment prior to corrosion testing in dynamic loops. 


\section{TABLE VIII}

\section{YANKEE STRETCH-FORMED FUEL ROD}

\section{Tentative Stretching Procedures for $0.015^{\prime \prime}$ Wall Thickness Tubing}

Dimensions and tolerance ranges of components and the required stretching methods to obtain three different pellet-tube clearange ranges after stretch are itemized below for a compartmented fuel rod. The pellet-tube ranges listed below are:

0 clearance: Tube and pellets are in contact.

0-2 mils clearance: Tube is contacting largest pellets only. $0.9-2.9$ mils clearance: Tube is not in contact with any pellet.

Pellet-Tube Clearance (After Stretch) $\quad 0$ mils $\quad 0-2$ mils $\quad 0.9-2.9 \mathrm{mils}$

w Components

Tube I.D. required (Eefore Stretch)

Pellet Diameter

Disc Diameter Required

\section{Stretching Method}

Percent Stretch with Ram

Percent Stretch without Ram

Total

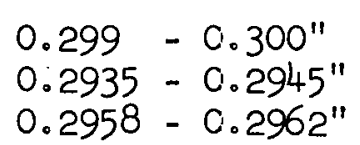

\section{Stretch Tube Characteristics}

Maximum Tube Diameter

Minimum Tube Diameter

Pellet-Tube
Contact
Achieved
$2.45 \%$

Pellet Expansion Space (length) 


\section{TABLE IX}

\section{YANKEE STRETCH-FORMED FUEL ROD}

\section{Tentative Stretching Procedures for 0.021 " Wall Thickness Tubing}

Pellet-Tube Clearance (After Stretch)

\section{Components}

Tube I.D. (Before Stretch)

Pellet Diameter

Disc Diameter

Stretching Method

With Pellet Rətaining Ram

Without Ram

$$
\begin{array}{ll}
0.2990^{\prime \prime}-0.300^{\prime \prime} & 0.299^{\prime \prime}=0.300^{\prime \prime} \\
0.2935-0.2945 & 0.2935=0.2945 \\
0.2958-0.2962 & 0.2968=0.2972
\end{array}
$$

$0.2995^{\prime \prime}-0.3005^{11}$
$0.2935-0.2945$

$0.2973-0.2977$

$1.75 \%(2.45 \mathrm{mils}) * 1.10 \%(1.54 \mathrm{mils})$ No ram needed $2.50 \%$ ( $3.55 \mathrm{mils}) \quad 2.15 \%$ ( $3.01 \mathrm{mils}) \quad 2.85 \%$ ( $4.0 \mathrm{mils})$

Total

Stretched Tube

Expansion Spaze for Pellets

in Stretched compartments.

Max. Tube I.D.

Min. Tube I.D.

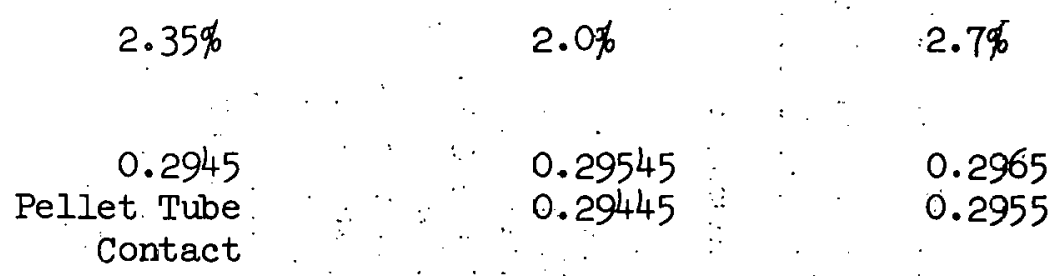

* Figures in parentheses indicate amount tube I.D. will reduce for the listed percentage stretch. 
No. of Coupons

25

25

25

25

33
Condition or Heat Treatment

\author{
as-received \\ polished \\ annealed at $1850^{\circ} \mathrm{F}$. \\ $50 \%$ weld coated and annealed \\ at $1850^{\circ} \mathrm{F}$. \\ sensitized
}

Results of the corrosion tests are not yet available.

1.4 Fabrication and Analysis of Fùel Elements for Critical Assembly and Irradiation Tests

J. J. Lombardo

Inspection of the 24-inch and 30-inch long MTR samples after brazing indicated a condition of general bowing in both samples. These samples were brazed in a vertical-position furnace and were straight in the jig when the $j i g$ was removed from the furnace. However, when the brazed bundle was removed from the $j i g$, it sprang into a bowed shape. . When the same jig was used for brazing in a horizontal-position furnace; no such bowing was encountered. The explanation of this behavior is believed to be as follows: during vertical brazing, pellets fell to the bottom of the tubes; during cooling from the brazing temperature, the greater contraction of the tubing over the solid pellet column produces elastic stresses which are not equally distributed; when removed from the straight $j i g$, stresses are released resulting in bowing of the bundle. This same behavior can not occur during horizontal brazing because a solid pellet column does not form.

The following pellets were prepared for use in the MTR in-pile loop tests:

\begin{tabular}{cr} 
U-235 Enrichment & No. of Pe \\
\cline { 2 - 2 } Depleted & 1200 \\
2.7 & 50 \\
5.4 & 175 \\
6.8 & 50 \\
10 & 160 \\
27 & 130
\end{tabular}

The $27 \%$ enriched pellets were subsequently found to chip and fracture upon fuel rod stretch-forming. After reprocessing and repressing, the new pellets were pressed and underwent fuel rod stretch-forming satisfactorily.

All of the in-pile test $100 p$ and process water samples are now complete except for the in-pile loop specimens containing the $27 \%$ enriched pellets. The 27\% enriched fuel specimen is ready to be brazed into a fuel bunde. A thorough examination was made and photographs were taken of all specimens. Photographs of the brazed bundles and control rod specimens are shown in Figures-7, 8; and 9 for the process water and in-pile loop tests. 


\section{WCAP-2 PROCESS WATER SPECIMENS}
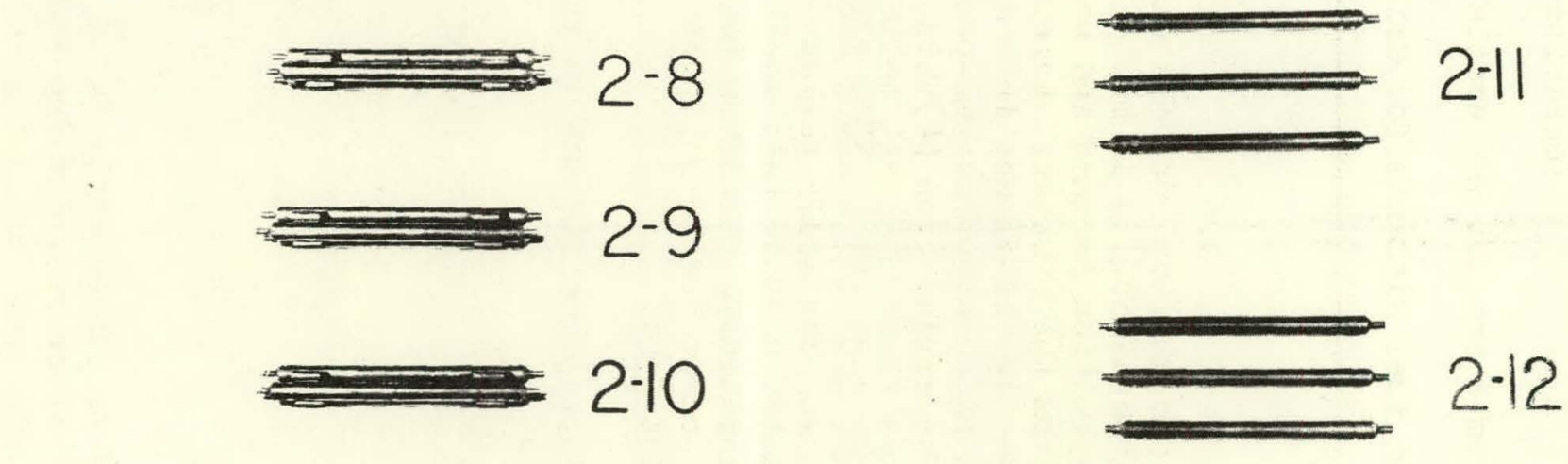

\section{$2 \cdot 13$}

Figure 7 Fuel Bundle Specimens to be Irradiated in Process Water in MTR (WCAP-2) 


\section{WCAP-4 LOOP TEST SPECIMENS}

$$
\text { 4-1 }
$$

$$
\text { 4-2 }
$$

\section{4-3}

\section{4-4}

Figure 8 Fuel Bundle Specimen to be Installed in the WCAP-4 In-Pile Test Loop. Specimens $4-1$ and $4-3$ will be in-pile; specimens $4-2$ and $4-4$ will be out-of-pile. 


\section{WCAP-4 LOOP TEST SPECIMENS

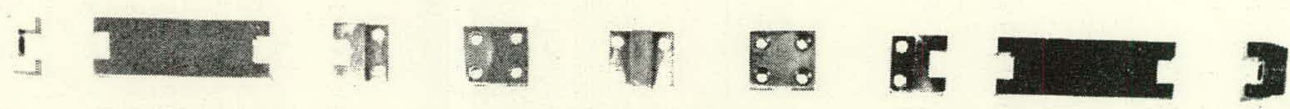

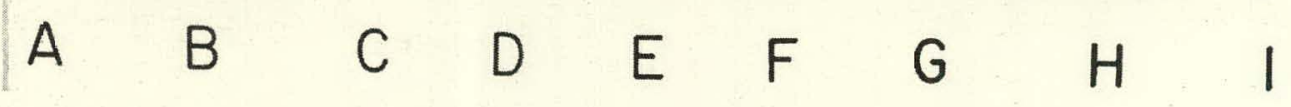 \\ 4-5

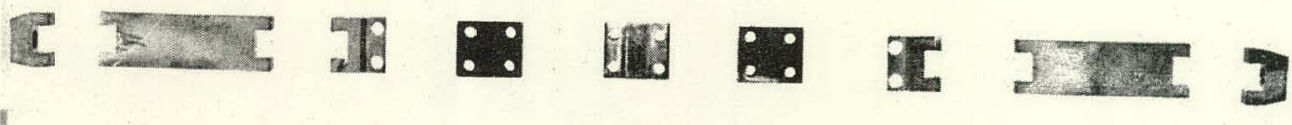 \\ $\begin{array}{llllllllll}A & B & C & D & E & F & G & H & \text { । }\end{array}$ \\ 4-6}

Figure S Arrangement of Control Rod Materials to be Installed in the WCAP -4 In-Pile Test Loop. Specimen $4-5$ will be in-pile;

Specimen $4-6$ will be out-of-pile. 


\subsection{NUCLEAR DESIGN AND REACTOR PHYSICS}

Nuclear Design Section:

Computer Analysis Group:

Reactor Physics Group:
H. W. Graves, Jr., Manager

G. H. Minton, Supervisor

W. H. Arnold Jr., Supervisor

Included in this project are studies and calculation on the core design optimization, kinetic and steady state reactor analysis, planning of criticality and irradiation experiments, shielding, and the reactor startup and operation.

\subsection{Core Design Optimization}

No work was performed under this subproject during the third quarter of 1958 .

\subsection{Core Steady State Analysis}

R. E. Wolf

R. G. St. Paul

R. J. French

Fuel Assembly Design

A nuclear analysis of various fuel assembly designs was made as part of an overall evaluation of fuel assembly bowing in the Yankee reactor. Two factors of importance from the nuclear standpoint were emphasized: flux peaking around control rod followers, and U-235 loading requirements. The results obtained to date are preliminary but do indicate trends for the several suggested designs. The following designs have been studied:

(1) A shrouded assembly design in which either the control rod or fuel assembly is surrounded by a thin steel "box".

This design is acceptable from the nuclear standpoint if the dimensions in the drawings are maintained. The additional steel due to the shroud is equivalent to a $3 \mathrm{mil}$ increase in clad thickness, but if clad thickness is reduced to 15 mils, there would be a net reduction in steel from the definitive design. The effect on fuel cost of the changes in amount of steel in the core can be inferred from previous studies, which indicate that a 6 mil increase in clad thickness causes a 19\% increase in the required U-235 loading and an increase in the nuclear fuel cost of $0.13 \mathrm{mills} / \mathrm{KWH}$ (for a 10,000 hour life, \$27/gm plutonium credit, and $4 \%$ investment charge).

(2) A "3-bundle" fuel assembly design in which the rods are divided into three axial sections.

Axial flux peaking can be minimized in a 3-bundle design, but only at the expense of U-235 loading. Two cases with a one inch gap 30 inches from each end of a 90 inch long core were considered. In the first case, the water-to-solid ratio was nearly that of the active core ( $\mathrm{UO}_{2}$ replaced by stainless steel), while the second case had a considerably higher fraction of water. The first case requires roughly a 5\% increase in U-235 loading to offset the poison effects of

$$
-36 \text { - }
$$


stainless steel, although it does not have too great a flux peak because of the increased absorption due to the steel in the gap. The second case results in an increase in the axial peak/average power density of $65 \%$. For a given lifetime, slightly higher reactivity would be required in this core due to the decrease in epithermal coversion of U-238. Both of these designs would have a more positive temperature coefficient.

(3) An "hour-glass" fuel assembly design in which the fuel rod spacing is closer at the midplane of the core than at the top and hottom plates.

Two sets of calculations were made to analyze the effect of lateral movement of a subassembly toward a zirconium control rod follower. Some lateral movement actually decreases the flux peaking since the "water holes" are more uniformly distributed when the movement of the fuel subassembly decreases the follower gap and creates an internal gap in the assembly. However, the internal gap may cause a higher peak than the follower gap. The reactivity effect due to the lateral movement is very small, indicating that reactivity transients due to mechanical movement would be negligible.

Fuel Bearing Control Rod Followers

A general study was also performed on the Yankee core in an attempt to estimate the effect of various design modifications on flux peaking in the fuel adjacent to a control rod follower. The study included the dependence of flux peaking on water gap thickness, the use of steel plates between the followers and fuel and the effect of using fuel-bearing followers. The results of this study indicate that a significant reduction in power peaking can be achieved with fuel bearing followers. If a U-235-Zircaloy-2 alloy is used, the power output of the core can be increased by approximately $10 \%$, whereas if low enrichment $\mathrm{UO}_{2}$ - stainless steel followers are used, an increase in core rating of over $20 \%$ appears possible.

The flux peaking which exists when a Zircaloy-2 control rod follower is in the active region of the core is due to the low absorption of Zircaloy-2 relative to that of the fuel and to the increased thermalization of neutrons in the adjacent water over that in the neighboring fuel regions. Previous studies indicate that a Zircaloy-2 follower and adjacent water channel give rise to a power peak in the neighboring fuel of the order to 20 to $30 \%$. This, correspondingly, reduces the maximum output of the core by 20 to $30 \%$ and aggravates the thermal bowing of fuel rods by increasing the radial temperature gradient near control rod channels. This peaking can be eliminated by increasing the neutron absorption properties of the control rod follower. If steel or another non-productive type of absorption is used, however, the loading requirements are increased and the control rod worth is reduced by a factor of almost two. A more practical solution to the problem is to use fissionable material in the control rod follower. 
The cost of fuel-bearing control rod followers will be greater than for Zircaloy-2, particularly since replacement will be required during the life of the plant. This increased cost must be balanced by the definite increase in maximum power capability, the reduced thermal gradient around control rod slots, and the improved utilization of primary coolant in. the core.

The main nuclear disadvantage resulting from the use of highly enriched material in control rod followers is the different burnup characteristics of high and low enrlchment material. The effect of this variation of power peaking is shown in Table $X$.

\section{TABLE X}

Effect of Fuel Burnup on Local Power Peaking for a U-235 - Zirclàoy-2 Control Rod Follower

$\begin{array}{cc}\text { Fuel Burnup - MND/Ton } & \begin{array}{c}P_{\text {edge }} / P_{\text {avg }} \\ 0 \\ 5,000\end{array} \\ 10,000 & 0.99 \\ 20,000 & 1.08 \\ 1.14 & 1.22\end{array}$

(The initial fuel loading in the follower is 8.5 weight percent U-235)

In the carculations of Table $X$ it was assumed that both the stationary fuel and the fuel contained in the follower were exposed to the same integrated flux. The 20,000 MWD/Ton burnup value is realistic for the peak burnup in a core which has an average fuel burnup of $8,200 \mathrm{MWD} / \mathrm{Ton}$. The table shows that most of the improvement in power peaking is lost when the core is exposed to a high fuel burnup.

A comparable study of the burnup characteristics of control rod followers composed of low enrichment $\mathrm{UO}$ in stainless steel rods indicates that a varlation in flux peaking no greater than $6 \%$ would occur for burnups similar to those considered in the above table. Thus, it seems more desirable to use a follower consisting of two perpendicular rows of stainless steel tubes filled with low enrichment $\mathrm{UO}_{2}$. This type of cruciform fuelbearing follower would be preferable to $a^{2}$ similarly shaped alloy of Zircaloy-2 and highly enriched $\mathrm{UO}_{2}$ : 
Flux Peaking Analysis

An experimental and theoretical study to determine the accuracy of various methods of calculating thermal neutron flux peaking in water channels and at the core-reflector interface was begun. Experiments were made to measure the flux in a central water slot and at the core edge of a critical assembly using both foils and fuel. A theoretical investigation involving the examination of various calculating procedures to obtain the desired flux plots was started. In performing these calculations for a few-group model, the thermal and fast group constants must be obtained and then used in one of the operational multi-region flux distribution computer codes. Of the many approximations available in such a calculation, only those considered most theoretically sound are being investigated. It is hoped that one of these will agree well enough with experiment to justify its use as a standard scheme to replace currently used approximation methods.

For the thermal constants, the microscopic cross-sections may be averaged over a Maxwellian or a Wigner-Wilkins spectrum. Both of these methods, obtainable from the SOFOCATE code for the IBM-704 computer are being considered.

For the fast constants, the MUFT-IV code for the IBM-704 computer is being examined. Four approximations which are an intrinsic part of the MUFT code itself involve a choice between the $\mathrm{B}_{1}$ and $\mathrm{P}_{1}$ approximations; the Selengut-Goertzel approximation is also available. All four possibilities are being applied to several water/metal lattices for which experimental data are available to determine the value of the second moment of the slowing down distribution at thermal energies given in the code. The results of these comparisons will determine the choice of procedure for calculation of fast group constants.

Another problem associated with the use of the MUFT-IV code is the choice of a source spectrum for the non-fuel region. In fuel regions the normal fission spectrum of neutron flux and current within the core should be considered. These spectra are obtained as the output of a MUFT calculation of fast group constants. The three spectra are shown in F1gure-10 for a typical Yankee First Core configuration. The normalization is such that the area under each curve is unity. Theoretical considerations indicate that the most applicable spectrum for use in a calculation of reflector constants is probably the spectrum of neutron current within the core, whereas, for the non-multiplying regions within the core, the spectrum of core neutron flux should be used.

After the fast and thermal constants have been determined, the neutron flux predicted by diffusion theory may be calculated by means of the WAINDA code, or transport theory may be applied through use of the SNG code. Both of these will be employed, using both 2 and 4 group theory in one dimension. The two dimensional diffusion theory program PDQ, will also be applied to the calculation of neutron flux distribution. The correlation of results obtained with diffusion theory and transport theory in one dimension will provide information required to evaluate the results obtained with PDQ. 


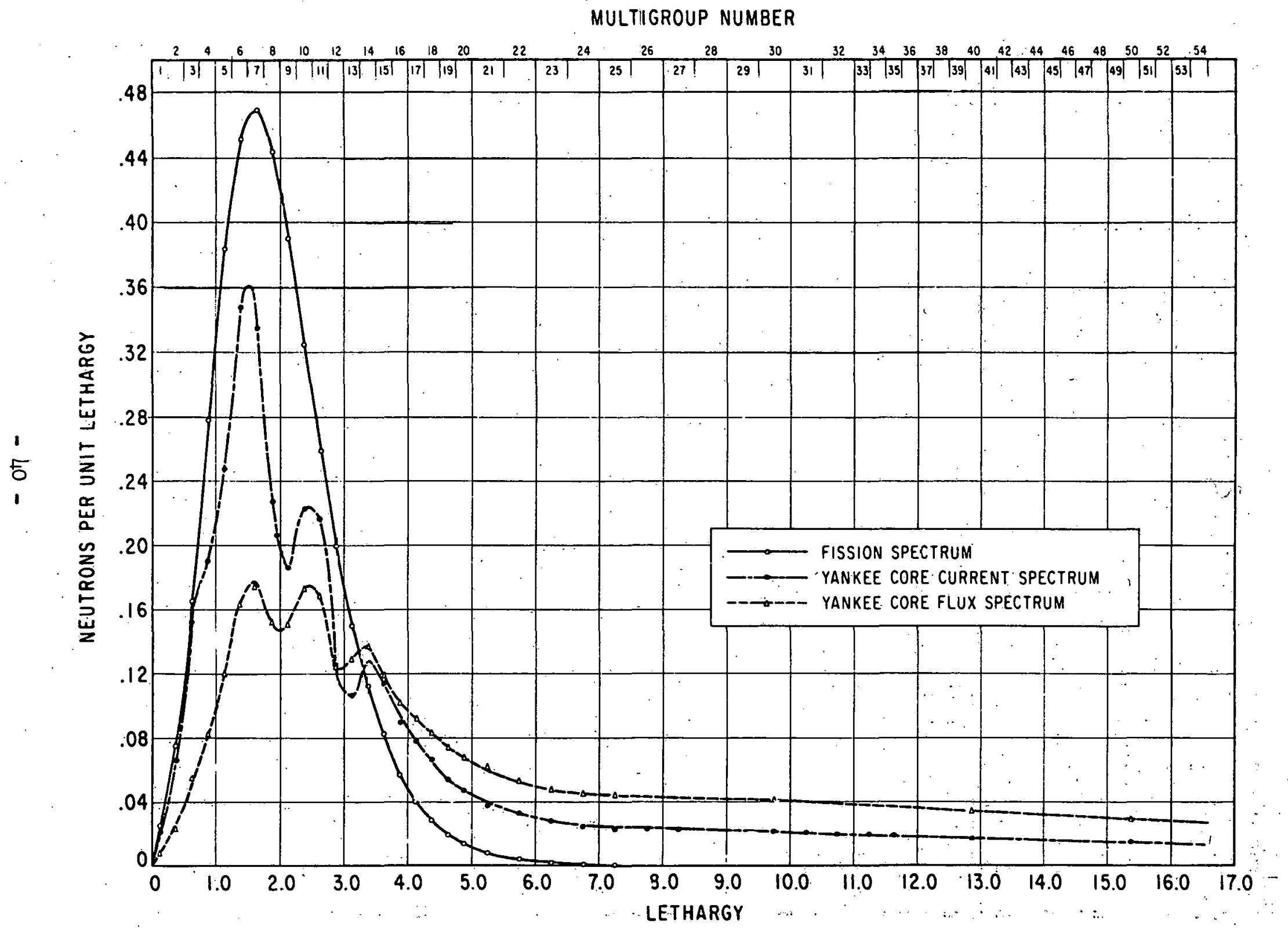

Figure 10 Neutron Spectra in the Yankee First Core Obtained by Use of the MUFT IV Program on the IBM-70L Computer 
Fuel Depletion Analysis

A detailed study of the advantages and limitations of various digital computer codes for the calculation of reactor fuel depletion is in progress. The object of the study is the establishment of final specifications in order to revise the CAP-1 code which will include the calculation of thermal neutron cross sections from a Wigner-Wilkens spectrum; it will also incorporate an epithermal fission factor $(\beta)$ as well as the fast fission factor $(\varepsilon)$ in the modified one group equation describing fuel depletion, plutonium buildup and reactivity.

Results obtained in this study indlcate that when all differences in basic nuclear data are eliminated between the CANDLE and MERLIN codes, very good agreement can be expected in the calculation of reactor lifetimes for uniform cores. A principal source of discrepancy which remains is due to epithermal fission in U-235. This discrepancy will be eliminated in the revised version. of the CAP-1 code which can then be introduced into the MERLIN code: With regard to the organization of the revised CAP-I code, it has been established that the calculation of changes in number density is relatively insensitive to the changes in thermal flux spectrum during life, so that frequent re-runs of the SOFOCATE code during the calculation of depletion will be unnecessary.

Loading Configurations

A preliminary study of loading configurations for the first Yankee core was completed. A comparison of uniformly loaded, two-region cycled, and two enrichment cores, all designed for a thermal output of $482 \mathrm{MW}$ was made. The conclusion is that, ignoring the effects of control rod programming, the two enrichment core is superior from the standpoint of allowable power output. Although the preliminary control rod programming study performed on the uniform core indicates this type of core is subject to power flattening throughout life using control rods, the analytical procedures used in the study have not yet been experimentally verified. A study of rod programming in the two enrichment core must also be made before definite conclusions can be drawn.

\subsection{Core Kinetic Analysis}

H. C. Hecker

T. Gogniat

\section{Kinetic Parameters}

Calculations of various kinetic parameters of the. Yankee First Core have been completed. A summary of the results is given in Table XI. The methods used and a more detailed description of results will be presented in a future Yankee topical report entitled: "Kinetic Parameters of the Yankee First Core". The methods employed have not yet been adequately checked against experimental values. 
TABLE XI

\section{Kinetic Parameters of the Yankee First Core}

\begin{tabular}{|c|c|c|}
\hline " & $68 \%$ & $516 \%$ \\
\hline Moderator Temp. Coefficient $\left(\frac{1}{k} \frac{\partial k}{\partial \mathrm{T}_{\mathrm{m}}} \times 10^{4 / \%}\right)$ & +0.1 to -0.65 & -0.8 to -2.6 \\
\hline Doppler Temp. Coefficient $\left(\frac{1}{\mathrm{k}} \frac{\partial^{\mathrm{k}}}{\partial \mathrm{T}_{\mathrm{f}}} \times 10^{4} /{ }_{\mathrm{F}}\right)$ & -0.13 to -0.42 & -0.15 to -0.50 \\
\hline Void Coefficient ( $\% \Delta \%$ vold) & - & -0.33 \\
\hline Neutron Lifetime $\left(Q^{*}-\right.$ sec. $)$ & $-1.5-2.4 \times 10^{-5}$ & $1.4-2.5 \times 10^{-5}$ \\
\hline Deláyed Neutron Fraction (Beff) & $0.0047-0.0070$ & $0.0047-0.0070$ \\
\hline
\end{tabular}

The wide range of values given for the moderator temperature coefficient is cue primarily to variations in the method of control and to computational uncertainty. At the reactor operating temperature, a small part of the spread is due to changes during core life. The uncertainty in the Doppler temperature coefficient is due to the spread in the available measured values of the logarithmic derivative of the $\mathrm{U}-238$ resonance integral. A nominal value of the void coefficient has been presented. The variations in neutron lifetime and delayed fraction are expected to occur as the core changes during life, although the lower value for $\beta$ is somewhat extreme.

The range in the moderator coeffic ient under various possible types of control is shown in Figure 11. The upper curve represents the maximum coefficient since boron poison-alone was assumed for purposes of control. The lower curve shows the most negative coefficient since a minimum boron concentration (control rods fully inserted) was assumed for control. Thus, these assumptions represent the extreme limits, and any other combination of control should fall within the curves show.

Reactor Transient Analysis

The analysis of an uncontrolled rod withdrawal accident during reactor startup requires a representation of the average temperature of the fuel $\vec{T}_{f}$. The importance of $\overline{\mathrm{T}}_{f}$ arises from its effect on reactivity through the 


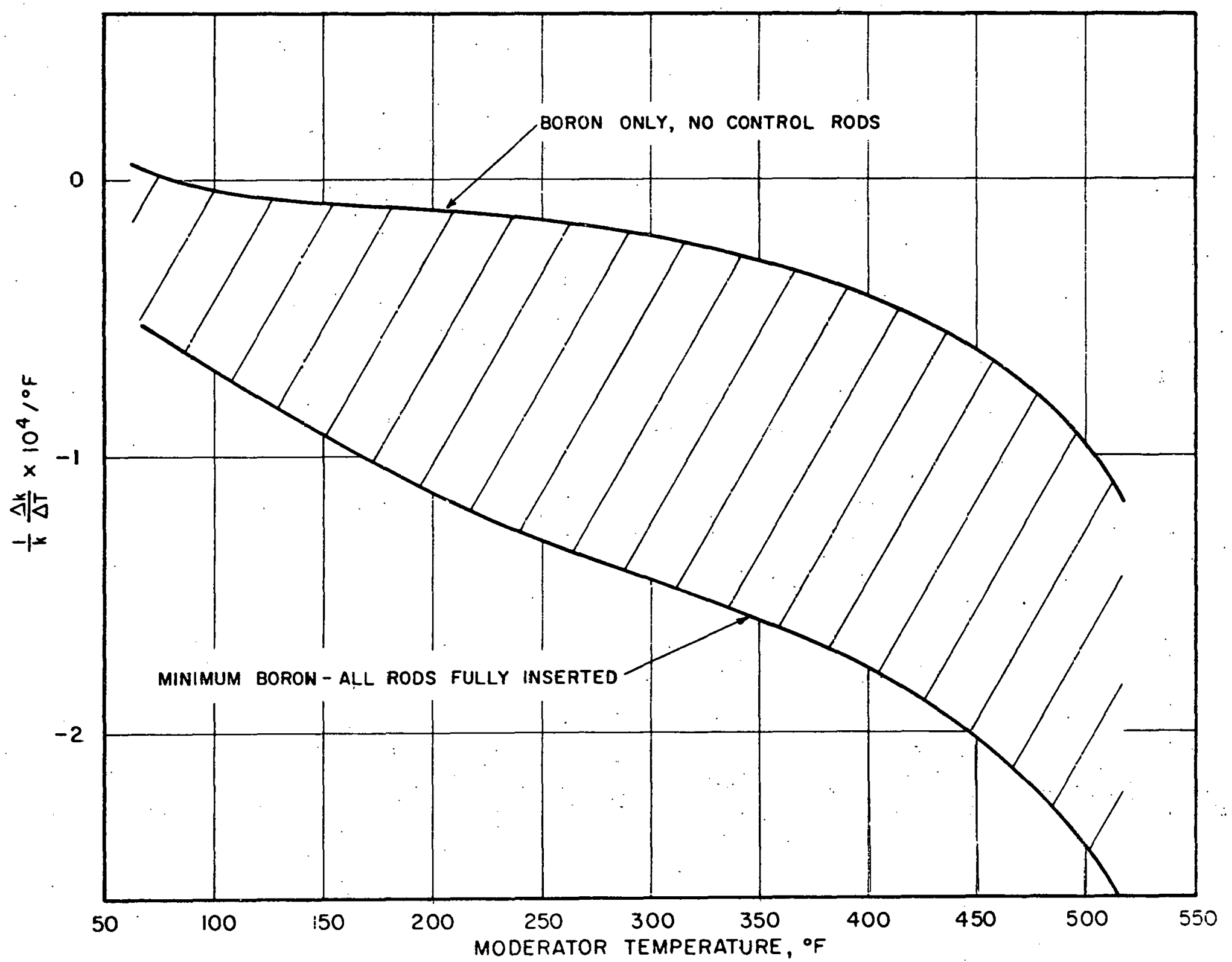

Figure 11 Possible Range of Yankee First Core Moderator Temperature Coefficient Due to Various Methods of Control 
Dopper coefficient. When using the analog computer in the analysis, various models can be used to represent the transient behavior of $\overline{\mathrm{T}}_{\mathrm{f}}$. Three models were investigated to determine how each affected certain plant variables during an uncontrolled rod withdrawal accident. These models were:

(1) Sectionalized fuel element.

(2) First moment approximation.

(3) Second moment approximation.

The procedure used in the computer analysis was as follows:

(1) A somewhat simplified Yankee plant was represented.

(2) $\overline{\mathrm{T}}_{f}$ was derived by sectionalizing the fuel element into 5 .radial regions of equal thickness.

(3) The rods were.withdrawn at some given ramp rate.

(4) Recordings were made of plant variables such as heat generated, $\overline{\mathrm{T}}_{\mathrm{f}}$ and $\overline{\mathrm{T}}_{\mathrm{sS}}$ (average steel temperature).

(5) The procedure was repeated, except that the first moment approximation model was substituted for the sectionalized fuel element model.

(6) Similarly, the second moment approximation was substituted for the first moment approximation.

Results obtained from a typical run for the core power and the average fuel temperature are shown in Figures-12 and 13. The results indicate fairly good agreement between the second moment approximation and the sectionalized model with a clear indication of the discrepancies to be expected from the use of the first moment approximation. Experience with the sectionalized model and the second moment approximation have led to the conclusion that from the standpoints of convenience in use and economy of equipment, the sectionalized model is to be preferred. This model will provide the basis for development of a new analog computer representation of the Yankee plant for use in start-up transient analysis.

2.4 Control Rod and Chemical Poison Analysis

T. Williams

W. J. Eich

\section{Control Rod Heat Generation}

In an attempt to prevent excessive corrosion of the Yankee control rods ( $80 \%$ silver, $15 \%$ indium, and $5 \%$ cadmium), a suitable protective cladding may be desirable. In designing such a clad for these cruciform rods, it is necessary to know the maximum induced gamma heating in a typical rod. Assuming a hardened gamma spectrum over the core and an overall core $\phi$ peak/ $\phi$ avg. of 4 (not including local flux peaking), a maximum gamma heating of 46.2 watts/cc was calculated.

$$
-44-
$$




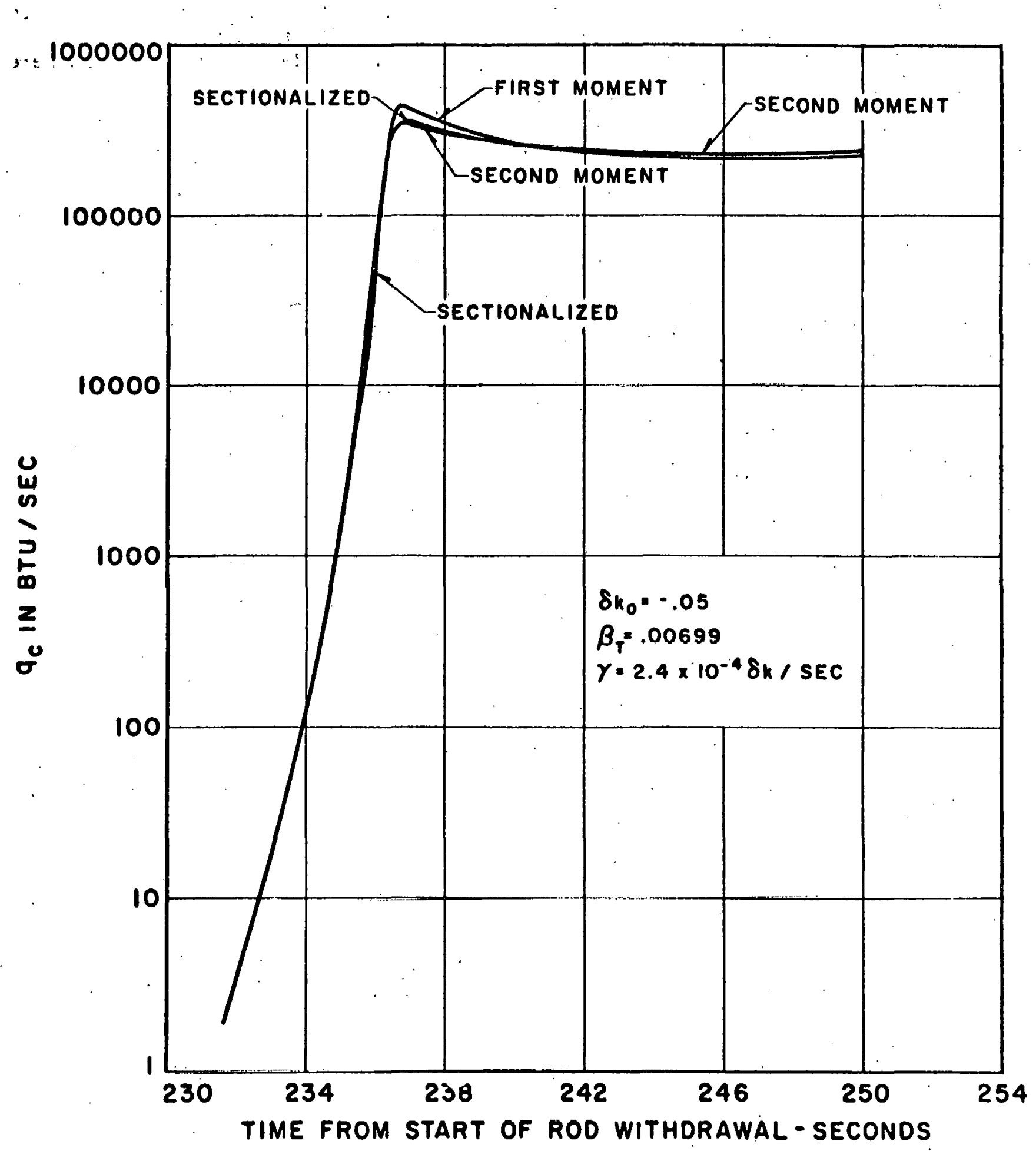

Figure 12 Transient Behavior of the Yankee First Core Power for Three Analog Computer Representations of the Fuel Rod Heat Transfer 


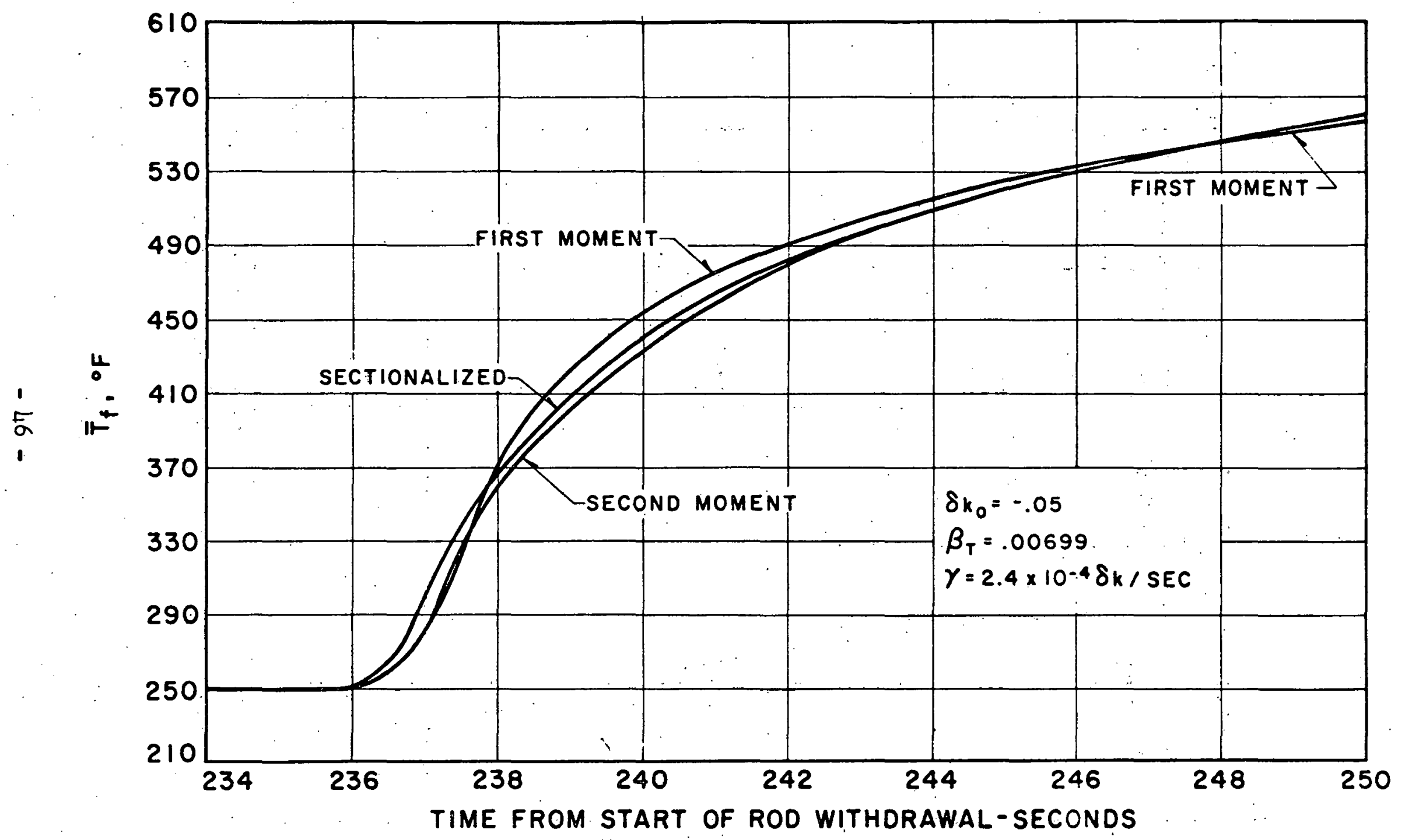

Figure 13 Transient Behavior of the Average Fuel Temperature for Three Analog Computer Representations of the Fuel Rod Heat Transfer 
Control Rod Programming

In a preliminary analysis of the reference control rod program for the Yankee reactor, the flux synthesis technique was used to obtain $r-z$ power distributions. The accuracy of one flux distribution obtained by the synthesis technique is being checked by the two-dimensional PDQ code. This PDQ problem is also being used to determine whether an axial xenon tilt can be detected by the monitors in the neutron tank.

\subsection{Critical Experiment Design and Analysi.s}
R. Wolf
J. Jedruch
V. Grob
W. Eich

Power Distribution Comparisons

A power distribution has been calculated for a cylindrical loading of the Yankee 2.23:1 water/uranium metal ratio critical experiment core containing 3476 fuel rods and five aluminum alloy control rod followers. The power plot is shown in Figure-14 and includes the experimental points previously obtained. All points were normalized to an average power density of unity. The calculated power distribution was found using the PDQ code which utilizes 2-dimensional diffusion theory with two groups of neutrons to obtain neutron flux distribution and multiplication factors for a multi-region reactor core. Agreement between the calculated power distribution and the experimental points is good. The discrepancy at the edge of the core may be due to the necessity of homogenizing the fuel region in the $\mathrm{PDQ}$ code.

Measurements have been made at the Westinghouse Reactor Evaluation Center of flux shapes from a $2.23: 1$ critical assembly containing a central control rod. A calculation is being performed on the same configuration to check the simulation of control rods in a core region by a uniformly distributed poison. This work is required to evaluate the analytical methods used in the control rod programming analysis. More accurate values for the macroscopic poison cross section equivalent to a control rod will also result from the analysis of these data.

An additional experimental confirmation has been obtained for the assumption of separation of variables in the solution of the diffusion equation. A series of measurements of flux in the axial direction has been made at various radial distances from the axis of symmetry of the 2.23:1 water/ uranium metal ratio $\mathrm{CRX}$ core, and the data have been fitted by means of the COFIT code. The following results have been obtained: 


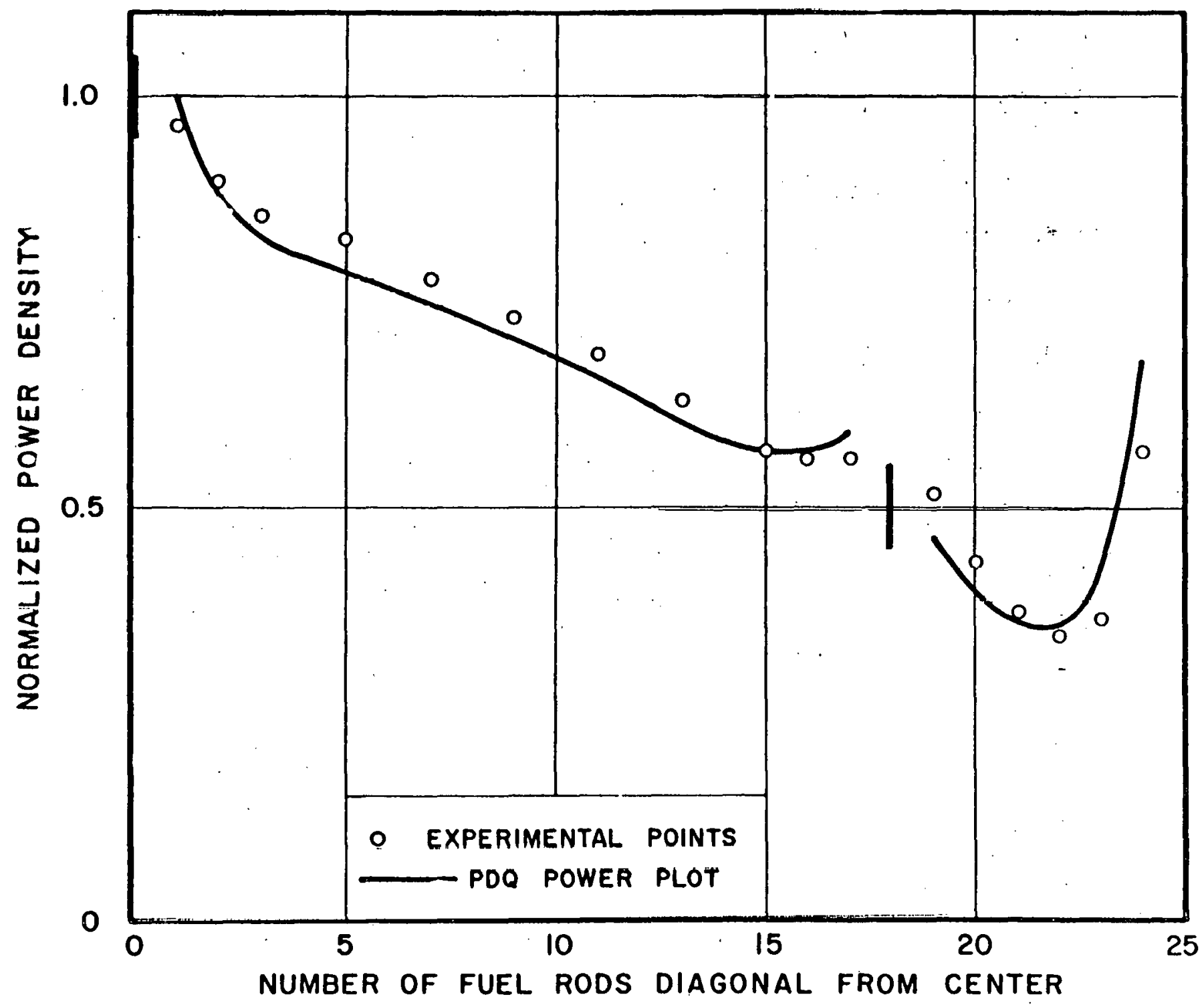

Figure 14 Comparison of Calculated and Experimental Power Distributions in the 2.23:1 $\mathrm{W} / \mathrm{U}$ Ratio CRX Core 
TABLE XII

Axial Buckling at Various Radil of the $2.23: 1 \mathrm{~W} / \mathrm{U}$ Ratio Yankee CRX Core

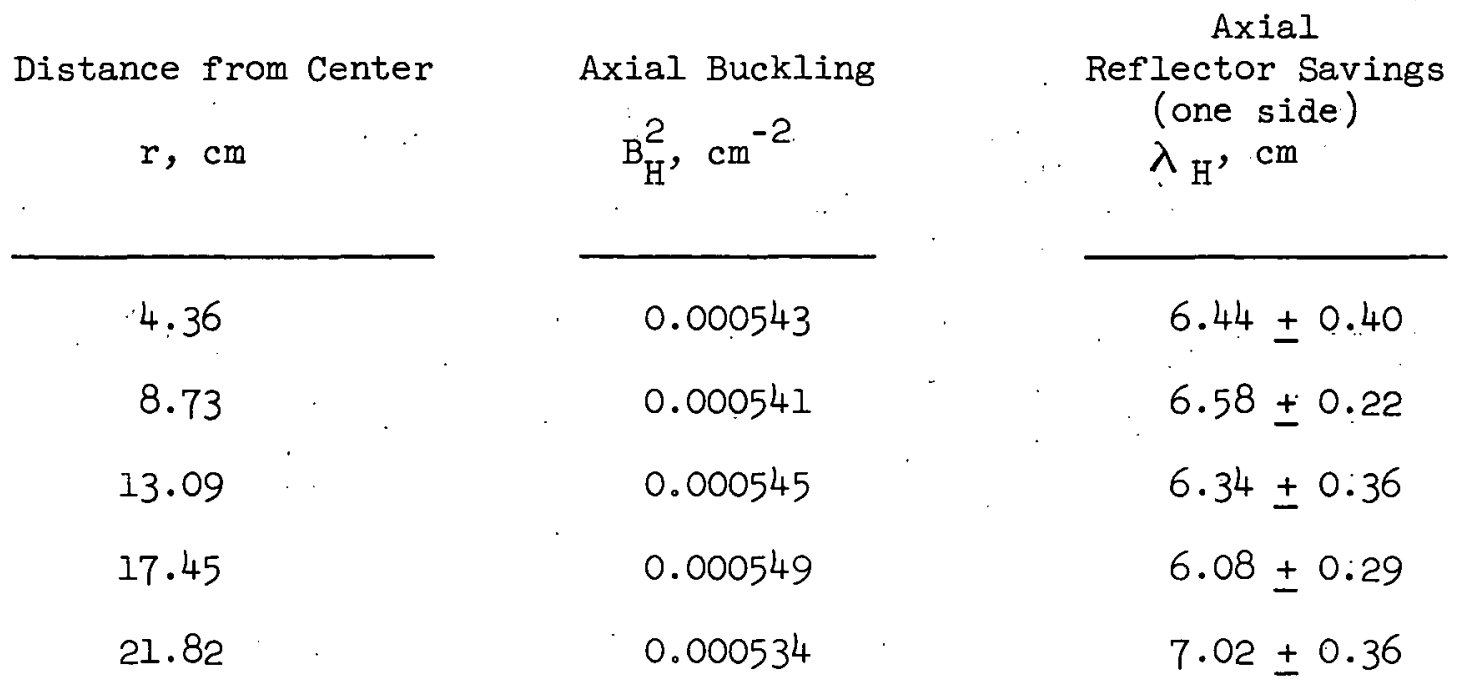

These results show agreement to within $3 \%$ and justify the assumption of separability.

Following the achievement of criticality with the 2.23:1 water-to-uranium ratio CRX core, a re-evaluation of the procedures for calculating the critical mass was initiated. The new procedure of calculation accounts for such additional effects as the epithermal fission in U-235, resonance absorptions in U-235 and stainless steel, and new flux disadvantage factors calculated from integral transport theory. The use of a U-238 resonance integral fitted to give the correct critical masses of the 3:1 (1862 rods) and 2.23:1 cores ( 3048 rods) led to a prediction of 1323 rods for the critical mass of the $4: 1$ core. This compares very well with the experimentally obtained value of 1314 rods.

Rod Worth Studies

Evaluation of the measurements performed on the $3: 1$ water/uranium metal ratio CRX core continued with the calculation of the total worth of a bank of nine control rods moved as a unit. The calculation was based on the measurement of flux shape in the axial direction in the core, where the flux was measured by irradiation of gold and copper foils. A part of the flux traverse corresponding to the upper region of the core, which contained the banked rods, has been fitted to obtain the best argument of an exponential function by means of the EXFIT code - a least squares curve fitting program for the IBM-704 computer. The axial buckling was 
thus obtained for various core sizes and positions of the bank of nine control rods and was then used to calculate the total worth they would have if fully inserted. The results of these. studies are as follows:

\section{TABLE XIII}

Total Control Rod Worth of the $3: 1 \mathrm{~W} / \mathrm{U}$ Ratio CRX Core Nine Control Rods Moved in a Bank

$\begin{array}{ccc}\text { No. of Fuel Rods } & \frac{\text { Depth of Insertion }}{3244^{-}} & \frac{\text { Total Rod Worth }}{30 \mathrm{~cm}} \\ 3244^{\circ} & 80 & 20.4 \% \\ 3536 & 82: & 18.6 \\ 3536 & 82 & 19.7 \\ 2064 & 42 & 20.3\end{array}$

These results are reasonably consistent with each other, although somewhat higher than expected from measurements of single rod worths.

A study is being conducted of the experimental control rod. worth data from the $3: 1 \mathrm{~W} / \mathrm{U}$ ratio Yankee critical core. The experimental data were obtained by fully inserting various control rod combinations and determining the amount of poison (boric acid) needed to make $k_{\text {ff }}=I$. The rods were then withdrawn and the amount of additional poison heeded to make $k_{1}=1$ was obtained. Thus, the boron equivalent of each rod or group of rofis was obtained. The core parameters were found using the SOFOCATE code which determines the thermal constants averaged over a Wigner-Wilkins flux spectrum. The experimental rod worths were then found from the following equation:

$$
\Delta k / k=\frac{f_{1}-f_{2}}{f_{1}}+p=\frac{\left(\frac{\varepsilon a u}{\varepsilon a}\right)^{2}-\left(\frac{\Sigma a u}{\Sigma a}\right)^{2}}{\left(\frac{\Sigma a u}{\Sigma a}\right)^{1}}
$$


where. $\cdot\left(\frac{\varepsilon a u}{\varepsilon a}\right)^{1}=\cdots f_{1}=\begin{aligned} & \text { the fraction of all thermal neutrons that are absorbed } \\ & \text { in uranium with the control rod fully inserted }\end{aligned}$ $\left(\frac{\varepsilon a u}{\varepsilon a}\right)^{2}=f_{2}=\begin{aligned} & \text { the fraction of all thermal neutrons that are absorbed } \\ & \text { in uranium with the control rod fully out }\end{aligned}$

$\mathrm{p}=$ period correction, caused by failure to adjust boron concentrations to exact values required for criticality

The experimental rod worth $(\Delta \mathrm{k} / \mathrm{k})$ for the central control rod was then compared to a $(\Delta \mathrm{k} / \mathrm{k})$ theory' for thep central control rod, obtalned by using perturbation theory. Ther theoretical value was $24 \%$ below that obtalned by this experiment. This difference can be attributed to resonance absorption in the control rod, which the theoretical calculation does not take into consideration.

\section{Temperature Coefficient Comparisons}

Computations of the moderator temperature coefficient of the CRX core, at moderator temperatures below $80^{\circ} \mathrm{C}$., were continued. Extensive work was performed on the $3: 1$ core, but agreement with experimental results has not yet been attained.

\section{Data Reduction}

A description of the new JOFIT code is given in toplcal report YAEC-86, "JOFIT - A Bessel J Least Squares Fitting Program for the IBM-704 Computer" issued in October 1958. The code is designed to fit the reduced results of foil irradiations in a neutron flux to the best argument of the Bessel $\mathrm{J}_{0}$ function. Prior to final release, the JOFIT code was thoroughly tested and its performance found to be satisfactory.

\subsection{Irradiation Experiment Design and Analysis}

W. J. Eich

Piping near the purification cubicle of the MTR in-pile test loop is located close to radiation-sensitive instrumentation. It was determined that three inches of lead shielding around the pipe will reduce the level of radiation from fission products in the coolant to a safe level for the instrumentation. 
Nuclear design data were calculated for the MTR process water irradiation experiments for a pellet having a 0.294 inch diameter within either a 15 or 21 mil stainless steel clad. Table XIV sumarizes the calculations.

\section{TABLE XIV}

"Unperturbed" Fluxes $\left(10^{13} \mathrm{n} \mathrm{cm}^{-2} \mathrm{sec}^{-1}\right.$ ) Required for Clad Surface Heat Fluxes of $4.5 \times 10^{5} \mathrm{Btu} / \mathrm{ft}^{2}-\mathrm{hr}$

$\begin{array}{ccc}\text { Enrichment }(\%) & \frac{15 \text { Mil Clad }}{21 \text { Mil Clad }} \\ 2.7 & 8.9 & 9.2 \\ 5.4 & 4.6 & 4.9 \\ 6.8 & 3.8 & 4.0\end{array}$

\subsection{Shielding Analysis}

No work was performed under this subproject during the third quarter of 1958.

\subsection{Startup Experiment Assistance}

No work was performed under this subproject during the third quarter of 1958. 


\subsection{CHEMISTRY}

Chemistry and Ceramics Section:

R. F. Sterling, Manager

Studies of stablilty, corrosion effects, removal of nuclear poisons, crud problems, fuel element rupture problems and the specification of the primary coolant are included under this project.

\subsection{Properties and Removal of Chemical Neutron Absorbers}

N. Michael

Ion Exchange of Radiolsotopes

Mixed Fission Products

Decontamination factors were reported in YAEC-87, Quarterly Progress Report for the April to June, 1958 period for three candidate ion exchange resins Rohm \& Haas XE-150, -154 and -170 - using a synthetically prepared solution of mixed corrosion products. In order to learn the degree of selectivity in pick-up of the different elements, experiments were performed with separate corrosion elements - chromium, cobalt, and iron. Since fresh Oak Ridge National Laboratory radioisotopes were. used in these experiments, re-runs were made with mixed corrosion products for more accurate comparison of decontamination factors. Each of the three resins was tested separately with four solutions: 1) iron $0.06 \mathrm{ppm}$, 2) chromium $0.0007 \mathrm{ppm}$, 3) cobalt $0.012 \mathrm{ppm}$, and 4) corrosion product mixture (i.e., a mixture of $\mathrm{Fe}, \mathrm{Cr}$, and Co in above concentrations). In testing $\mathrm{XE}-150$ and $\mathrm{XE}-170$ resins, solution $\mathrm{pH}$ was adjusted to 8.5 with $\mathrm{NH}_{4} \mathrm{OH}$; in the case of XE-154, solution $\mathrm{pH}$ was adjusted. to 8.5 with $\mathrm{LiOH}$. A.1000 $\mathrm{ml}$ solution sample at $130^{\circ} \mathrm{F}$. was passed through $100 \mathrm{ml}$ of resin in each test. The mean decontamination factors of the three resins are compared below:

\section{Decontamination Factors}

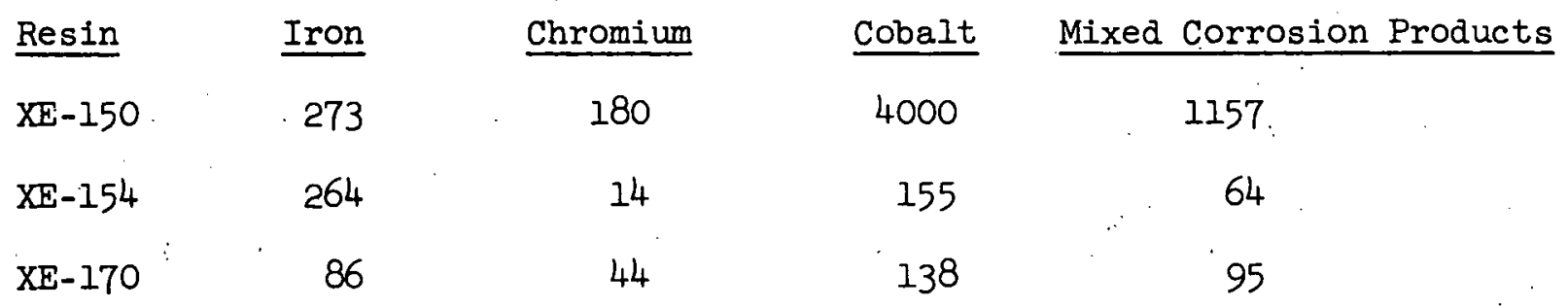


The values given above for $X E-150$ and $X E-170$ tested with mixed corrosion products are somewhat higher than those previously reported in Quarterly Progress Report YAEC-87 - 335 and $7 \cdot 7$, respectively. The reason for this difference is twofold:

1. The material tested is from a different 1sotope shipment and the chemical properties of the two possibly differ, e. g., oxidation states and colloldal form may not be alike.

2. Column throughput in these tests was $1000 \mathrm{ml}$ compared to $1500 \mathrm{ml}$ previously.

Borlc Ac1d Removal Studies

Studies have been conducted to compare the capacity of several candidate ion exchange resins for use in removing borlc acid from the Yankee primary coolant system during reactor startup. The experiments were concluded, and Rohm and Haas XE-78 anton resin has been selected as the reference resin for this application. A $40 \mathrm{ppm}$ boron solution and Nalcite SBR and Rohm and Haas XE-78 anion resin were used. Before addition of the acid, water $\mathrm{pH}$ was adjusted to $10 \mathrm{with} \mathrm{LIOH}$. Flow rate during the experiment was $25 \mathrm{ml} / \mathrm{min}\left(1.9 \mathrm{GPM} / \mathrm{ft}^{3}\right)$ at a temperature of $130 \mathrm{~F}$. . Spent resin was eluted with $\mathrm{NaOH}$. The eluent was analyzed to determine total boric acld capacity of each resin. The -78 has a capacity, under the conditions outlined, of $3.9 \mathrm{lbs} / \mathrm{ft}^{3}$ and the SBR a capacity of $3.3 \mathrm{lbs} / \mathrm{ft}^{3}$. Capac1ty results reported in the YAEC -87 Quarterly Progress Report should be revised as a result of corrections submitted by the (W) APD Analytical Laboratory. The conditions of the test were as follows: Boric acid was added to $\mathrm{L} 1 \mathrm{OH}$ solution to give a total boron concentration of $94.5 \mathrm{ppm}$ boron. The rȩvised boric acid capacity of $\mathrm{XE}-78$ with this test solution is $5.6 \mathrm{lbs} / \mathrm{ft}^{3}$, with SBR it is $3.7 \mathrm{lbs} / \mathrm{ft}^{3}$.

\section{Pressure Drop and Filtration Studies}

Hydraulic characteristics of XE 150 and "Neva-Clog" filter medium - the respective mixed-bed reference resin and under-drain filter for the Yankee Reactor - were investigated. Both filter and resin data showed a straight-line relationship for pressure drop vs. flow rate on logarithm coordinates. Pressure drop for the "Neva-Clog" increased from 0.2 to 4 psi on increasing the flow rate from 2 to $8 \mathrm{GPM} / \mathrm{ft}^{2}$ - area. The pressure drop for the resin over the same flow range is 0.05 to 0.3 psi per foot of bed depth. During the study of hydraulic characteristics; approximately 13 galions of demineralized water was sent through the column. The effluent was collected and filtered with Wahtman No. 40 paper. The resin particles on the filter were counted and the size of the largest particle measured. A total of 150 particles was found with sizes up to a maximum of 50 microns. The preceding results are well within the guaranteed retentivity of the "Neva-Clog" filter. Information obtained from the use of this type filter in other reactors indicates. that it is a most reliable resin bed support medium. 


\subsection{Corrosion of Materials of Construction}
D. D. Whyte
A. Krieg

Corrosion of AISI 304 Stainless Steel in High Temperature Borated Water

Revaluation of the results of corrosion tests of AISI 304 stainless steel In high temperature borated water is in progress. Specimens originally electrolytically descaled have been descaled chemically using the basic permanganate-ammonium citrate procedure. The results of Test No. MEDA-I (Boron -as boric acid $=39^{\circ} \mathrm{ppm}, \mathrm{pH}=9.8 \mathrm{with}$ lithium hydroxide) are complete and are shown graphically in Figure-15. : No significant change from the previous results obtained with electrolytic descaling has been observed. The chemical descaling treatment was particularly effective in removing scale easily and completely. This treatment produced some attack on the base metal ( $1.1 \mathrm{mg} / \mathrm{dm} 2$ in 5 minutes). The results shown in Figure-15 are corrected for base metal attack. Preliminary indications are that the residual scale (after electrolytic descaling) was more difficult to remove chemically in all of the remaining tests (MEDA-2, MEDB-1 and MEDB-2). The descaled weight changes after chemical descaling are substantially higher for the three remaining tests than those previously obtained by electrolytic descaling. The final draft of Topical Report YAEC -68 covering the revaluation of the four tests in the (W) Materials Engineering Department test loops is being prepared.

Dynamic Screening Tests of Yankee Primary System Materials

Screening tests of proposed Yankee Primary System materials have been continued under high flow conditions at various levels of boron concentration in the presence of lithium hydroxide. The results of tests performed in the absence of lithium hydroxide are shown in. Table XV for comparison with the results of the $\mathrm{pH}$ adjusted tests shown in Table XVI. The effect of $\mathrm{pH}$ adjustment has been to decrease the extent of gross corrosion of AISI 304 stainless steel, AISI 410 stainless steel and Inconei. The effect on $\mathrm{Ag}-\mathrm{In}-\mathrm{Cd}$.corrosion is at present uncertain. The gross corrosion of Zircaloy-2 appears to be independent of $\mathrm{pH}$ adjustment.

(W) APD loop "A" Test No. 7 (Table XVI) was performed under conditions which were intended to investigate the feasibility of a chemical stability study in the WCAP-4 in-pile loop test at MPR. The detalled water chemistry data for Test No. 7 are summarized in Table XVII. The results indicate that the analytical procedures used are sufficiently precise to account for boron concentration changes as a function of dilution by make-up water addition. No evidence for boron "hide-out" within the accuracy of the analytical procedure was detected. Lithium concentrations were more difficult to follow at the low concentration range used.. In general, the feasibility of a chemical stability in-pile experiment was indicated. 


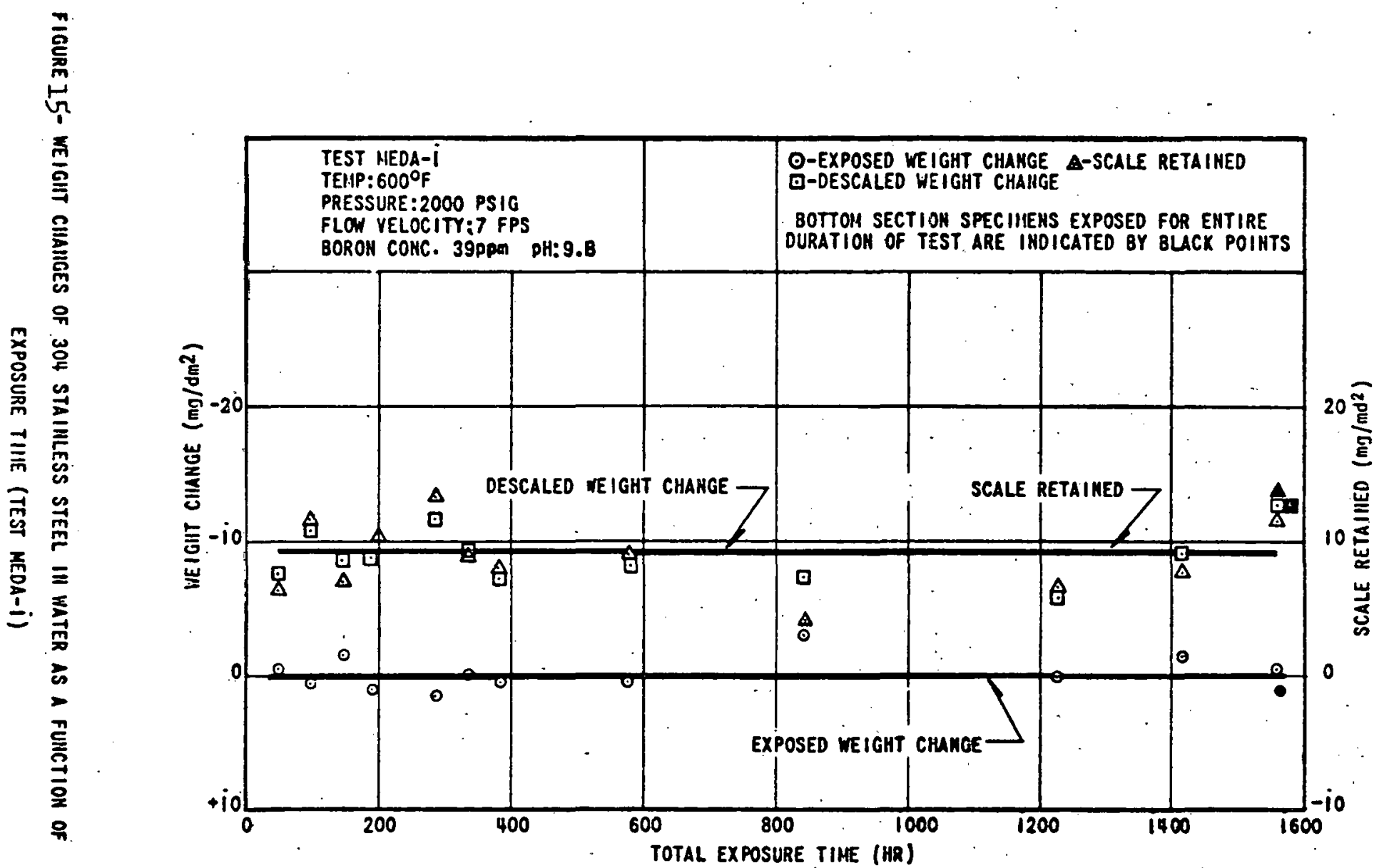


Results of Screening Corrosion Test Numbers 3,4 and 5 of Yankee Primary System Materials for One Month in High Temperature Water

Test No.

Test Conditions

Temp., OF

Pressure, psig

Flow, fps

Duration, hr.

$\mathrm{H}_{2}, \mathrm{ml}(\mathrm{STP}) / \mathrm{kg}$.

B (as boric acid),ppm

$\mathrm{pH}$

Specimen Results

\section{AISI $304 \mathrm{~s} / \mathrm{s}$}

\section{a: quenched}

b. heat sensitiged

c. as-received

d. polished

e. weld coated, $50 \%$

f. with Nicrobraze -50

$\mathrm{Ag}-\mathrm{In}-\mathrm{Cd}$

$410 \mathrm{~s} / \mathrm{s}$

Inconel

$\mathrm{Zr}-2$

Hafnium

* Weight after exposure minus original weight.

* Original weight minus weight after chemical descaling (corrected for attack of descaling solution on base metal).

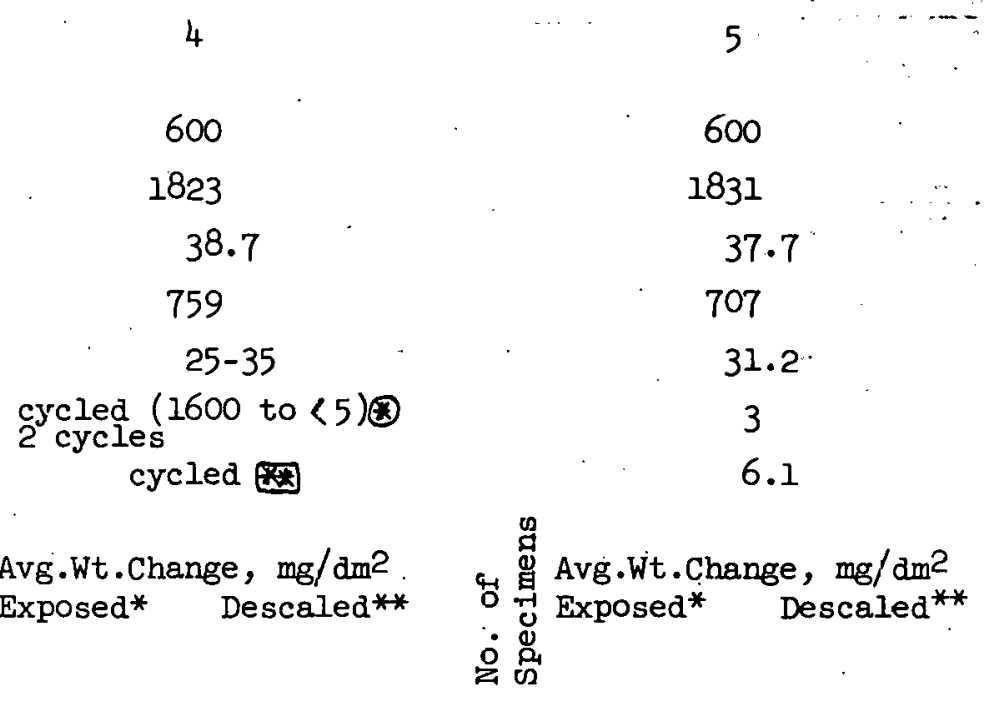

$\begin{array}{ccccc}-13.1 & -33.3 & 1 & -16.9 & -46.7 \\ -12.5 & -33.3 & 2 & -20.1 & -52.3 \\ -13.7 & -32.7 & 1 & -21.7 & -62.2 \\ -11.3 & -33.6 & 2 & -13.8 & -42.2 \\ -10.1 & -27.0 & 1 & -14.9 & -40.2 \\ - & - & 1 & -14.9 & - \\ +22.6 & - & & & \\ -75.0 & -142.7 & 3 & +154.5 & - \\ -41.1 & -80.9 & 2 & -31.8 & -84.6 \\ +13.7 & - & 2 & -13.4 & -42.6 \\ - & - & 2 & +24.2 & -\end{array}$

High boron- average ppm boron= 1630 ; low boronaverage ppm boron $=<5$

High boron- average $\mathrm{pH}=5.7$; low boron- average $\mathrm{pH}=6.0$ 


\section{$\underline{T A B L E}$ XVI}

Results of Scrəening Corrosion Test Numbers 6,7 and 8 of Yankee Primary Systen Materials for One Month in High Temperature Water

Test No.

Test Conditions

Temp., OF

Pressure, psig

Flow, fps

Duration, hr.

$\mathrm{H}_{2}$, ml (STP)/kg

B (as boric acid), ppn

$\mathrm{pH}$ ( $\mathrm{Li}, \mathrm{ppq})$

$\mathrm{O}_{2}$, ppm

I Specimen Results

AISI, $304 \mathrm{~s} / \mathrm{s}$

6
600
1828
38.8
714
27.1
1561
$5.9-6.3(0.98)$
.$<0.1$

8

591

1808

38.6

691

30.5

Nominal 1600 to $<5$ ( 2 cycles)

2 cycles

0.3

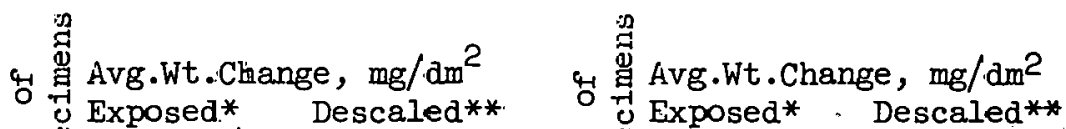

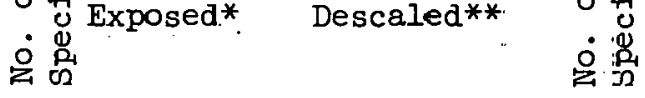

Exposed* . Descaled** 范 ${ }^{*}$ Exposed* Descaled**

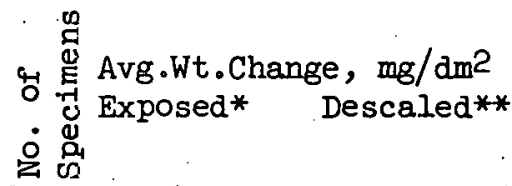

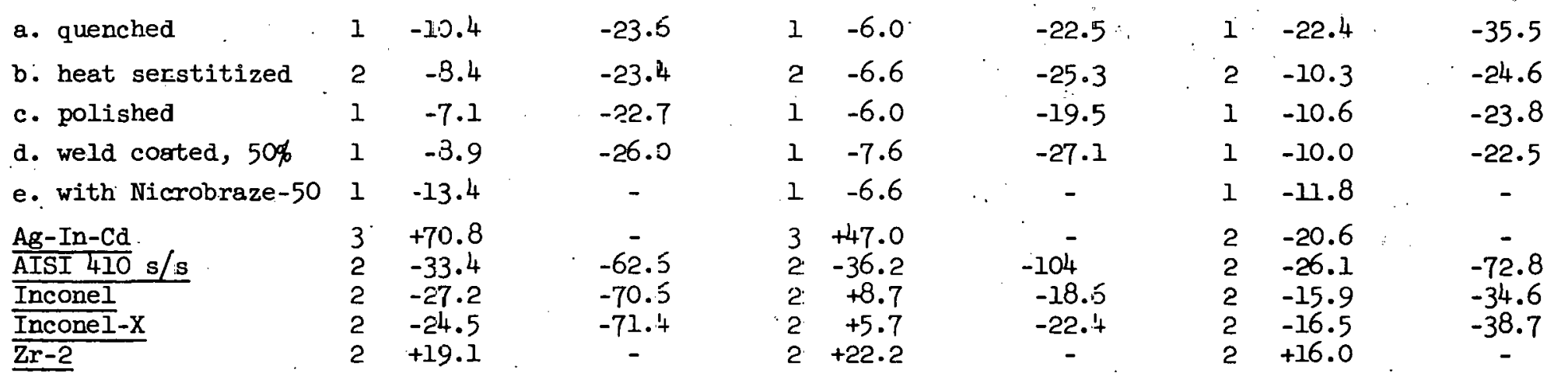

* Weight after exposure minus original weight.

* Original weight minus weight after chemical descaling (corrected for attack of descaling solution on base

(2) High boron- average ppm boron= 1790; low boronaverage ppin boron= 11.6 : metal).

High boron- average $\mathrm{pH}=6.1$ (lithium $=1.28 \mathrm{ppm}$ ); Iow boron - average $\mathrm{pH}=8.6$ (lithium $=0.8 \mathrm{ppm}$ ). 
MTR "WATER CHEMISTRY STABILITY" EXPERIMENT SIMULATION

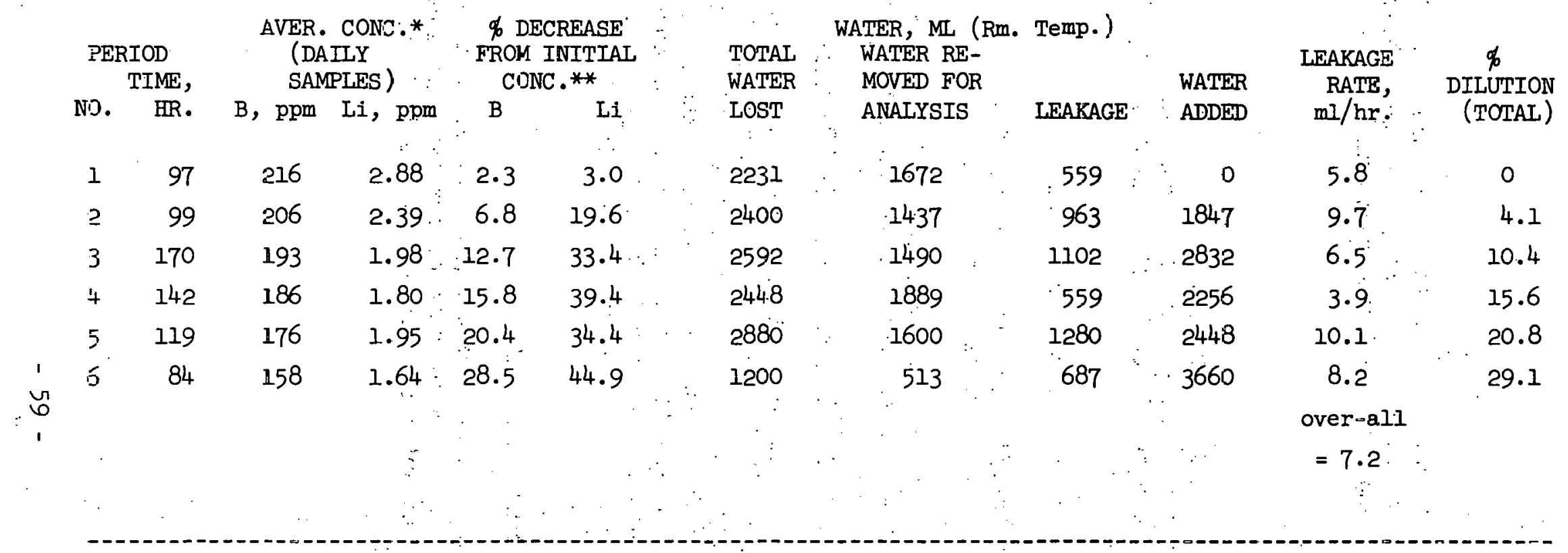

Test Conditions:

$\mathrm{T}=600^{\circ} \mathrm{F}$

$\mathrm{P}=1816$ psig

Flow $=33.6$ feet per second

Duration $=712$ hours

$\mathrm{H}_{2}, \mathrm{ml}$ (STP) per $\mathrm{kg}$. $=34.9$.

$\mathrm{B}$ (as boric acid), $\mathrm{ppm}=189$

Li as ( L.HOH), $\mathrm{ppm}=2.0$

$\mathrm{pH}=7.4$

$\mathrm{O}_{2}, \mathrm{ppm}=0.03$

Cl-, $\mathrm{ppm}=0.1 \mathrm{I}$

* Up to but not including water addition at end of period.

** Initial conc.: $\mathrm{B}=221 \mathrm{ppm} ; \mathrm{Li}=2.97 \mathrm{ppm}$. 
pH Control Agent Selection

Corrosion studies of Yankee primary system materials undertaken in static autoclaves to aid in the determination of a $\mathrm{pH}$ control agent have been completed. Two tests were conducted simultaneously under the following conditions:

Flow - static

Pressure - 1525 psig

Temperature - 600 F.

Water Chemistry - $1600 \mathrm{ppm} \mathrm{B}$ (added as $\mathrm{H}_{3} \mathrm{BO}_{3}$ ) $\mathrm{pH}$ - adjusted to $10 \pm 0.5^{3}$ before addition of $\mathrm{H}_{3} \mathrm{BO}_{3}$ (controlled with $\mathrm{KOH}$ or $\mathrm{LiOH}) 30 \mathrm{cc} \mathrm{H}_{2} / \mathrm{Kg} \cdot \mathrm{H}_{2} \mathrm{O}\left(\mathrm{ST}^{3}\right)$ $\mathrm{O}_{2}=<0: 1 \mathrm{ppm}$

Conclusions from the corrosion studies are as follows:

1. The corrosion rate of $80 \mathrm{Ag}-15 \mathrm{In}-5 \mathrm{Cd}$ and Nicrobraz-50 is much greater in water containing $\mathrm{KOH}$ than in water containing $\mathrm{LLOH}$.

2. The corrosion of all other materials was slight and little difference was observed for corrosion in water containing either LiOH or $\mathrm{KOH}$.

Dynamic Tests of $80 / \mathrm{Ag}-15 / \mathrm{In}-5 / \mathrm{Cd}$ Alloy in Boric Acid Solution

The ef'fect of boric acid on the corrosion behavior of unplated $80 / \mathrm{Ag}-15 / \mathrm{In}$ $5 / \mathrm{Cd}$ alloy was investigated at $600^{\circ} \mathrm{F}$. under semi-dynamic conditions ( 0.1 fps) in water containing $\mathrm{H}_{3} \mathrm{BO}_{3}$, and either $\mathrm{LiOH}$ or $\mathrm{KOH}$. The results are that the presence of $9145 \mathrm{ppm} \mathrm{H}_{3} \mathrm{BO}_{3}(1600 \mathrm{ppm} \mathrm{B})$ in the LiOH solution decreased the weight gain of $\mathrm{Ag}$-In-ed from $107 \mathrm{mg} / \mathrm{dm}^{2} / \mathrm{mo}$ (without $\mathrm{H}_{3} \mathrm{BO}_{3}$ ) to $34 \mathrm{mg} / \mathrm{dm}^{2} / \mathrm{mo}$. The presence of $9145 \mathrm{ppm} \mathrm{H}_{3} \mathrm{BO}_{3}(1600 \mathrm{ppm} \mathrm{B}$ ). in the $\mathrm{KOH}$ solution decreased the gorrosion rate of $\mathrm{Ag}^{3} \mathrm{In}-\mathrm{Cd}$ from $76 \mathrm{mg} / \mathrm{dm}^{2} / \mathrm{mo}$ (without $\mathrm{H}_{3} \mathrm{BO}_{3}$ ) to $21 \mathrm{mg} / \mathrm{dm}^{2} / \mathrm{mo}$.

Simulated Reactor Startup and Shutdown Tests.

Two dynamic autoclave corrosion tests are being performed to determine the effect of concentration cycling of boric acid on corrosion of Yankee primary system materials. One autoclave contains $\mathrm{I}$ ppm of $\mathrm{Li}$ as $\mathrm{LiOH}$ and the other contains no lithium. 
Test conditions are:

$\begin{array}{ll}\text { Flow } & -0.1 \text { fps } \\ \text { Temperature } & -600 \mathrm{~F} \\ \text { Pressure } & -1525 \mathrm{psig} \\ \text { Water Chemistry } & -\mathrm{pH}-\text { test } 1-5.8 \text { (controlled with } 3.4 \text { ppm LiOH) } \\ & \mathrm{pH}-\text { test } 2-4.8 \\ & 30 \mathrm{cc} \mathrm{H}_{2} / \mathrm{Kg} \mathrm{H}_{2} \mathrm{O} \text { (STP); } \mathrm{O}_{2}=<0.1 \mathrm{ppm} \\ & \text { Boron }-1600 \mathrm{ppm} \text { to } 5 \mathrm{ppm} \text { cycled up and down every } 14 \text { days. }\end{array}$

Results to date are listed.in. Table XVIII.

Reaction of Oxygen with Hydrazine in Borated Water

In view of published information that the reaction rate of hydrazine with oxygen is a function of solution $\mathrm{pH}$, a study is being conducted to determine the reaction rates as a function of temperature and time in the presence of shutdown borlc acid concentrations. The first test was complicated by the effect of boric acid on the hydrazine added. Oxygen. analysis was difficult due to the presence of hydrazine and boric acid which interfered with the analytical procedures employed. (Modified Winkler Method). A reliable analytical technique was developed which permitted a second test to be performed in a dynamic autoclave by: effecting. a reaction between water containing $1600 \mathrm{ppm}$ boron as boric acid and $7 \mathrm{ppm}$ of dissolved oxygen, and an equimolar amount ( $7 \mathrm{ppm}$ ) of hydrazine:- The results of the test are as follows:

\begin{tabular}{|c|c|c|c|c|}
\hline Time (min.) & Temp. $\left({ }^{\circ} \mathrm{F}.\right)$ & $\underline{0}_{2}$ & $\underline{N}_{2} \mathrm{H}_{4} \stackrel{(\mathrm{ppm})}{ }$ & $\underline{\mathrm{pH}}$ \\
\hline 0 & 71 & 7.0 & 0 & 4.8 \\
\hline $\mathrm{N}_{2} \mathrm{H}_{4}$ added & -- & -- & 7.0 & $5 \cdot 9$ \\
\hline 30 & 122 & 3.0 & 3.6 & 5.6 \\
\hline 45 & 173 & 1.2 & 1.9 & 5.4 \\
\hline 60 & 211 & 1.0 & 1.6 & 5.4 \\
\hline 75 & 254 & $<0.02$ & 1.5 & 5.4 \\
\hline 90 & 303 & $<0.02$ & 1.4 & 5.4 \\
\hline 105 & 351 & -- & 1.3 & 5.4 \\
\hline 120 & 402 & -- & 1.2 & 5.4 \\
\hline 135 & 424 & -- & 1.1 & 5.4 \\
\hline
\end{tabular}




\section{TAELE XVIII}

SIMULATED REACTOR STAFTUP AND SHUTDOWN TEST RESULTS

\section{Expose:d Weight Change (mg/dm²)}

Spec. Comp.

Nicrobraz-50

AISI 304: S/S Senșitized

Zircaloy-2

กิ

$A g-I n-C d$

A.ISI 304 S/S Quenched

AISI 410 Stainless Steel

AISI $304 \mathrm{~s} / \mathrm{S}$ As-received

Zircaloy-2 vs. Ag-In-Cd

Zircaloy:-2 vs AISI 304 S/S Qựenched

AISI $304 \mathrm{~s} / \mathrm{S}$ Quenched vs. Ag-In-Cd

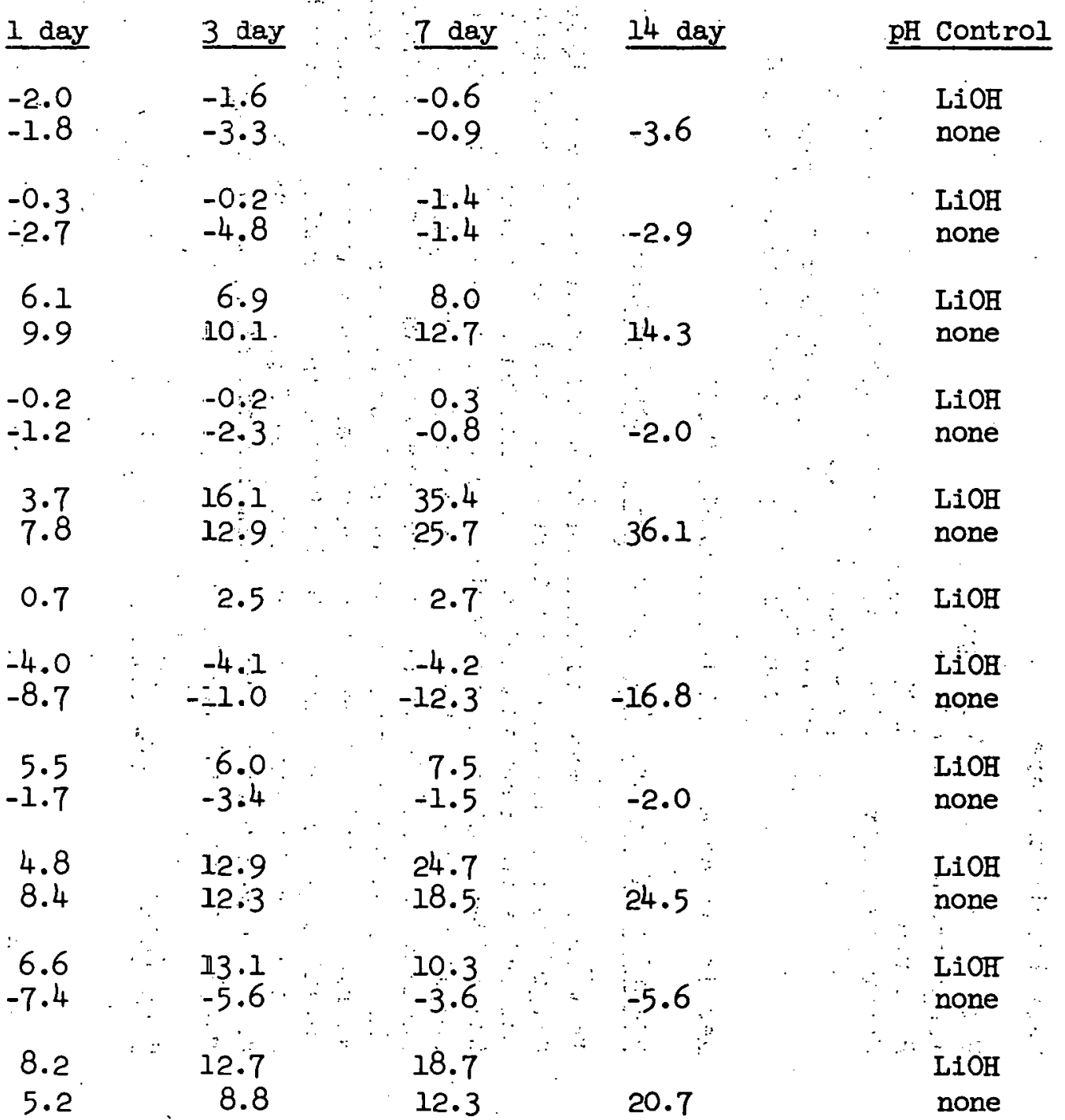


The results indicate that hydrazine is effective in removing oxygen at a temperature below $254^{\circ} \mathrm{F}$. The further reduction in hydrazine content above this temperature was caused by the effect of elevated temperature on the hydrazine. The fact that there was not an equimolar reaction between hydrazine an ozygen is indicative of oxygen removal by autoclave materials. The next series of tests will determine the time required for hydrazine: to remove essentially all oxygen from the water under the same conditions as the preceding test except that constant reaction temperatures of approximately $200^{\circ} \mathrm{F}$ and $250^{\circ} \mathrm{F}$ will be maintained.

Silver - Indium - Cadmium Studies - Crud Transport Problems

Silver-indium-cadmium crud transport problems were evaluated by (WAPD Reactor Engineering Department personnel with the following results:

1. Forty $\mathrm{mg} / \mathrm{dm}^{2} / \mathrm{mo}$ of crud from corrosion of the control rods would not present shielding difficulties in the Yankee reactor. Four hundred plus $\mathrm{mg} / \mathrm{dm}^{2} / \mathrm{mo}$ corrosion would begin to present problems.

2. Dissolution of unplated $\mathrm{Ag}$-In-Cd samples in the in-pile test loop (100\% dissolution of all specimens postulated for calculation purposes to occur at 10 months exposure) would present no shielding problems.

3.4 Interactions Between Chemical Absorber, Corrosion Products and Fission Products
R. F. Sterling
C. C. Thomas

The study of the effects of Van de Graaff electron beam irradiation on crud deposition, at both neutral and elevated $\mathrm{pH}$ was concluded and the data were analyzed. The final draft of topical report YAEC-93, "Corrosion Product Transport and Deposition Under Ionizing Radiation" covering the investigation is being prepared. Conclusions which were drawn include the following:

1. The only deposits attributable to radiation-induced deposition were found on the directly Lrradialed surfuces (Zircaloy-2 and AISI 304 stainless steel) rather than on the specimens.

2. No significant difference was noted in the amount of iron deposited under radiation at $\mathrm{pH} 7$ and at $\mathrm{pH}$ iO on AISI 304 stainless steel.

3. The deposition of iron on Zircaloy-2 at $\mathrm{pH} 10$ is greater than on AISI 304 stainless steel at $\mathrm{pH} 10$.

4. In future studies, the use of test specimens that do not contain elements in common with the crud would facilitate the evaluation of the results obtained in the experiments. 
5. The size of the crud particles appear to increase with $\mathrm{pH}$.

6. Comparison of these results with previous experimenter's data shows considerable difference in the apparent crud release rates found at $\mathrm{pH} 7$ and in the location of the crud deposits at elther pH. The need for additional crud deposition studies is indicated to determine the cause of such differences.

\section{-3.5 Decontamination and Waste Dispasal Studies}

R M. Watkins

The best method of measuring the effectiveness of a proposed decontamination procedure is to actualiy determine its ability to remove a deposited. radioactive oxide film from a sample of material similar to that from which the plant system is to be fabricated. In an effort to do this, contaminated specimens of austenitic stainless steel tubing (3/8 inch in diameter) from the original SIW steam generator have been obtained. The necessary equipment for handiing the radioactive pipe specimens was procured, and after receiving (W) APD Health Physics and Isotope Committee approval for the proposed tests, experimentation was begun.

The basic permanganate-citrate cleanup procedure which appears to be most promising for Yankee reactor application was tested first. The experimental results obtained were most encouraging as D. F. values in excess of 1500 ( $99.93 \%$ activity removal) were achieved in static tests. A series of cleanup trials indicated that the temperature of the basic permanganate reagent is a significant variable in determining the success of the decontamination operation and that the exposure time to the amonium citrate solution should be increased beyond the one hour period originally recommended for optimum decontamination efficiency. The results of an exposure time dependence study show that the $D$. F. values rise linearly with time during the first few hours of contact with the amonium citrate reagent. (See Figure-16)

Metallographic examination was performed on several specimens of the SIW steam generator tubing after treatment with the decontaminants under study. No significant damage to the base metal was found. It was noted, however, that in the treatment of austenitic stainless steel, low $\mathrm{pH}$ complexing agents such as oxallc ac1d are more corrosive than ammonium c1trate. The first signs of mild 1ntergranular attack were noted in the examination of tubing speclmens treated at $100^{\circ} \mathrm{C}$. for two hours with a 10\% oxalic ac1d solution (after the standard preliminary treatment with the basic permanganate reagent as described in Quarterly Progress Report YAEC-52). No such attack was evident in the case of a similar treatment with the $10 \%$ amonlum cltrate solution suggested for application in Yankee reactor decontamination (See Figures-17a and 170 ). 


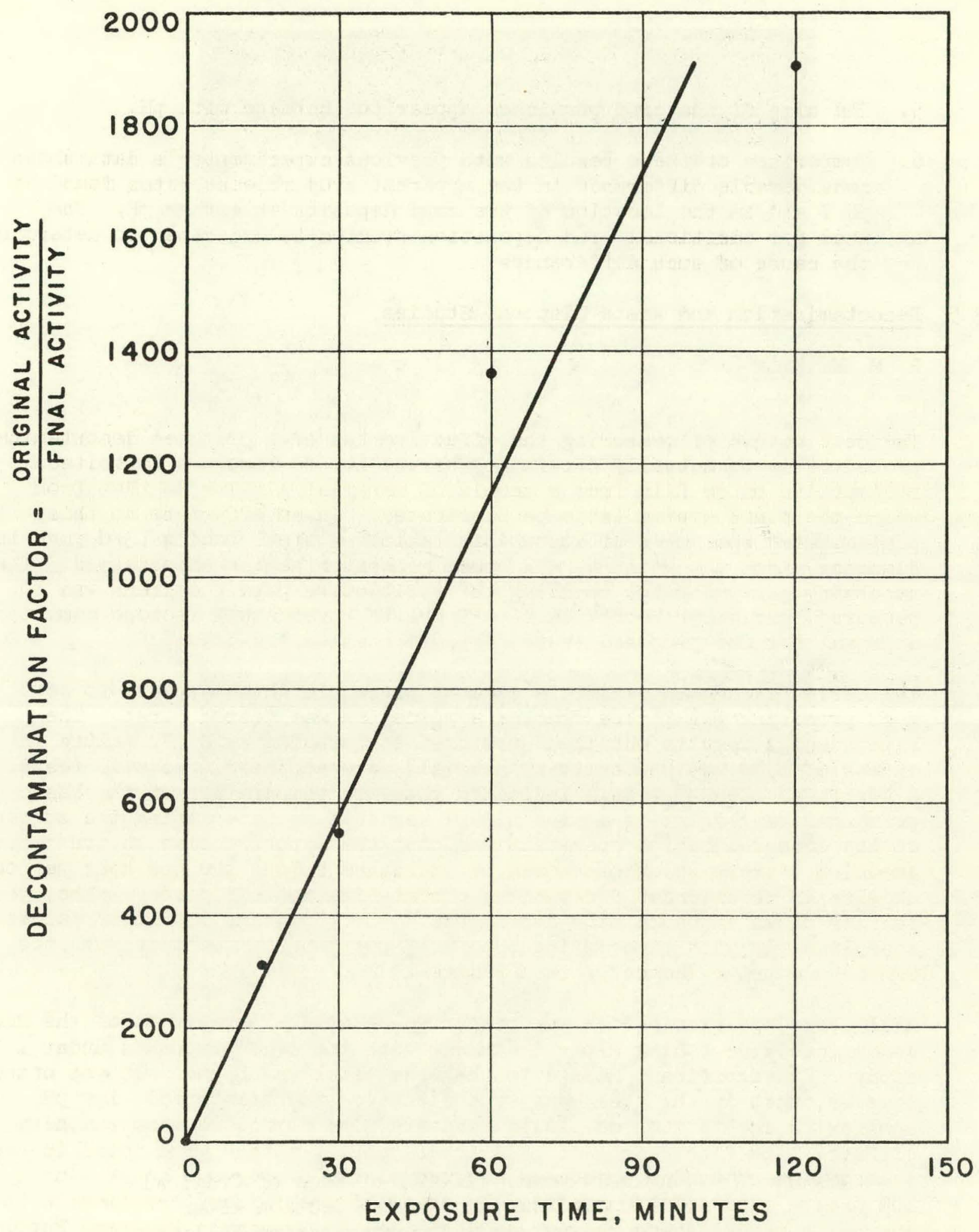

Figure 16 Relation of Exposure Time in Ammonium Citrate Solution to Decontamination Factor Achieved in Basic Permanganate Citrate Decontamination 


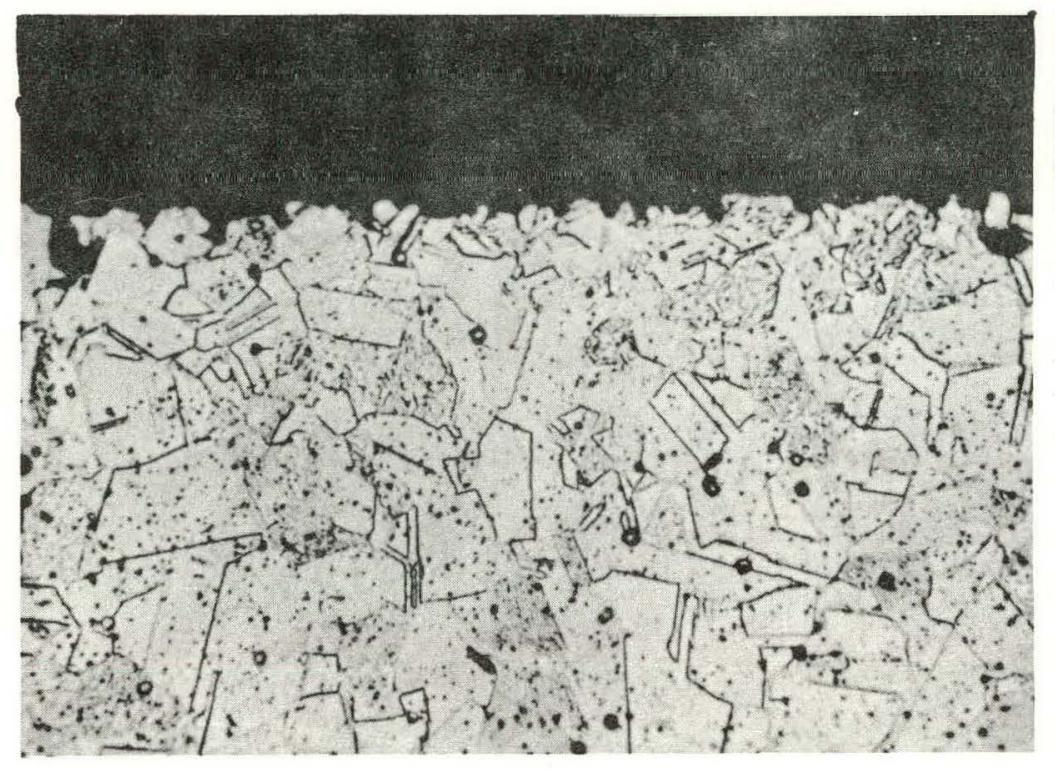

Figure 17a Photomicrograph (1000X) of Edge of Original SIW Steam Generator lubing Section After Basic Permanganate Decontamination Followed by 10\% Oxalic Acid Treatment

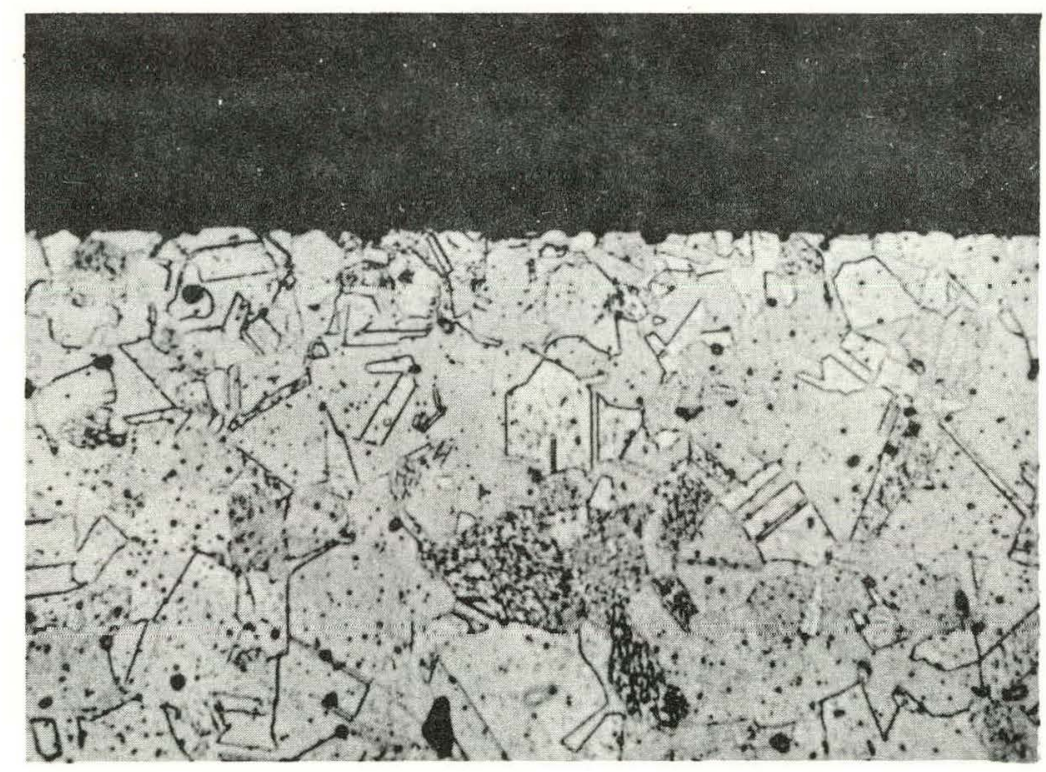

Figure 17b Photomicrograph (1000X) of Edge of Original SIW Steam Generator Tubing Section After Basic Permanganate Decontamination Followed By 10\% Ammonium Citrate Treatment 
Information was obtained on the decontamination procedure for stainless steel reactor components developed by Turco Products Inc. of Los Angeles, California at a meeting held with Turco Products personnel at (W) APD. The Turco "4501 Process" for radioactive decontamination was discussed in detail and samples of the reagents used were provided for use in decontamination studies at (W) APD.

The Turco process involves six steps and makes use of three separate reagents in contrast to the four steps and two reagents employed in the basic permanganate-citrate procedure described in topical report YAEC-90, "A Study of Decontamination Agents for Use in the Yankee Reactor" to be issued in December, 1958. Basically, the Turco "4501 Process" consists of the following:

1. Immersion in Turco 4501 (an amber colored highly alkaline liquid containing potassium hydroxide, potassium salts of organic acids, aliphatic amines, and a small amount of phenolic material).

2. High pressure water rinse.

3. Immersion in Turco 4502 (a highly alkaline solution containing up to 3.8 pounds per galion solids. These include potassium permanganate, alkaline potassium salts, small amounts of fluoride salts and inhibitors).

4. High pressure water rinse.

5. Immersion in Turco.4512 (a highly inhibited phosphoric acid containing a detergent).

6. High pressure water rinse.

This procedure was applied in the cleanup of contaminated specimens cut from original SlW steam generator tubing. For comparison purposes specimens from the sume tube section were decontaminated by use of the basic permanganate-citrate procedure. The experimental conditions and D. F. values obtained in these tests are given in Table XIX. 
TABLE XIX

SlW Steam Generator Tubing Decontamination Test Results

\begin{tabular}{|c|c|c|c|}
\hline Reagent Designation & $\begin{array}{l}\text { Time } \\
\text { (min) }\end{array}$ & $\begin{array}{c}\text { Temperature } \\
\mathrm{C}_{\mathrm{C}} \\
\end{array}$ & Total.D.F. \\
\hline Turco 4501 & 90 & 133 & 1.07 \\
\hline Turco 4502 & 90 & 106 & 2.94 \\
\hline Turco 4512 & 30 & 71 & 222 \\
\hline Basic Permanganate & 90 & 110 & 3.85 \\
\hline Ammonium Citrate & 120 & 100 & $>1500$ \\
\hline
\end{tabular}

It appears that the basic permanganate citrate procedure is not only more simple in its application, but is also capable of producing substantially better decontamination results than those which can be achleved by the Turco 4501 process.

\subsection{Crud Inhibition, Suspension, and Removal}

D. G. Sammarone

Calculations were made to determine the feasibility of running crud deposition experiments in (W) APD Loop "A". These experiments were intended to determine whether crud would preferentially deposit on cooled surfaces having a heat flux of $30 ; 000-50,000 \mathrm{BTU} / \mathrm{Hr}-\mathrm{ft}^{2}$ under high (10.5) or neutral $(6.5) \mathrm{pH}$ conditions to simulate conditions in the Yankee steam. generator.

It was recommended that experiments should not be run because:

1. Carbon steel wool would have to be used to produce detectable amounts of crud. This crud would not be a close enough simulation to crud found in the steam generator.

2. It would require a "hot" facility to be able to run experiments which relate activity build up with crud deposition. Such facllities are not available at (W) APD. 
3. The size of the equipment required to simulate heat flux would be bulky and could not be conveniently accommodated in the present (W) APD Loop "A" area.

4. A considerable amount of uncertainty exists as to whether crud bulldup is a function of the heat flux that exists across the surface on which the deposition occurs.

It was therefore decided not to assemble and install the equipment considered for this experiment on (W) APD Loop "A", but rather to find out whether preferential crud deposition exists at all on cooled surfaces. This will be performed by sectioning portions of the Van de Graaff crud deposition loop from (a) the heat exchanger and (b) thermally insulated piping immediately adjacent to the heat exchanger, and using the alkaline permanganate-c1trate decontamination procedure which has proven so effective on stainless steel in removing crud and corrosion products. It w11l be then determined whether any olgniflcant difference in total crud and corrosion product exists between the two situations. 
Mechanical and Thermal Section:

A. G. Thorp, Manager

This program includes the design and development of mechanical features of fuel assemblies, control rods, support structures, the reactor vessel closure, and fuel handling tools.

4.1 Fuel Assemblies and Control Rod Design

L. Ba.log

C. Johnson

Control Rod Design

'Tests completed on the spring-loaded control rod joint indicated satisfactory performance. The joint design was incorporated in the coupling section between the control rod and follower for the channel mock-up for fuel handling tests. The design of the coupling section and the socket for adapting the control rod shaft were proportioned for adaption to the new Universal Handling Tool, and the test model was altered accordingly. The control rod is now complete and ready for test in the Yankee channel mock-up program.

A fuel bearing control rod follower sonsisting of fuel rods cuutuining UO pellets was designed for use in a comparison study with a solld Zircaloy-2 follower. The fuel-containing follower would produce a substantially lower flux peak in the fuel adjacent to the follower in the reactor core. An analysis of the mechanical design of the fuel rod follower indicated that the mechanical performance should be more than adequate providing that fabrication techniques can be developed for maintaining accuracy of construction.

Fuel Assembly Design

Analysis of the problem of fuel assembly bowing was continued and included an investigation of a number of design alternatives. The studies resulted in the tentative selection of a "Compromise Design" for use in the Yankee reactor. The "Compromise Design". Is based upon the use of the brazed ferrule fuel subassembly design concept, but incorporates a sertes of small changes in the design to increase clearances adjacent to the control rods to reduce thermal bowing of the complete assembly. A cross section of the "Compromise Design" is shown in Figure-18. The design consists of elght subassemblies which are free to float axially and which surround a ninth rigid center subassembly fixed rigidly to a new type of handling socket. The elght outer assemblies are guided on each end in the handling sockets and are tled together at various axial stations by thin straps in such a way that all subassemblies must bow the same amount. 


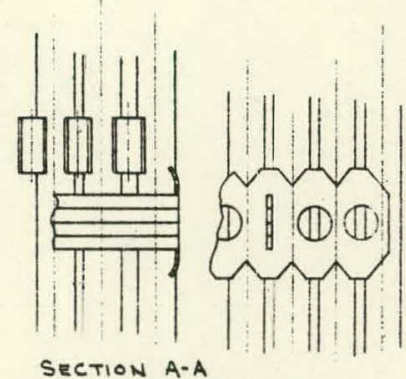

SECTION A-A

A?

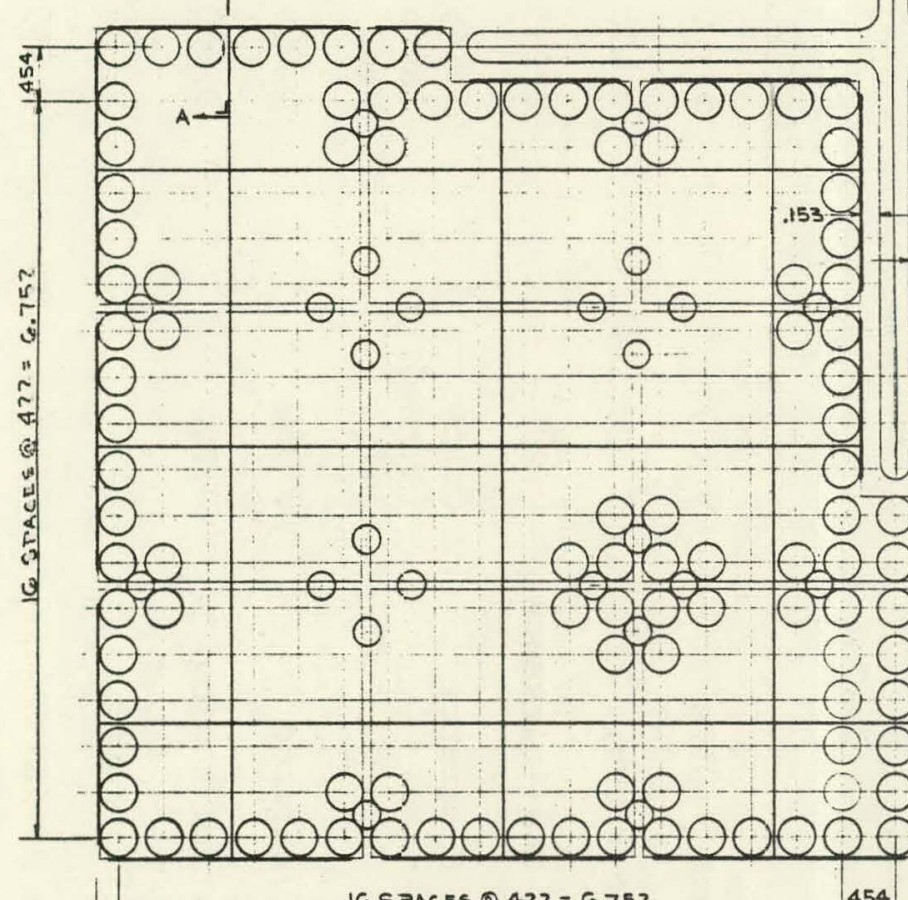
7.543
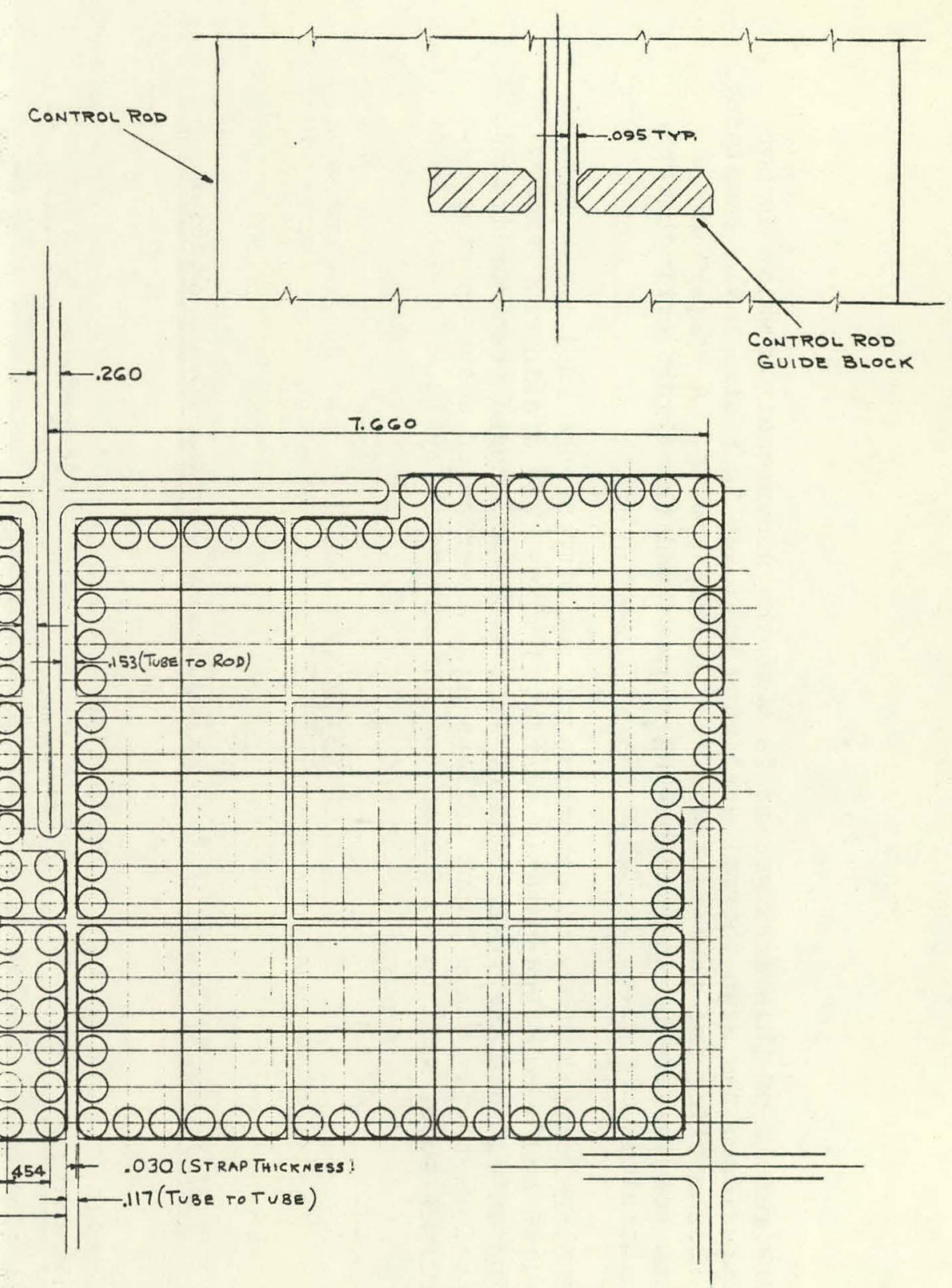

Figure 18 Yankee Fuel Assembly - Compromise Design 
The result of this arrangement is that the subassemblies which do not experience the high thermal gradients will act to restrain the remaining subassemblies and thus minimize the thermal bowing. A comparison of the results of the thermal bowing studies and the significant design dimensions are given in Table XX.

The analytical study to determine the ability of the fuel tubes to withstand a cold hydrostatic test at 3750 psi was continued. Analysis indicated that the fuel cladding will withstand these test conditions satisfactorily and without collapsing. A series of tests on stretchformed tubes will be conducted to confirm the analysis.

\section{TABLE XX}

\section{Fuel Assembly Design Data and Results of Thermal Bowing Studies}

Design

Parameters

\begin{tabular}{|c|c|c|c|}
\hline \multirow{2}{*}{ 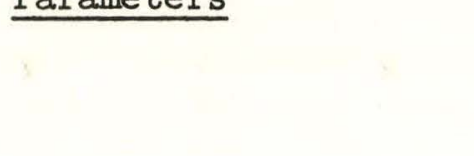 } & & \\
\hline & & $\begin{array}{l}\text { First } \\
\text { Iteration }\end{array}$ & $\begin{array}{c}\text { Second } \\
\text { Iteration }\end{array}$ \\
\hline Subassembly Size & $9 \times 9$ & $6 \times 6$ & $6 \times 6$ \\
\hline Fuel Rod Pitch & 0.425 in. & 0.418 in. & $0.422 \mathrm{in.}$ \\
\hline Control Rod Thickness & 0.285 & 0.245 & 0.265 \\
\hline Nominal Clearance & $\begin{array}{l}0.119 \\
\text { (Strap) }\end{array}$ & $\begin{array}{l}0.165 \\
\text { (Strap to Control } \\
\text { Rod) }\end{array}$ & $\begin{array}{l}0.123 \\
\text { (Strap to } \\
\text { Control Rod) }\end{array}$ \\
\hline Guide Clearance & 0.062 & 0.095 & 0.095 \\
\hline Fabrication Bowing & 0.060 & 0.060 & 0.060 \\
\hline Socket Tolerance & 0.020 & 0.020 & 0.020 \\
\hline Thermal Bowing & 0.146 & 0.095 & 0.106 \\
\hline Control Rod Bowing & 0.015 & 0.015 & 0.015 \\
\hline Additional Tolerance & 0.017 & 0.017 & 0.017 \\
\hline Net Clearance & -0.077 & +0.053 & 0.000 \\
\hline
\end{tabular}

Definitive

Design

Compromise Design
First

Strap to Control (Strap to Rod) Control Rod) 
4.2 Control Rod Drive Mechanism
L. Balog
R. Goldstein
A. Bishop

Progress at the (W) Atomic Equipment Department on the fabrication of the positive engagement type control rod drive mechanism indicates that the mechanism will be completed in December. A cut away drawing of the mechanism is shown in the 1llustration on Page 10 .

The design and construction of a test stand for the control rod drive mechanism prototype was continued. The test stand will serve as a facility for cold tests where loads can be readily varied and maintenance and inspection of the mechanism can be performed with a minimum of effort. After completion of the cold tests and any necessary development modifications, pressure and temperature tests will be conducted with the mechanism mounted on an autoclave.

A DC power supply was designed for supplying power to the control rod drive mechanism. Quotations were requested for the detailed design and construction of the power supply, and an order was placed with a supplier.

Analysis of the cooling requirements for the control rod drive mechanisms was completed. Experimental data obtained for the friction grip type mechanism were utilized as a basis for computing the cooling requirements for the positive engagement type control rod drive mechanism. ; Under operating conditions the analysis indicated a heat load for cooling of $1.3 \mathrm{KW}$ per mechanism.

4.3 Design of Core Support Structure and Fuel Handling Tools
L. Baloy
G. Ens

Core Support Structure

Topical report YAEC-77, "Deflection and Stress Analysis of the Yankee Core Support Structure" was issued in October, 1958. The report describes the experimental investigation on plastic models to determine the various design parameters and the structural rigidity of the assembly. The report suggests a rational method of semi-theoretical analysis of the problem based on Reissner's small deflection theory.. This takes into account the effect of tranverse shear and normal stress deformation.

Core Baffle

The initial stress and deflection studies on the one-quarter scale core baffle model were conducted over a wide range of pressures. By means of a dimensional analysis study it was found that the deflections at several points in the baffle were somewhat greater than desired. The baffle model was returned to the (W) APD Model Shop where additional 
ribs were welded to the baffle structure. By the addition of these added supports, the stiffness of the plates which had undergone the largest deflections was increased substantially. After the se changes were incorporated, deflections were again measured. Calculations will now be performed to determine the extent of deflections in a full size baffle. From analyses conducted to date, it appears that the largest deflection in the full size baffle will not exceed 0.045 inch.

\section{Fuel Handing Tool}

The basic design of a hydraulically actuated Iniversa.l Handling Tool, including the hydraulic system, was completed. The tool is capable of handling the control rod, control rod follower, control rod drive shaft, fuel assembly and guide tube. The total weight of the tool. is approximately 305 pounds, and its overall length is 72 inches. The maximum cross sectional dimension of the tool, taken across a set of hydraulic cylinders, is approximately 11 inches. The tool was designed for a static load of 6000 pounds and to operate at a hydraulic pressure of 100 psi.

\section{Yankee Channel Mock-Up}

The (W) APD Model Shop continued work on the Yankee Channel Mock-Up. At present, the design changes made necessary by the Universal Handing. Tool are being incorporated into the handling sockets of the Guide Tube Adaptor and the Fuel Assembly Nozzles. The majority of the large tower components, including the Drive Shaft Assembly and Control Rod Stand, were completed.

4.4 Design for Critical Experiment and Irradiation Tests

No work was performed under this subproject during the third quarter of 1958. 
5.0 THERMAL AND HYDRAULIC DESIGN

Thermal and Hydraulic Design Section:

A. G. Thoórp, Manager

The work performed under this project is directed toward the development of a design which will have satisfactory thermal and hydraulic characteristics under conditions of steady state, transient, and emergency operating conditions.

5.1 Thermal Design

C. Johnson A. Bournia E. McCabe A. Petrovas

Fuel Temperature Study

The maximum temperature at the center of the fuel, the average temperature of the hottest pellet, and the average temperature of the fuel in the core were calculated for various thermal outputs of the Yankee first core, - based on a $\mathrm{UO}_{2}$ conductivity of $1.0 \mathrm{BTU} / \mathrm{hr}-\mathrm{ft}-\mathrm{F}$. In this study the 0.294 inch diameter pellet. was considered. The average temperature of the coolant was kept constant at $514 \%$. Also, in this study, it was assumed that the gap, between pellet. and tube, is filled with $85 \%$ xenon and $15 \%$ krypton. It was further assumed, whenever the pellet expanded more than the tube, that the minimum effective gap was. 0.0002 inch. An average constant coefficient of expansion for $\mathrm{UO}_{2}$ of $6.2 \times 10-6$ in/in - ${ }^{\circ}$. was used in the study. The results are shown in Figure 19.

Loss of Flow Accident

Programming of the loss of flow accident for the IBM-704 computer was begun and is now being checked. A problem model is being used that is similar to the one used in the hand calculations described in topical report YAEC-72, "Studies of Thermal Behavior Under Loss of Pump Power Transient Conditions", i.e. the pressure drop of the average channel of infinite radial extent is compared to the hot channel'. Most of the program

development has been completed.

In-Pile Test Loup Loss of Flow Accidents

A hazards analysis was made on loss of flow accidents in the in-pile test loop. Using flow rates that have been obtained experimentally from the actual loop, steady state analyses were performed to determine the final conditions for two pump operation and single pump operation for an inlet temperature assumed to be constant. An analysis was also made for the transient condition during the coastdown of two pumps, with or without 


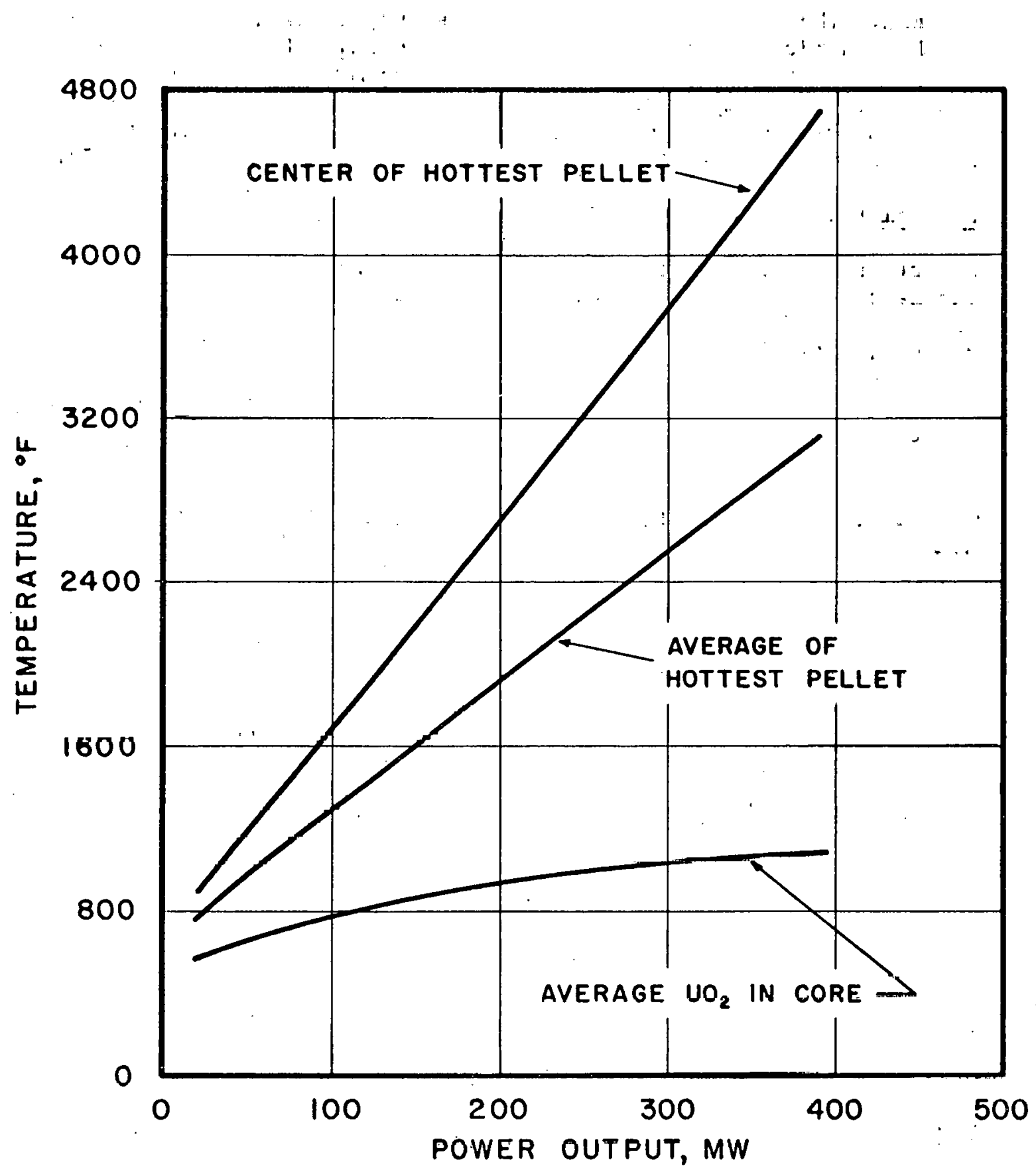

Figure 19 Power Output Versus Fuel Temperature for the Yankee First Core 
scramming, the coastdown from two to one pump operation without scramming, and the coastdown of one pump without scramming. For the transient calculations, the limiting condition was assumed to be loop outlet temperature reaching saturation temperature at 2000 psia. Thermal time constants are such that no detrimental condition is anticipated for any of the accidents. A topical report is being written on this study.

Internal Pressure of Fuel Rod

The internal pressure of the Yankee first core hot channel fuel rod was calculated based upon theoretical fission gas release rates. The calculations were for the end of core life, i.e. 10,000 hours of operation, and considered the initial radial and axial vold as well as the radial elastic deformation of the clad. Using these pressures, the tangential stress on the inside surface of the clad was calculated to be 7,000 psi for the non-compartmented and 27,800 psi for the compartmented fuel rod.

In the study of the compartmented rods, fuel rods having a disc spacing of 9 inches and 8 inches were considered. For the 9 inch compartment, the axial gap was assumed to be 30 mils in the hot condition. In the 8 inch compartment the hot gap was assumed to be 58 mils. The dimensions used are as follows:

Pellet Diameter, inch

Outside tube diameter, inch

Clad thickness, mils

Tube length, inches

Pellet length, total, inches

Compartment length, inches

Pellet length per compartment, inches

\section{Non-Compartment Design}

Compartment Design
Nine Inch Elght Inch Spacing Spacing

$\begin{array}{ccc}0.294 & 0.294 & 0.294 \\ 0.337 & 0.337 & 0.337 \\ 21.0 & 21.0 & 21.0 \\ 91.375 & -- & -. \\ 90.0 & -- & - \\ -- & 9.14 & 7.956 \\ \ldots & 9.0 & 7.8\end{array}$


The pressures and stresses calculated for the above cases are:

$\begin{array}{ccc}\begin{array}{c}\text { Non-Compartment } \\ \text { Design }\end{array} & \frac{\begin{array}{c}\text { Compartment } \\ \text { Design }\end{array}}{\begin{array}{c}\text { Nine Inch } \\ \text { Spacing }\end{array}} & \begin{array}{c}\text { Eight Inch } \\ \text { Spacing }\end{array} \\ 3,180 & \frac{7,780}{5,890} & 5,800 \\ 7,000 & 42,300 & 27,800\end{array}$

If the assumption and procedure used in this analysis are valid then the design of a compartmented fuel rod requires some modification. By increasing the initial void, the final pressures will be low and thus create tangential stresses below the elastic limit of stainless steel, approximately 17,000 ps 1 for AISI 304 stainless steel at $600^{\circ} \mathrm{F}$. The non-compartmented fuel rod has sufficient safety in the design that no additional modification is necessary.

Power Ratio Variation

A study was conducted to determine the axial position in the hot channel which will have the highest "power ratio" over the core life. The power ratio is defined as the instantaneous power density divided by the overall average power density. Information obtained from a study of control rod insertion in the first core was used as the basis for the power density distributions during core life. Axial power density distributions were calculated for various control rod positions. The study was predicated on control rods being inserted $77 \%$ into the core when $\mathrm{k}$ fo became 1.0 , with the assumption then being made that the control rods. would move at a constant rate from $77 \%$ inserted at beginning of core life to $0 \%$ inserted at end of core life. Also, it was assumed that all the control rods move in a blanket. Calculations showed that a point 2 feet from the botton of the core had the highest power ratio of 1.84. This can be compared to the overall maximum power ratio of 2.0 assumed heretofore.

Thermal Bowing.

A summary of thermal bowing results for the definitive design and compromise design is included in Table XX under Fuel Assembly Design.

A program was initiated for a laboratory test to measure bowing of a. subassembly from linear and non-linear temperature gradients. The experimental program is to be expanded in the future to include investigations of thermal bowing of a complete fuel assembly. 


\subsection{Hydraulic Design}

A. Bishop

\section{$\therefore$ R. Berringer}

Reactor Vessel Pressure Drop and Flow Studies

Topical Report YAEC-74, "Pressure Drop and Visual Flow Studies for a Heterogeneous Reactor Model" will be withheld pending the completion of flow distribution studies in the lower plenum of the pressure vessel model.

The final draft of topical report YAEC-76, "The Effect of Local Boiling on Pressure Drop and Flow Distribution in the Yankee Reactor Core" was completed. The report will be issued in December, 1958.

\section{Fuel Rod Assembly Pressure Drop Studies}

Pressure drop calculations of the flow and pressure relationships through a fuel rod assembly were investigated in light of experimental data. obtained on a fuel rod assembly model. The standard analytical formulae based on the equivalent diameter concept predicted the pressure drop within $+15 \%$ of the experimental data. The final draft of topical report YAEC-75, "Mudel Study of the Pressure Drop Relationships in a Typical Fuel Rod Assembly" will be completed in December, 1958, and will incorporate the results of experimental studies on the ferrule type fuel assembly in addition to the results obtained from the strap type fuel assembly study.

\section{Control Rod Hydraulic Shock Absorber Dashpot Tests}

Drop tests were conducted on the hydraulic shock absorber prototype. Drag forces acting on the simulated control rod assembly were calculated. The actual weight of the simulated assembly was 350 pounds. The effective weight was approximately 250 pounds after including the effect of drag. High-speed motion pictures indicated the lightest spring (initial load 17.5 pounds, spring rate - 15 pounds per inch) allowed the velocity pressure of the water on the bottom of the dashpot to reduce the avaliable. dashpot action by approximately 40\%. Additional tests were conducted with a heavier spring. The test results indicate that the heavy spring. alleviated the difficulty of pre-compression, but a new piston taper will be necessary to provide optimum deceleration rates. New tapers will be machined and tested before the final design is selected. A topical report will be prepared covering the design and testing of the control rod shock absorber. 


\subsection{CONTROL ROD DEVELOPMENT}

Metallurgy Section:

Chemistry and Ceramics Section:
R. K. McGeary, Manager

R. F. Sterling, Manager

Specifications for reactor control rod material and control rod design are to be developed under this project.

J. R. Schettig

Dynamic Corrosion Testing of Silver-Indium Cadmium Alloy

Corrosion specimens of silver-indium-cadmium were exposed to borated water with lithium hydroxide and with potassium hydroxide to determine the effect of boric acid on the corrosion behavior of the alloy. Results are given in subproject 3.3 under the article entitled: "Dynamic Effects of Ag-In-Cd Alloy in Boric Acid Solution".

Nickel Plating of Silver-Indium-Cadmium

A test program to evaluate nickel plating and copper with nickel plating on $\mathrm{Ag}$-In-Cd was continued. The copper transitional layer was used to provide a metallurgical bond through diffusion between the nickel plate and the base metal. Varying amounts of copper (from zero to $1 / 2 \mathrm{mil}$ ) were electroplated and diffused into the base metal and the nickel plate by heating the specimens to 550 and $600^{\circ} \mathrm{C}$. for various times. Data obtained from the metallographic examination of the spectmens are being processed.

Cross-sectioned specimens of each type of plated specimen are to be exposed to simulated Yankee operating water conditions to determine the corrosion resistance of the diffusion zone. Test conditions in (W) APD Loop "A" are to be $600^{\circ} \mathrm{F}$. temperature, $1823 \mathrm{psig}$ pressure, 38.7 fps flow, $25-35 \mathrm{ml} / \mathrm{kg}$ (STP) of hydrogen, less than $0.1 \mathrm{ppm} 0_{2}, \mathrm{pH}$ of 10 by the addition of LiOH (no boron added) for a one month period.

Considerable difficulty has been experienced by (W) APD in obtaining a set of Ag-In-Cd specimens having a satisfactory nickel plate for use in the in-pile test loop experiments. The plating of two Ag-In-Cd control rods by the Bart Manufacturing Company for the PWR Project at the Bett1s Plant appeared to be satisfactory. A final set of specimens will be nickel plated by the Bart Manufacturing Company. 


\subsection{INSTRUMENTATION AND CONTROL}

Instrumentation and Control Section: $\quad$ C. F. Obermesser, Supervisor

This project covers the investigation and development of an overall control system and instrumentation including analyses of system functions and development of specifications for system components.
S. Ehrenpreis
J. Gallagher
J. Cunningham
D. Rathbone

Analysis of the Transient Behavior of the Steam Pressurtzer

Effort continued on the development of a digital computer program for analysis of the transient behavior of a steam pressurizer. This program will be ut1lized in the development of an analog model for the steam pressurizer for use in the analysis of the transient response of the controlled Yankee plant. Programming of the equations describing the pressurizer has been completed and initial test runs of the program are in progress. 


\subsection{PLANT SYSTEMS DEVELOPMENT}

Reactor Systems Design Group: Plant Systems. Design Group:
P. B. Haga, Supervisor

H. A. Smith, Supervisor

The work under this project is directed toward providing the analysis, conceptual design, and preliminary parameters of the plant systems.

\subsection{Chemical Handling and Control Systems}

No work was performed under this subproject during the third quarter of 1958 .

\subsection{Reactor Handling Tools}
E. V. Anderson
A. F. Fritz
H. S. Kresny

Head Gasket and Seal Ring Handling Fixture

Several improvements were made in the design of the head gasket and seal ring handling fixture. Previously.it was necessary to actuate approximately six mechanisms individually to release or pick up the seal ring. In addition, the gaskets were released automatically when the fixture contacted the vessel flange. In the new conceptual design, all of the seal ring fixtures are actuated with one vertical motion by means of a simple linkage scheme connection. The gasket handling mechanisms are now tied in wi.th the linkage employed for the seal ring in order to have control over the release of the gaskets. Consequently, all mechanisms are now actuated with one vertical motion.

The actuating device for the mechanisms will be similar to that contemplated for the plate and barrel handling fixture. A mock-up of the barrel handling fixture is now being fabricated and will be tested in the (V) APD High Bay Building Deep Pit. The test results should be applicable to both types of handling fixtures. 


\subsection{PLANT SAFETY ANALYSIS}

Reactor Engineering Department:

W. E. Abbott, Manager

Large Plants Engineering:

A. E. Voysey, Manager

This project involves the investigation of overall plant operational safety which is included in the development of the final plant design.

No work was performed under this project during the third quarter of 1958 .

\subsection{CRITICALITY EXPERIMENTS}

Reactor Evaluation Section:

P. W. Davison, Manager

Performance of Criticality Experiments at the Westinghouse Reactor Evaluation Center on stainless steel clad UO fuel elements at differing water-to-metal ratios are included in the project. Reactivity parameters and control rod effectiveness are also to be determined.
S. S. Berg
W. H. Bergman
D. F. Hanlen

Critical Experiments

Core Configuration Changes

On July 15, 1958, the CRX 3:1 water/uranium metal ratio experimental program was completed. After removing the fuel, the core tank and spacer plates for the 3:1 core were removed and the counterparts for the 2.23:1 core were installed. The critical experiments on the new water/metal ratin rore were rompleter on September $2 l$.

On September 25, replacement of the 2.23:1 core accessorles by those for the 4:1 water/uranium ratio was completed and the new loading to critical was begun. 


\section{Critical Loadings}

The 2.23:1 ratio core was loaded to critical in eight steps to a critical loading of 3016 fuel units in a cylindrical configuration. After loading adjustments were made, the final "clean-just-critical" loading, without control rods, was determined to be 3046 fuel rods at $18.2^{\circ} \mathrm{C}$.

Loading the $4: 1$ core to critical was accomplished in five steps and was concluded with 1317 fuel rods and four control rods in a cylindrical configuration in the core. The "clean" loading was subsequently determined to be 1300 fuel rods at $18^{\circ} \mathrm{C}$.

\section{Flux Profiles for $2.23: 1 \mathrm{~W} / \mathrm{U}$ Ratio CRX Core}

Flux profiles were obtained by two general methods, fuel rod scanning and gold folls.

The folls are normally inserted $1-1 / 2$ unit cells (one fuel rod and associated moderator, or one-quarter of each of four fuel rods with enclosed moderator) from the midline and from 2 to 4 inches above the bottom lucite spacer plate (see Figure-20.) Figure-21 shows a radial profile from Run No. 17 made using gold foll techniques in the clean core. The values for reflector savings and bugkling were determined by the JOFIT code to be $8.52 \mathrm{~cm}$ and $34.6 \times 10^{-4} \mathrm{~cm}^{-2}$, respectively. Figure-22 is the axial proflle obtained on the same run, again using gold folls. The reflector savings and buckling are being obtained from the COFIT code application of this and similar curves. Figures-23 and 24 are fuel rod scans in the borated core, radial and axial respectively. The values of reflector savings and buckling with a moderator boron concentration of $443 \mathrm{ppm}$ are tabulated in Table XXI.

\section{TABLE XXI}

Reflector Savings and Buckling Using Fuel Scanning Techniques for the $2.23: 1 \mathrm{~W} / \mathrm{U}$ Rat1o CRX Core; Boron $=443 \mathrm{ppm}$

$$
\begin{array}{lll} 
& \frac{\lambda}{\text { Axial }} & 7.08 \pm 0.15 \mathrm{~cm} \\
\text { Radial } & 8.11 \pm 0.15 \mathrm{~cm} & (5.33 \pm 0.023) \times 10^{-4} \mathrm{~cm}^{-2} \\
& (24.6 \pm 0.02) \times 10^{-4} \mathrm{~cm}^{-2}
\end{array}
$$

An axial scan made by using a $1 / 4$ inch fission chamber is shown in Figure-25. A fuel rod was removed from position $x=0, y=18$, and a stainless steel tube sealed at the lower end was substituted. The detector was attached to a control rod drive shaft, and its position could thus be changed remotely by operation of the drive mechanism from the console. A reflector savings value of approximately $8 \mathrm{~cm}$ is indicated by the data obtained. 

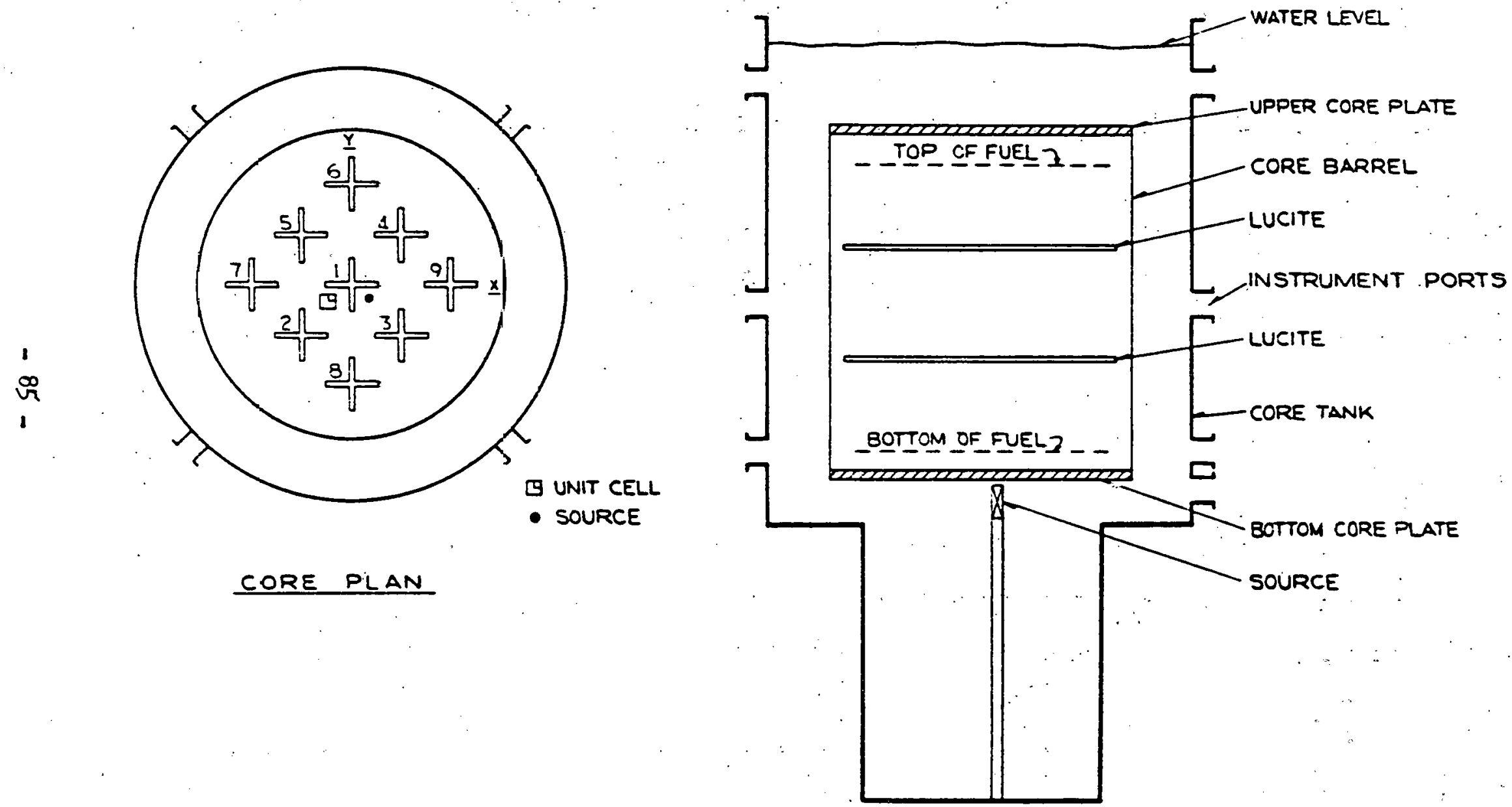

Figure 20 Yankee Critical Reactor Experiment Core Arrangement 


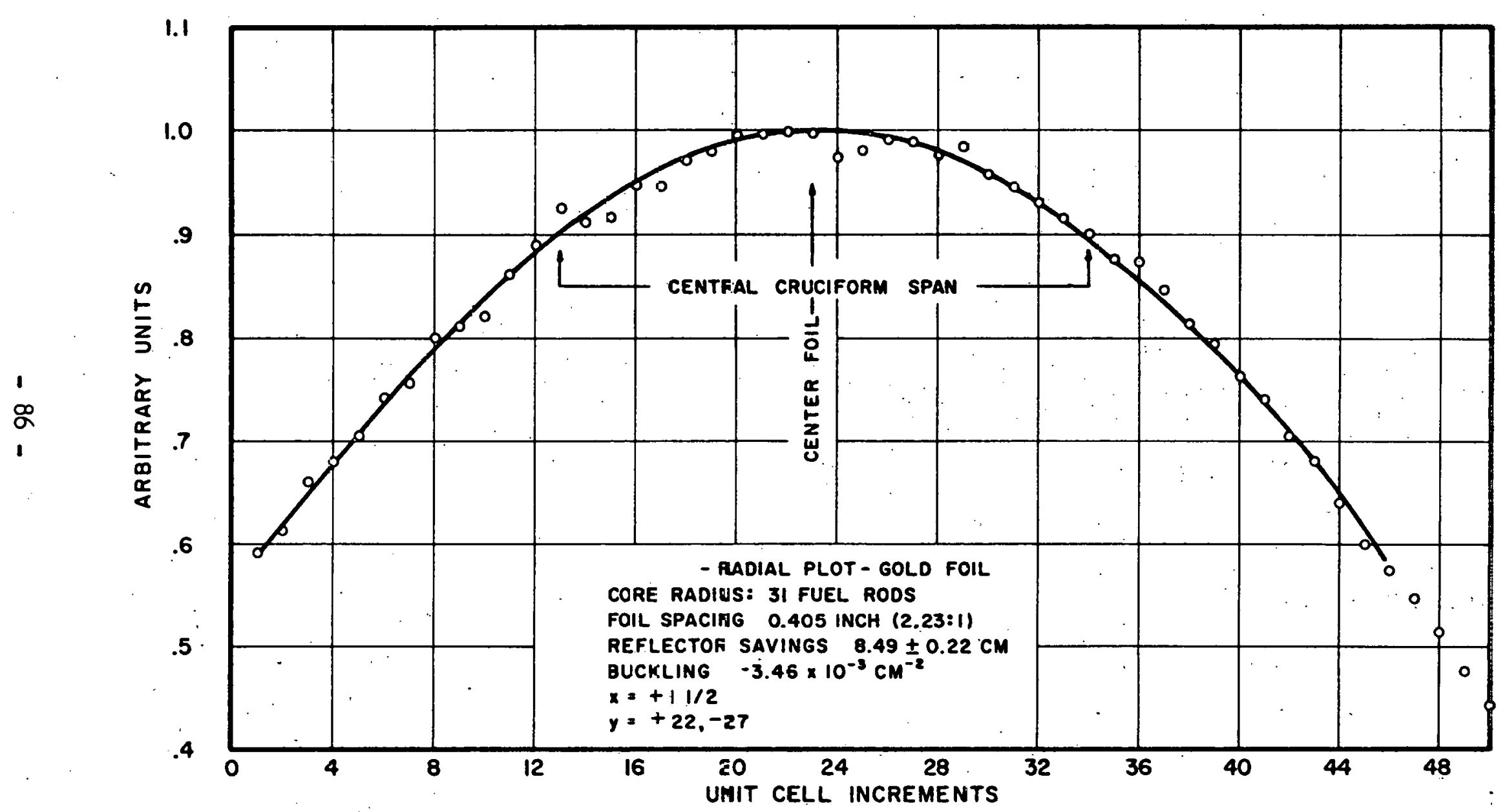

Figure 21 Radial Flux Profile Using Gold Foils for the 2.23:1 W/U Ratio CRX Clean Core 


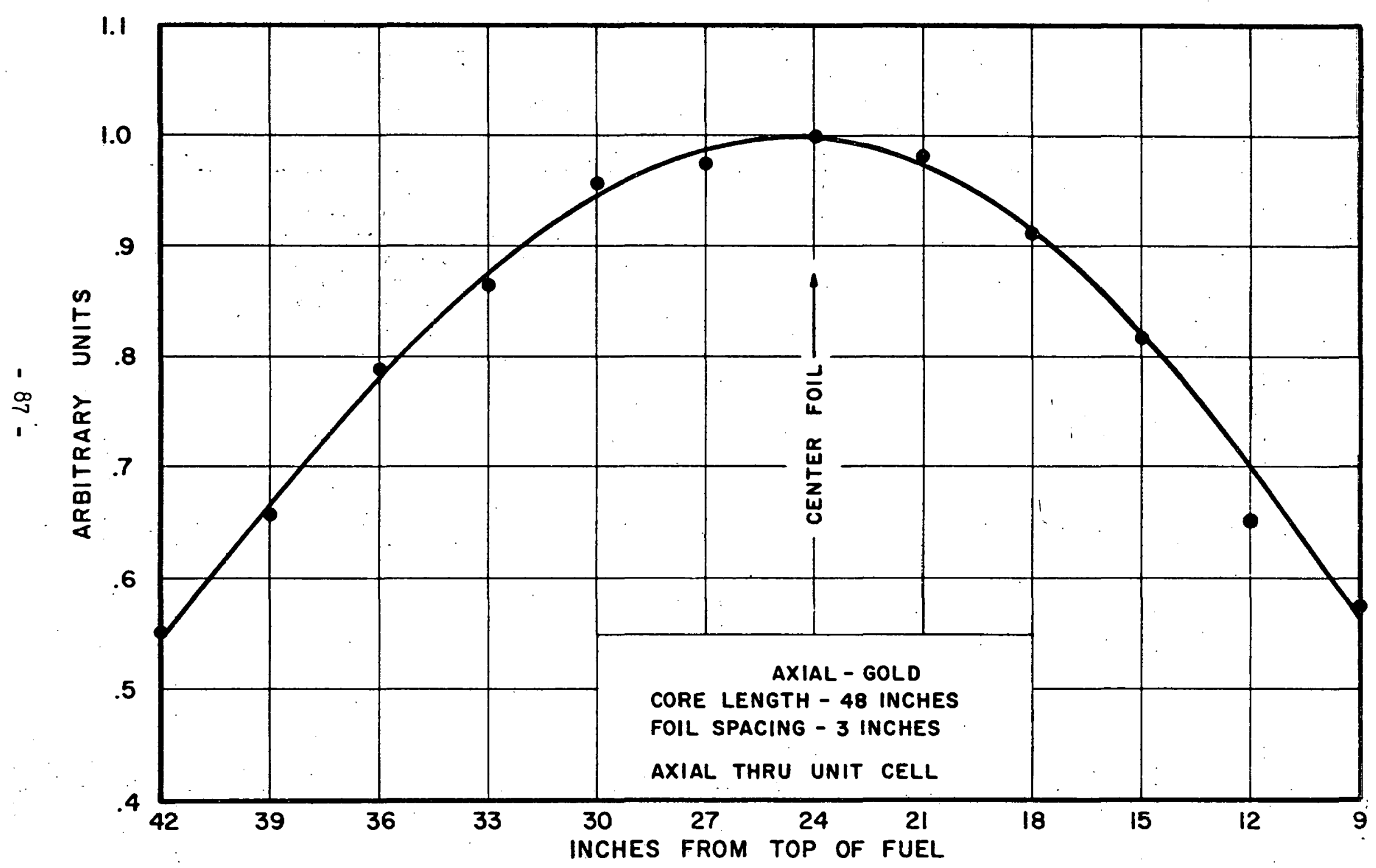

Figure 22 Axial Flux Profile Using Gold Foils for the 2.23:1 W/U Ratio CRX Clean Core 


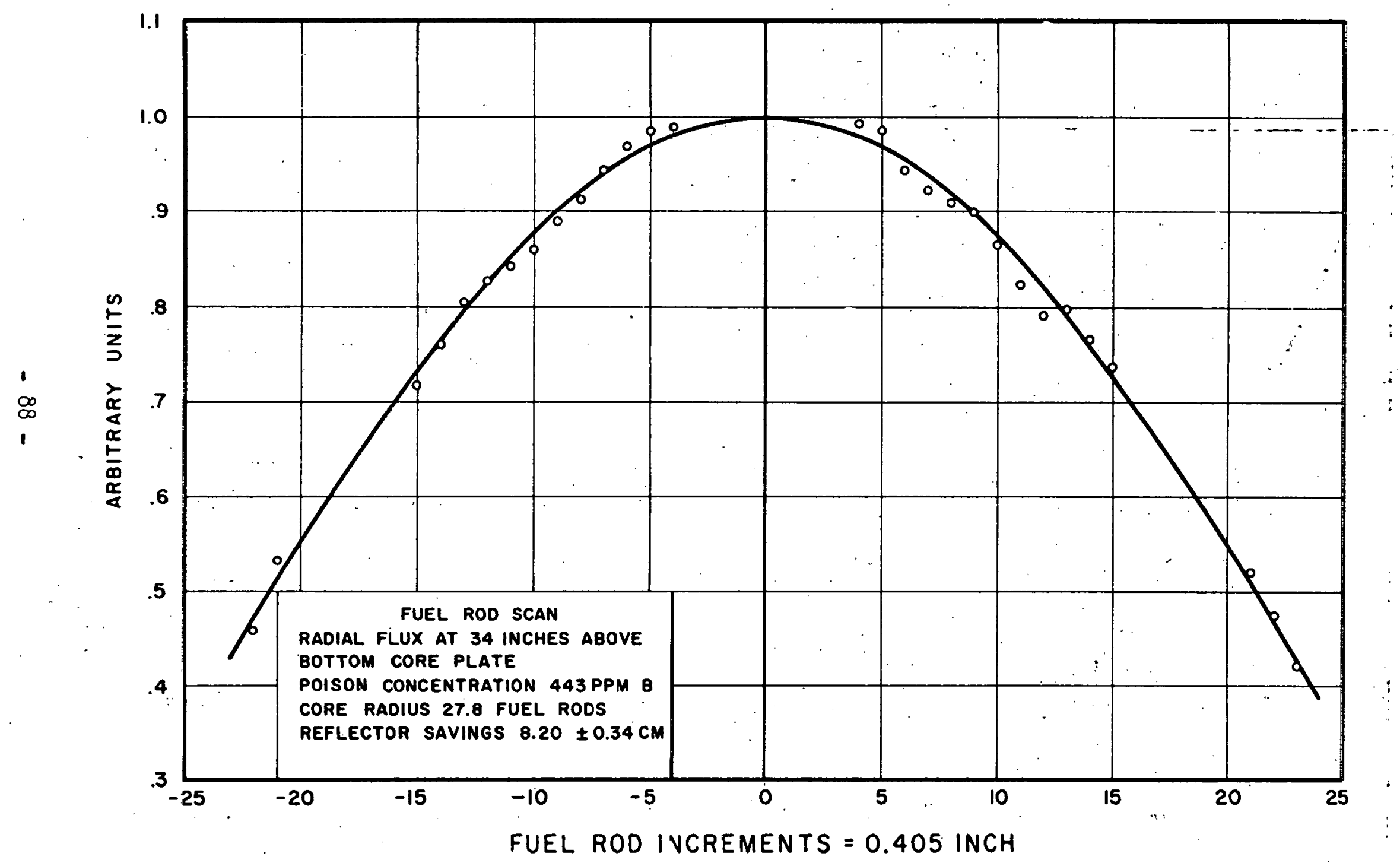

Figure 23 Radial Flux Profile Using Fuel Rod Scanning for the 2.23:I W/U Ratio CRX Borated Core 


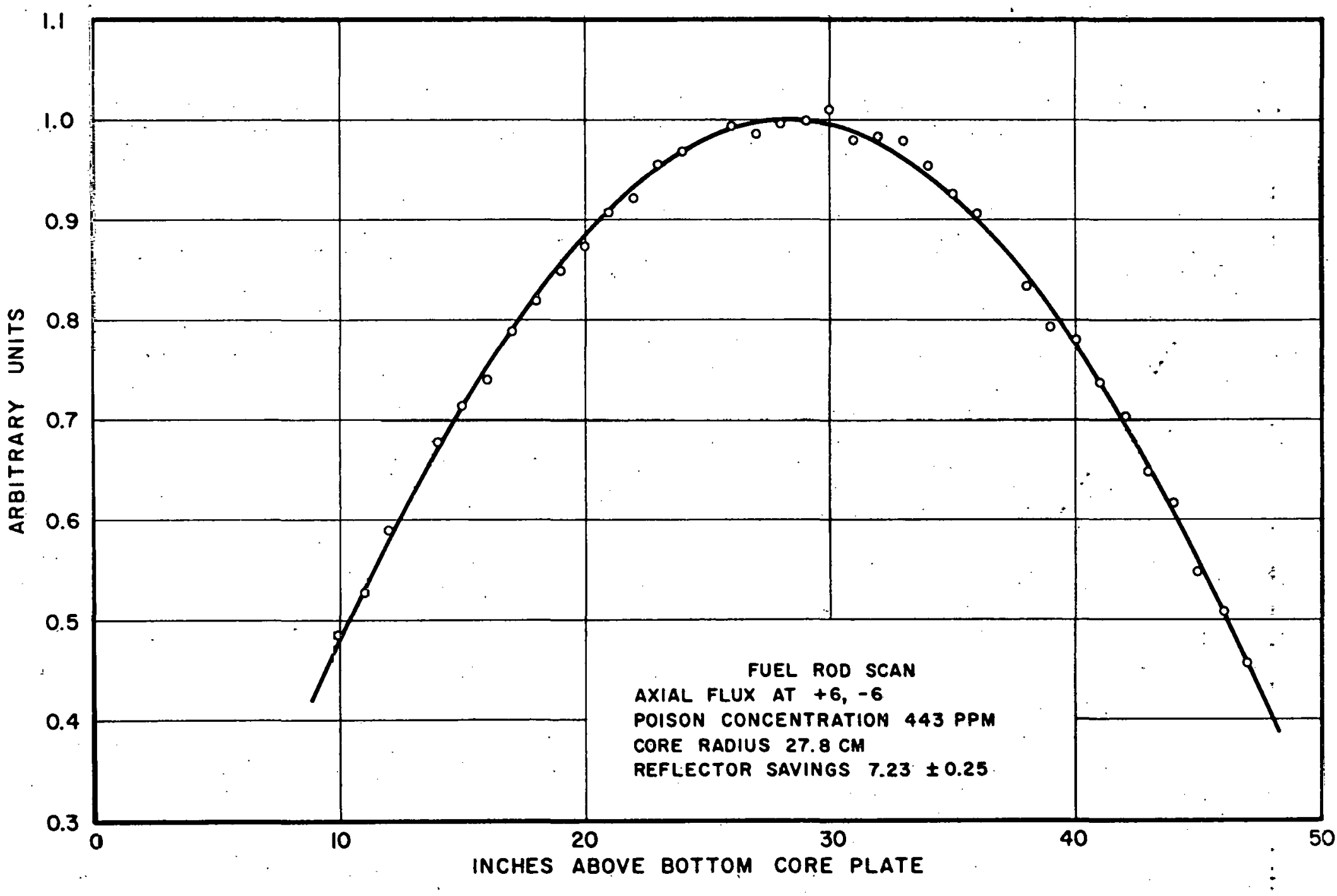

Figure 2L Axial Flux Profile Using Fuel Rod Scanning for the 2.23:1 W/U Ratio CRX Borated Core 


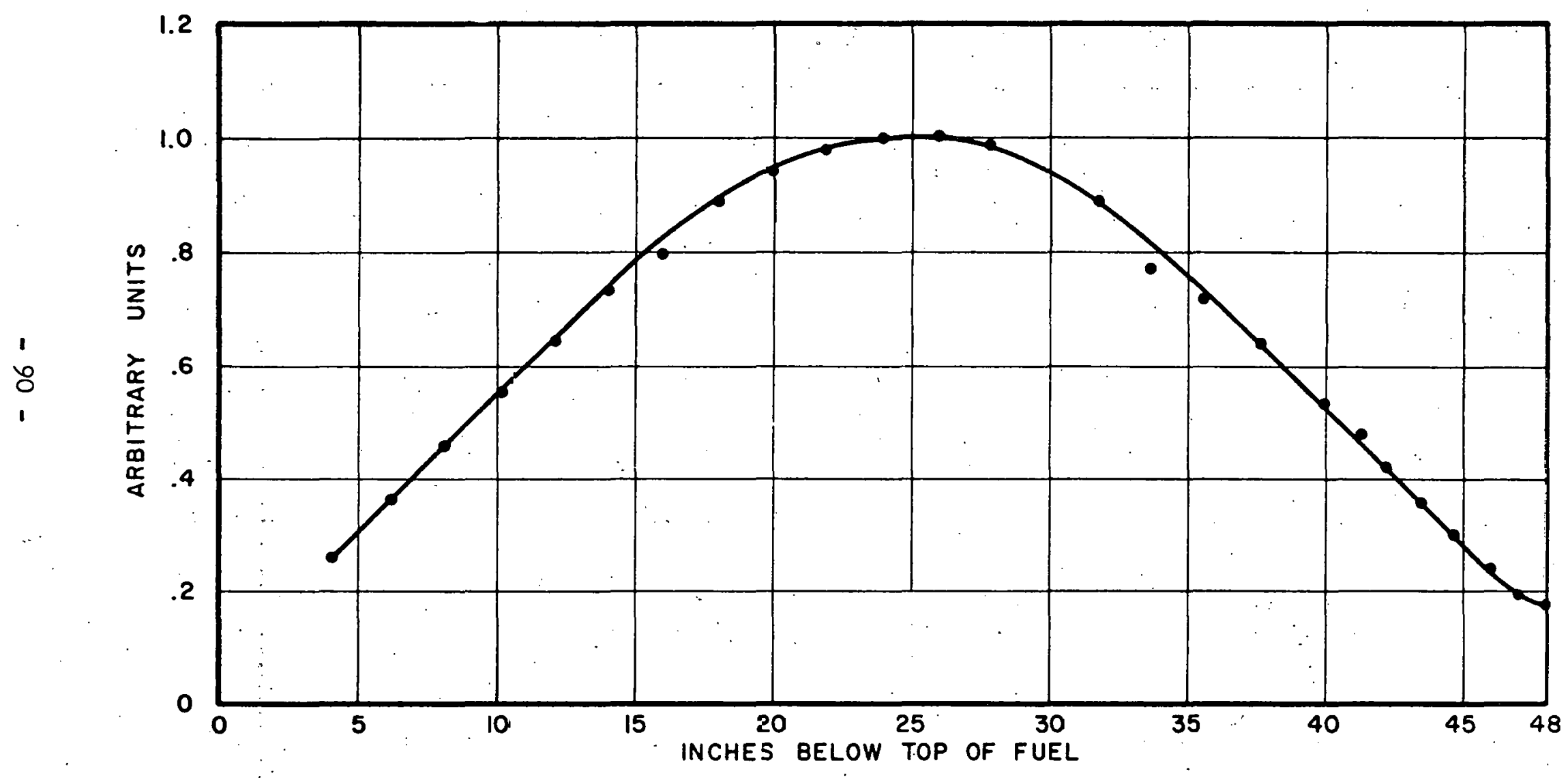

Figure 25 Axial Flux Profile Using a One-Quarter Inch Fission Chamber for the 2.23:1 W/U Ratio CRX Clean Core 
Flux Peaking in Water Slot for 2.23:1 Core

The curve shown in Figure 26 was obtained with fuel rods; it is superimposed on a profile obtained with gold foils across a water slot, through one radius and across the reflector peak. The water slot was obtained by removing the entire $x=0$ row of fuel rods. The maximum-to-normal ratio or flux in the water slot is 1.43 .

Flux Spectrum Studies for 2.23:1 Core

\section{Disadvantage Factor}

The disadvantage factor, the ratio of the average flux in the moderator to the average flux in the fuel, was measured for both the clean and poisoned core. The disadvantage factor, excluding the cadmium ratio correction, was $1.10+0.02$ for the clean core. There were 3065 fuel rods in the core, and contro: rods $2,3,4$ and 5 were banked at $106 \mathrm{~cm}$.

The disadvantage factor for the poisoned core, excluding the cadmium ratio correction, was $1.12+0.02$. The core was poisoned with a concentration of $400 \mathrm{ppm}$ of boron. There were 4613 fuel rods ir the core with control. rods $2,3,4$ and 5 at $110 \mathrm{~cm}$.

It appears that the best value of the disadvantage factor uncorrected for the cadmium ratio of $\mathrm{U}-235$ is $1.11 \pm 0.02$. The assigned error is based on the errors associated with weighing and counting plus an estimated error due to other factors. Using the cadmium ratio correction factor of $0.96 \pm 0.02$ obtained from the cadmium ratio measurement, the corrected disadvantage factor is then:

$$
(1.11 \pm 0.02) \times(0.96 \pm 0.02)=1.07 \pm 0.03
$$

Resonance Escape Probability

The experimental detarmination of the resonance.cscape probability, $p$, involves the measurement of the ratio of resonance capture to thermal capture in U-238. This quantity, which is designated by $\rho$, is related to $P$ by the expression $p=1 /(1+\rho f F)$, where $f$ is the thermal utilization and $F$ is the ratio of thermal absorption in the U-238 to the total thermal capture in the fuel.

The value of $\rho$ as determined by gamma ray spectroscopy was $3.25 \pm 0.1$. The clean core irradiation run (No. 29) was made on August 1. There were 3065 fuel rods in the core and control rods $2 ; 3,4$ and 5 were banked at $106 \mathrm{~cm}$. The value of $\rho$ for the poisoned core ( $400 \mathrm{ppm}$ of boron) as measured by gamma ray spectroscopy was $2.75 \pm 0.1$. There were 4613 fuel rods in the core with control rods $2,3,4$ and 5 at $100 \mathrm{~cm}$. 


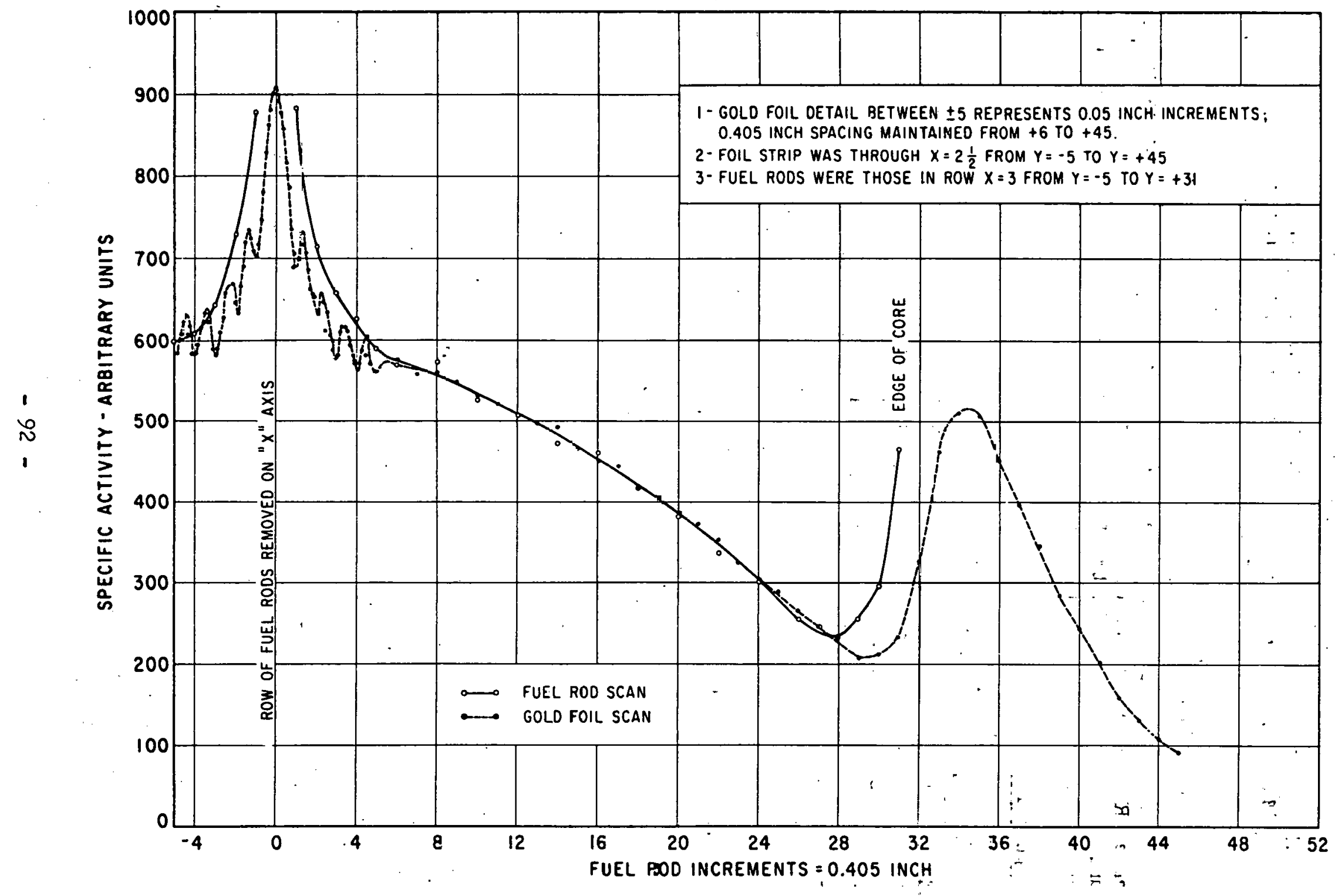

Figure 26 Radial Flu= Profile Using Gald Foils Through a Water Slat and Reflector Peak for the 2.23:1 W/J Ratio CRX Clean Core 
The value of the cadmium ratio leading to $\rho$ for the poisoned core was $2.365 \pm 1 \%$. Because the parameter of interest is the inverse of the admium ratio minus one, this $1 \%$ error manifests itself as a $3 \%$ error in $\rho$.

Cadmium Ratio of U-235

An aluminum U-235 alloy with the same macroscopic cross section as the Yankee CRX fuel. element was used in this measurement. The cadmium ratio was found to be $4.00 \pm 0.04$ in the fuel rods and $4.49 \pm 0.04$ in the moderator. These measurements were made with a clean moderator.

Peripheral Fuel Rod Worth in the 2.23:1 Core

The change in reactivity associated with the addition or removal of peripheral fuel rods was determined by measuring the reactor period before and after the fuel was removed. To accomplish this, peripheral fuel rods were connected by cords through a system of pulleys to the control room. After the stable reactor period had been determined, the fuel was selectively lifted out of the core by pulling on the appropriate cord. After the resultant period was measured, another group of fuel rods was removed. This procedure was continued until a maximum of 13 fuel rods had been extracted.

The peripheral fuel worth for the clean core containing 3190 fuel rods is $3.5 \times 10^{-5} \Delta \mathrm{k} / \mathrm{k}$ per fuel rod. In the core of 4745 fuel rods with borated moderator, $2.1 \mathrm{x} \cdot 10^{-5} \Delta \mathrm{k} / \mathrm{k}$ per fuel rod was obtained.

Void Coefficient of Reactivity in the 2.23:1 Core

A procedure similar to that used to determine the peripheral fuel rod worth was used to evaluate the effect of voids in the core. Two effects were measured by the following steps: 1) Thin walled aluminum tubes were installed in the core between adjacent fuel rods; the bottom ends of the tubes were sealed, and thus the tubes were filled with air; reactivity measurements were thus determined for an air void plus aluminum 2) Reactivity measurements were made on the same aluminum tubes filled with water 3 ) The effect of the voids alone were determined by subtracting the measurements of Step-2 from Step-1. The coefficients determined are shown in Table XXII.

TABLE XXII

Void Coefficients for the 2.23:1 W/U Ratio CRX Core

$\% \Delta \mathrm{k} / \mathrm{k}$ per of void

$\begin{array}{llll} & \text { Al } & \text { Al-air } & \text { Air } \\ \text { Borated moderator } & -0.40 & -0.37 & -0.31 \\ \text { Clean moderation } & -0.50 & -0.46 & -0.35\end{array}$


These values are for voids distributed along radii of the core and do not represent the average void coefficient. It should be mentioned that the borated core had a volume approximately 1.6 times that of the clean core.

Temperature Coefficient in the $3: 1$ and 2.23:1 Cores

The temperature coefficient of reactivity was studied in the $3: 1 \mathrm{~W} / \mathrm{U}$ ratio $\mathrm{CRX}$ borated core and in the 2.23:1 W/U ratio CRX borated and clean core. Analysis of these experiments is not yet complete.

Control Rod Worth

A variety of control rod worth studies were made in both the clean and borated core. The central control rod worth was established in the clean core of 3030 fuel rods by the differential technique, i.e., plotting the differential reactivity at a number of points along the length of the control rod and integrating the area under the differential curve thus obtained. A total worth of $6.1 \% \Delta k / k$ was determined.

The central control rod and various rod groups were evaluated by adding increments of boron to the moderator and determining the total worth. The core loading for these measurements was 4704 fuel rods; Figure-20 indicates the location of the control rods. A total worth of $4.1 \% \Delta \mathrm{k} / \mathrm{k}$ in this core was indicated. Figure-27 is the rod worth curve of contról rod No. 1 .

Other measurements included comparisons of the worth of a Ag-In-Cd control rod with the worth of a Ag-Ca rod in the central position (Rod No. 1). The $\mathrm{Ag}-\mathrm{In}-\mathrm{Cd}$ rod was found to have a worth 1.04 times that of the $\mathrm{Ag}-\mathrm{Cd}$ rod. This measurement was made with a clean moderator. A set of control rods was obtained from the PWR Group at the Bettis Plant enabling a comparison to be made between the worths of a Ag-In-Cd and a hafnium control rod. Measurements were made with $180 \mathrm{ppm}$ boron in the moderator indicate that the hafnium rod worth was 1.01 times that of the $\mathrm{Ag}-\mathrm{In}-\mathrm{Cd}$ rod. A comparison of Li-Al and stainless steel was also made; the data that were obtained are now being analyzed. 


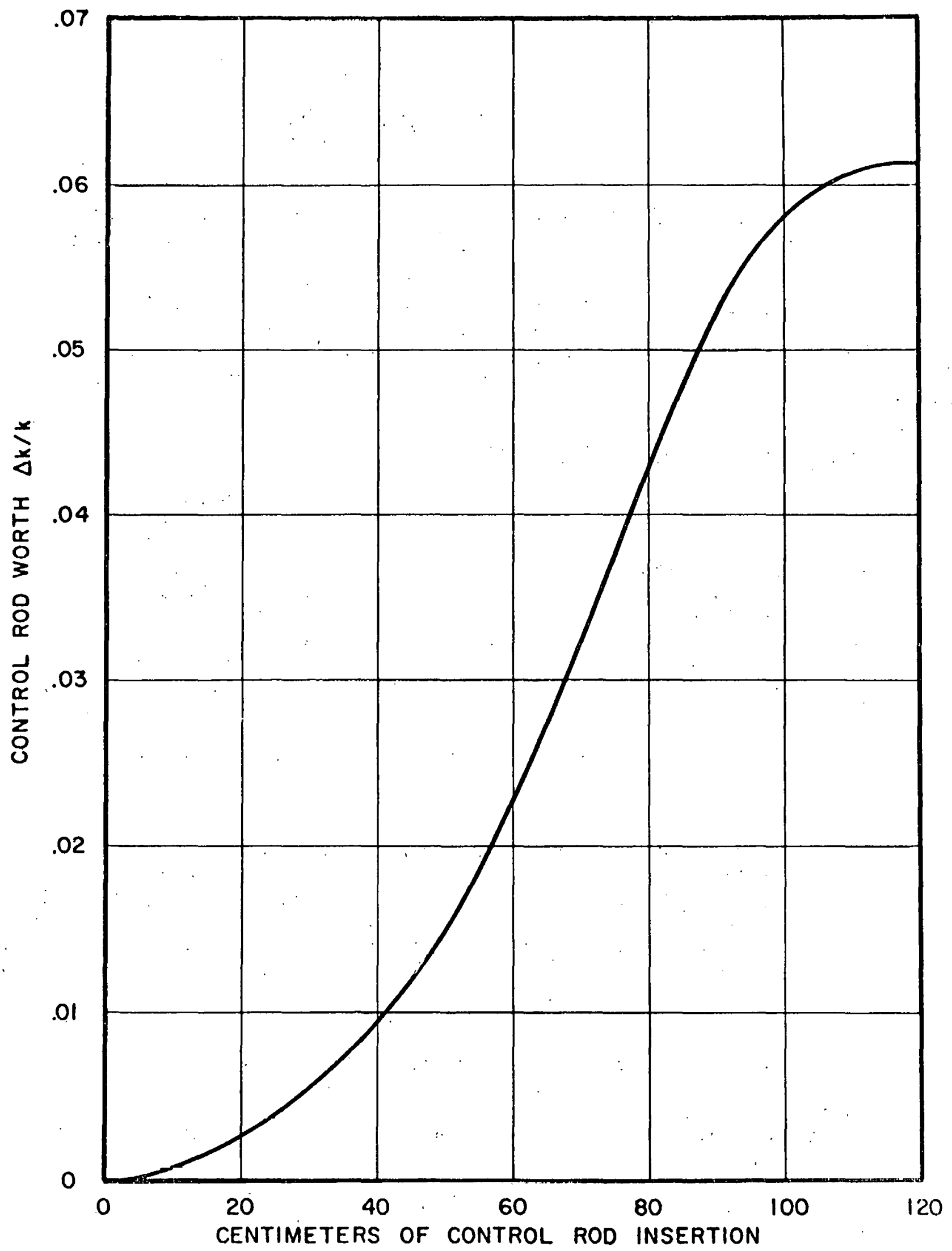

Figure 27 Central-silver Cadmium Control Rod Worth in a Clean Core Containing 3030 Fuel Rods 


\subsection{RADIATION DAMAGE EXPERIMENTS}

Mechanical and Thermal Design Section:

Metallurgy Section:
A. G. Thorp, Manager

R. K. McGeary, Manager

This project involves the design and procurement by Westinghouse APि of a pressurized water loop for in-pile irradiation tests in the MTR; the installation and operation of the in-pile loop; the performance of radiation damage experiments to demonstrate irradiation stability of Yankee core elements and post-irradiation examinations.

\subsection{Design and Fabrication the In-Pile Test Loop}
A. Bishop
C. D1shman

The loop fabrication and component testing continued on schedule except for late deliveries of the main flow control valve and Honeywell and Bristol instrumentation. The late deliveries affected loop testing procedures due to adjustments and calibrations that were necessary after the components were installed. Instrumentation and individual component operational checks were continued. Component replacement was required in several locations.

Tests conducted at the Westinghouse Atomlc Equipment Department indicated that the loop pumps would not rotate when ldle at flow rates through the pump in the normal direction of up to $25 \mathrm{gpm}$.

Tests conducted at the Lummus Company indicated flow rates through the loop at room temperature for one, two, and three pumps to be $6.1 \mathrm{gpm}$, $8.95 \mathrm{gpm}$, and $11.1 \mathrm{gpm}$, respectively. The predicted flow extrapolation to operating conditions of $550 \mathrm{~F}$. and $2000 \mathrm{psi}$ for two pumps indicated an average velocity of $10.3 \mathrm{ft} / \mathrm{sec}$ past the fuel samples. This corresponds to a maximum outlet velocity past the samples of $11.1 \mathrm{ft} / \mathrm{sec}$ at $600 \mathrm{~F}$.

A complete hydraulic analysis of the loop was conducted using the latest available information. The analytical results as well as the latest experimental data are shown in Figure-28. Figure-29 shows the testing arrangement of the primary cubicle and components, primary detector cubicle control'panel internals, and a section of the purification system. Figure-30 shows the purification system and data logger.

Lummus Company technicians were trained in the analytical procedures to be used in the performance of the final operational test with conditioned water and in the vacuum filling procedure to be used in loop filling. Various leaks were detected and the cold hydrostatic leak rate was reduced from $100 \mathrm{psi} / \mathrm{hr}$ to $40 \mathrm{psi} / \mathrm{hr}$. Further progress is expected in reducing 


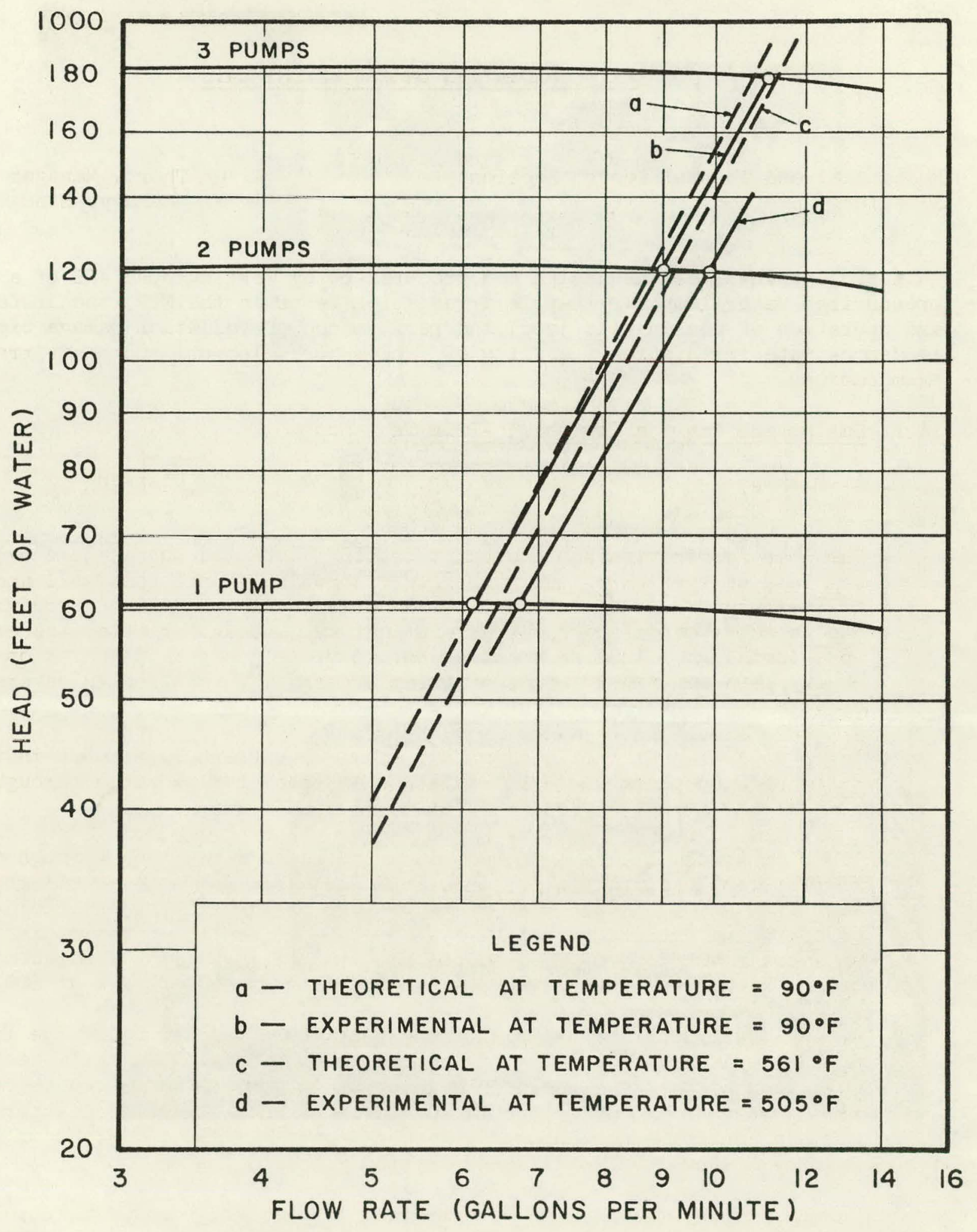

Figure 28 WCAP-4 In-Pile Test Loop Primary System Head Curves 


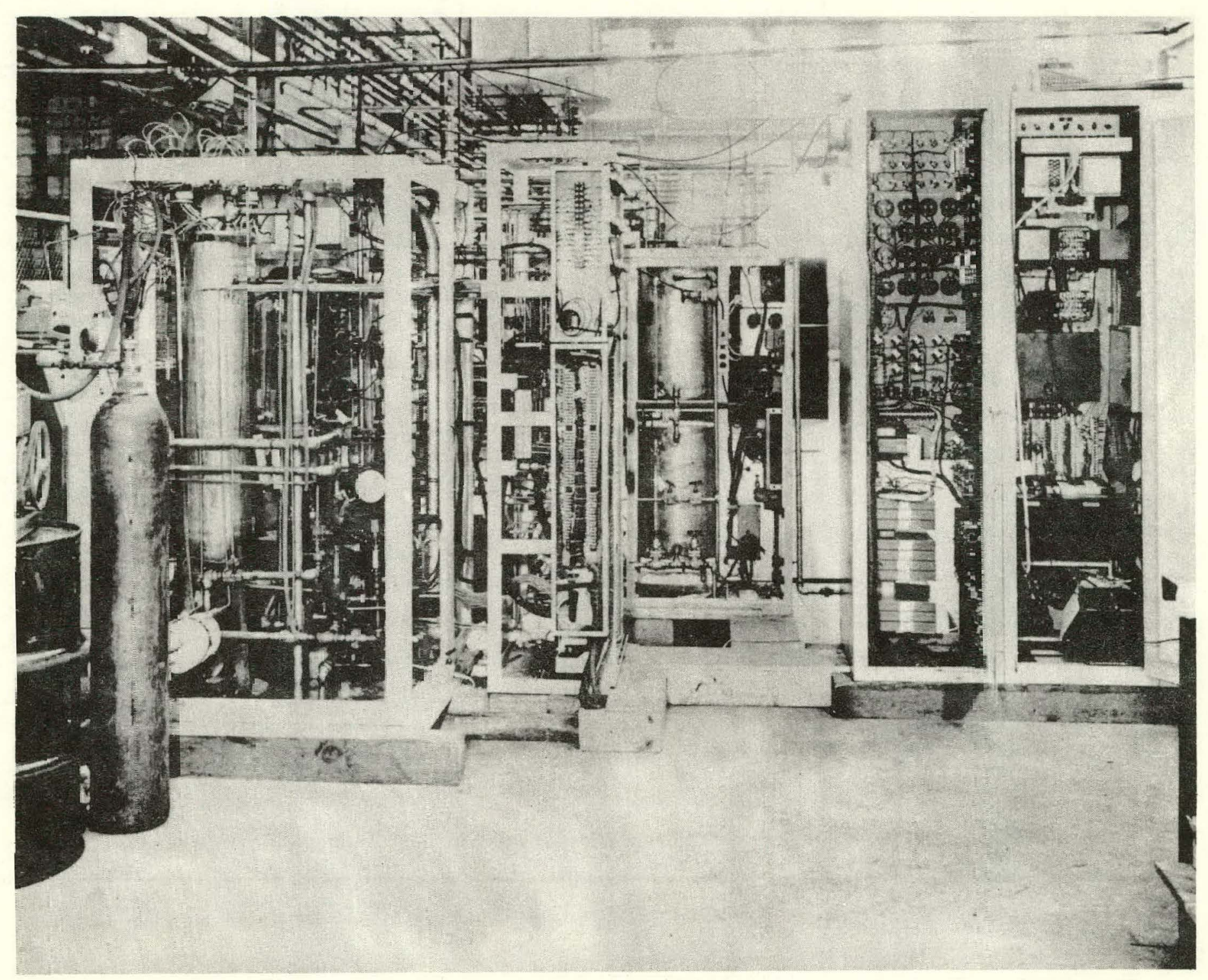

Figure 29 WAAP-L In-Pile Test Loop (Primary Cubicle a.t Left) 


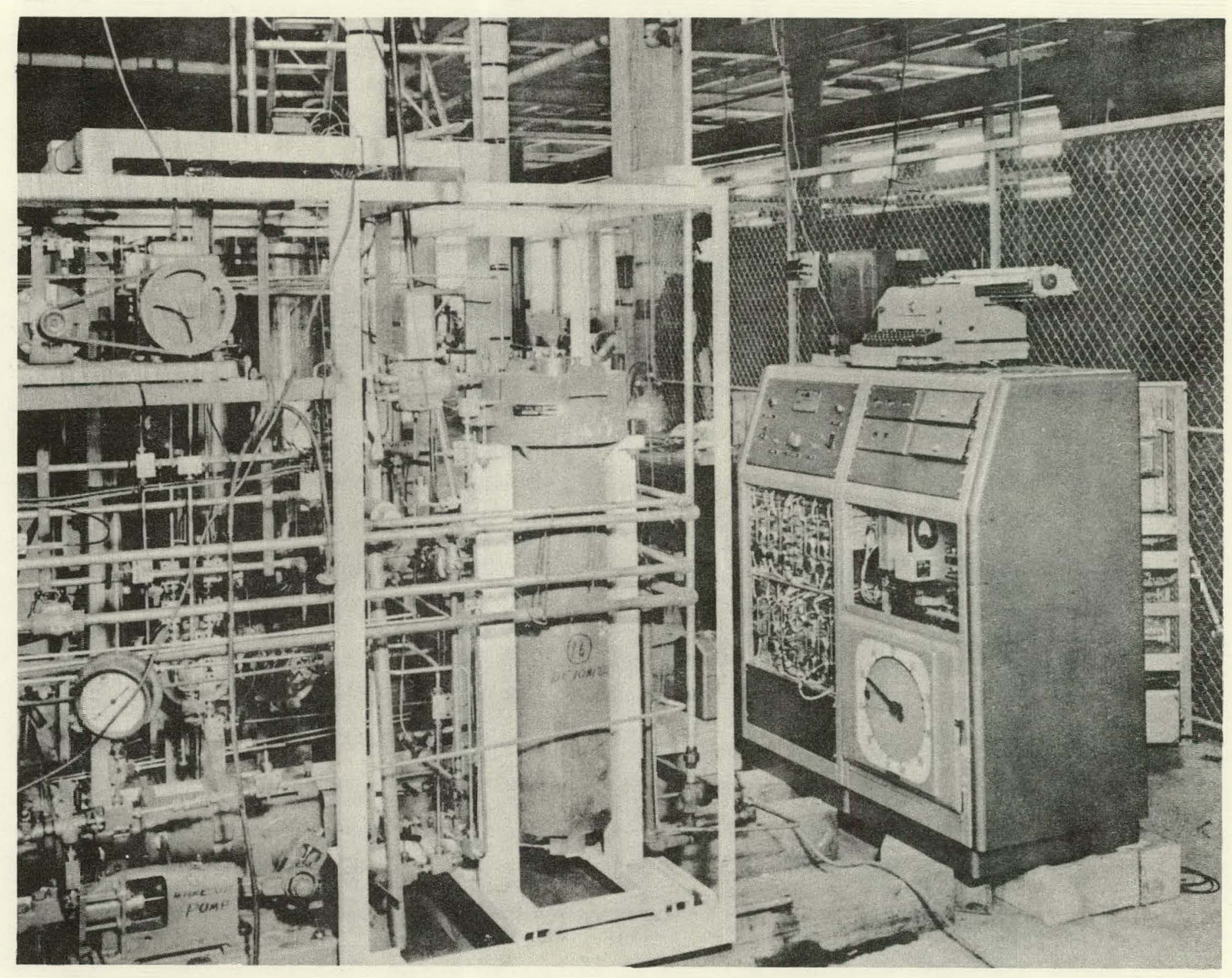

Figure 30 WCAP-4 In-Pile Test Loop - Data Logger and Purification System 
the leak rate. Storage vessels and the pressurizer were volume calibrated. During hot operation with several known leaks, the leak rate was found to be approximately $200 \mathrm{ml}$ of water per hour over a 24 hour period. Metering of make-up water was found to be inadequate and alternate procedures are being investigated.

\subsection{Performance of Radiation Damage Experiments}

J. J. Lombardo

Post-Irradiation Examination of WCAP-1 and WCAP-2 Capsules

Results obtained from the post-irradiation examination of WCAP-1-2, 1-4, 2-3, and 2-6 process water capsules by KAPL are as follows:

1. Fine hairline cracks were observed in the ferrule brazes at 4 to $6 \mathrm{X}$ magnification that were undetected by the unaided eye.

2. Helium in appreciable amounts was identified in the gas sample after burn-ups of approximately 10,000 MWD/T.

3. A high percentage of water vapor was determined by analysis, presumably resulting from insufficient drying of fuel pellets or insufficient protection from moisture after drying.

4. Xenon and krypton release was a small proportion of the gas sample.

5. No grain growth within pellets was observed.

6. No significant fuel tube diameter or length changes were observed.

7. No bowing of bulging of the fuel tubes was observed.

Final results of the post-irradiation examination of the four capsules have not been received from KAPL.

Post-Irradiation examination of the WCAP-2-4 process water capsule received by KAPL has been delayed because of repair and decontamination of their disassembly hot cell facility. The latest information from KAPL indicates that the hot cell facility will not be available for use until the middle of November. 
WCAP-2-8, 2-9, 2-10, 2-11, 2-12, and 2-13 Capsules

WCAP-2-8 through 2-13 process water capsules were sent to the MTR during the third quarter of 1958. A description of the six capsules is given in Table-XXIII.

\section{TABLE XXIII}

Description of WCAP-2-8 through 13 Process Water Specimens

Capsule No.

$2-8$

$2-9$

$2-10$

$2-11$

$2-12$

B-5

2-13
B-6

Tube No.

$A-1, A-2, A-3$

$A-4, A-5, A-6$

A-7, A-8, A-9

B-1

B-2

B-3

B- 4

B-5

C-1

$\mathrm{C}-2$

$\mathrm{C}-3$
Configuration

Disc in center \& ends

"

"

Disc at one end

No discs

Disc at both ends

Disc at one end

No discs

Disc at both ends

Compartmented

Compartmented

Non-compartmented
Clad Thickness

21 mils

21 mils

21 mils

21 mils

15 mils

21 mils

21 mils

15 mils

$21 \mathrm{mils}$

21 mils

$21 \mathrm{~m} 1 \mathrm{ss}$

15 mils

1. Cladding consists of AISI 304 stretch-formed stainless steel.

2. Tubes in Capsules 2-8 through 2-12 are 5.1 inches in length.

3. Tubes in Capsules 2-13 are 30.78 inches in length.

4. Tubed in Capsules $2-8$ through $2-12$ contain $\mathrm{UO}_{2}$ pellets enriched to $5.4 \%$ in U-235.

5. Each tube in Capsule 2-13 contains 39 UO pellets enriched to $2.7 \%$ in U-235, 2 pellets enriched to $5.4 \%$ and 6 pellets enriched to $6.8 \%$.

WCAP-2-13 capsule was inserted at the beginning of Cycle 113 in the MTR. The remaining capsules will be inserted at the beginning of the next cycle. 
WCAP-2-2, 2-5, and 2-7 Capsules

The three remaining process water capsules being irradiated at the MTR have received the following accumulated unperturbed thermal nvt at the end of Cycle Ill:

Capsule Number

WCAP-2-2

WCAP $-2-5$

WCAP-? -7 nvt

$9.8 \times 10^{20}$

$10.0 \times 10^{20}$

$9.4 \times 10^{20}$ 


\section{APPENDIX}

Section A - Design Data

Yankee Atomic Electric Company Reactor

I. Mechanical and Thermal

(All dimensions are for the "cold" core unless otherwlse specified.).

Total Heat output, Btu/hr

Total Heat Output, MW

Coolant Flow:

Total Rate, Ibs/hr

Heat Transfer Rate, Ibs/hr

Flow Area in Fuel Rod Cross Section, $\mathrm{ft}^{2}$

Velocity Along Fuel Rods, ft/sec

Pressure, psi

System Pressure, Nominal

System Pressure, Maximum

System Pressure, Minimum

System Pressure, Design

Total Drop Across Vessel

Drop Across Core

Heat Transfer

"Active" Surface, $f t^{2}$

Average Flux, Btu/hr-ft ${ }^{2}$

Maximum Flux, Btu/hr-ft2

Average Film Coefficient, Btu/hr-ft ${ }^{2}-{ }^{\mathrm{F}}$

Burnout Flux Ratio

$$
(\mathrm{Q} / \mathrm{A})_{\mathrm{BO}} /(\mathrm{Q} / \mathrm{A})_{\max } \mathrm{PO}^{* *}
$$

Bettis Plant Correlation, Btu/hr-fth

Thermal Conductivity of $\mathrm{UO}_{2}, \mathrm{Btu} / \mathrm{hr}-\mathrm{ft}-\mathrm{F}$

Temperature, ${ }^{\circ} \mathrm{F}$

Coolant in the Primary Loop, Average

Coolant in the Fuel Bearing Portion of the Core, Average

Coolant Rise in Core, Average

Coolant Rise in Vessel, Average

Film Drop, Average

Center of Fuel, Maximum

Outlet of Hol Charriel

$\Delta \mathrm{T}_{\mathrm{m}}$ at Heat Exchanger

Steam Temperature

Steam Pressure, psia

Coolant at Inlet to Vessel
First Core

$1,388 \times 10^{6}$ $392^{*}$

$37.8 \times 10^{6}$

$34.0 \times 10^{6}$

15.4

14.0

$$
2,000
$$

2,150

1,850

2,500

29.7 .

13.7

15,400

87,000

450,000

6,050

2.19

$9.80 \times 10^{5}$

1

514

516

33

14.4

651

4,700

603

37

475

540

499

* If center fuel temperature of $4500^{\circ} \mathrm{F}$ is used, the total heat output can be raised to $428 \mathrm{MW}$. Lifetime is reauced proportionately.

* POB - Point of Burnout. 


\section{Yankee Atomic Electric Company Reactor (Continued)}

First Core

Hot Channel Factors

$F_{Q}$, Heat Flux

5.17

$F_{\theta}$, Film Drop

$F_{\Delta T}$, Coolant Rise

7.36

3.36

General

Total Core Area, $\mathrm{ft}^{2}$

Equivalent Core Diameter, ft

Length-to-Diameter Ratio of Core

Length-to-Diameter Ratio of a Flow Channel

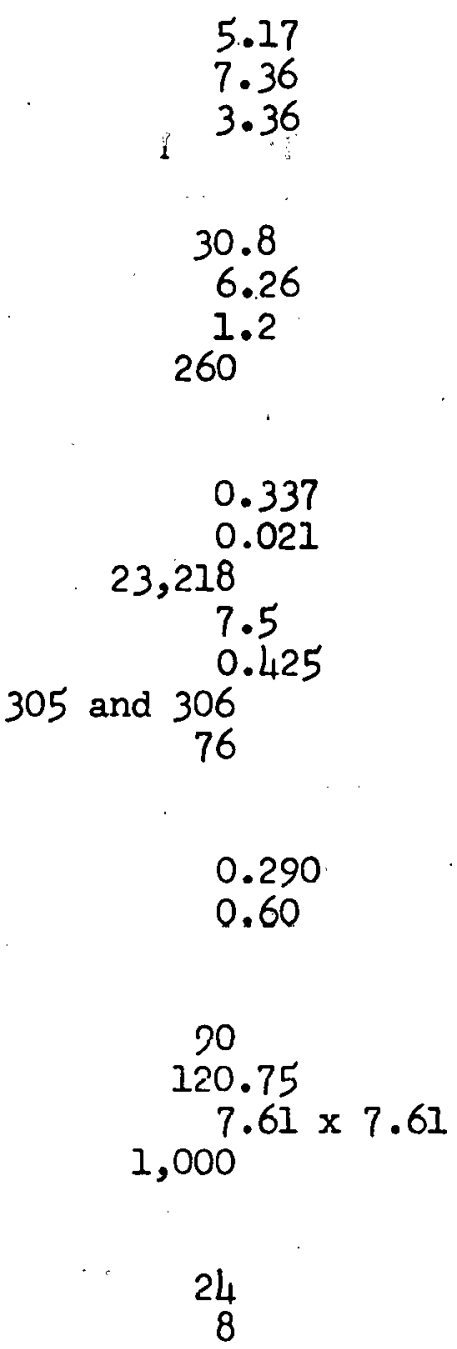

Fuel Rod

Outside Diameter, in.

Tube Wall Thickness, in.

Total Number of Rods

Fuel Length Per. Rod, ft

Rod Lattice, in.

Rods Fer Fuel Assembly

Total Number of Fuel Assemblies

76

Fuel Pellet

Diameter, in.

Height, in.

0.60

Fuel Assembly

"Active" Length, in.

Overall Length, in.

Sectional Dimensions, in.

Weight, lbs

8

Active

Shim

(The following dimensions are for the "hot" core.)

First Core

Fuel Rod

Outside Diameter, in.

0.339

Rod Lattice, in.

0.427 
Yankee Atomic Electric Company: Reactor (Continued)

II. Nuclear

First Core

Total Heat 0xtput, MW

Lifetime, $\mathrm{hr}$.

Burnup, MWD/Metric Ton Uranium, avg

Core Average Diameter, in.

Core Active Height (Between Fuel Ends), inches

Core Materials (Between Fuel Ends)

Fuel $\left(10.07 \mathrm{gm} / \mathrm{cm}^{3}\right)$

Water $\left(0.7814 \mathrm{gm} / \mathrm{cm}^{3}\right)$

Zirconium $\left(6.56 \mathrm{gm} / \mathrm{cm}^{3}\right)$

Stainless Steel $(8.03 \mathrm{gm} / \mathrm{cm} 3)$

Void (Gap Between Clad and Pellet)

Total

$$
\begin{gathered}
\text { Volume, in.3 } \\
\hline 138,000 \\
198,800 \\
12,600 \\
44,600 \\
4,900 \\
398,900
\end{gathered}
$$

$\mathrm{B}^{2}$, Geometric, $\mathrm{cm}^{-2}$ (Assumes Reflector Savings of $7.5 \mathrm{~cm}$ ) Volume Ratio, $\mathrm{H}_{2} \mathrm{O} / \mathrm{U}\left(18.7 \mathrm{gm} / \mathrm{cm}^{3}\right)$

Initial Enrichment (Atom Percent)

Final Enrichment (Atom Percent)

Resonance Escape Probability, p

Fast Fission Factor, $\varepsilon$

Age, $\tau, \mathrm{cm}^{2}$

$$
\begin{array}{r}
392 \\
10,066 \\
8,208 \\
75.1 \\
90 \\
\text { Wt., } 1 \text { bs. } \\
\hline 50,200 \\
5,610 \\
2,980 \\
12,900 \\
-- \\
\hline 71,690
\end{array}
$$

Typical performance data and nuclear parameters based on initial enrichement of $3.02 \%$ for the first core:

Initial Conversion Ratio

$k_{\text {eff }}$ (Cold, Clean)

(Hot, Equil. Xe) (Hot, Clears)

Pu Obtained, kg

Pu-240 Content (Atom Percent)

Fraction of Energy from:

$$
\begin{aligned}
& U-235 \\
& U-238
\end{aligned}
$$

$\mathrm{Pu}$

Nominal Shutdown Concentration of Chemical Poison,

Gms. Natural Boron/Liter of $\mathrm{H}_{2} \mathrm{O}$

Moderator Temperature Coefficient, $\frac{1}{\mathrm{k}} \frac{\partial \mathrm{k}}{\partial \mathrm{T}} / \mathrm{F}$ at $516^{\circ} \mathrm{F}$

Fuel Temperature Coefficient, $\frac{1}{k} \frac{j k}{j l} / \%$ at $516^{\circ} \mathrm{F}$
0.691

1.191

1.065

1.110

99.5

9.14

0.728

0.067

0.205 


\section{Section B - Information Availability \\ Westinghouse Atomic Power Department}

During the previous periods of the R\&D Program, the availability to (B) APD of documents and other sources of technical information from AEC facilities and contractors, pertaining to Nuclear Power Reactors was reported in the following:

1. The first year of the Contract (June 6, 1956 to June 30,.1957), was covered in detail by Report YAEC-30 dated September 30, 1957, entitled "Information Availability Report.

2. YAEC-44, Quarterly Progress Report, gave data on document availability for the period from July 1 . to September 30, 1.957 .

3. YAEC-52, Quarterly Progress Report, advised of the availability of documents and reports during the October 1 to December 31, 1957 quarter.

4. YAEC-65, Quarterly Progress Report, advised of the availability of documents and reports during the January 1 to March 31, 1958 quarter.

5. YAEC-87, Quarterly Progress Report, atvised of the availability of documents and reports during the April 1 to June 30, 1958 quarter.

The avallability of reports and documents during the third quarter of 1958 has continued to improve. Most reports of value and interest to the R\&D Frogram are received under the "Standard" and "Positive" distribtuion systems. Other reports, when ordered thru the TISE, are received promptly if available at the TISE; otherwise, a prompt and informative report with definite information is received.

The following quantities and types of reports and microcards were received by (i) APD as a result of being on the "Standard" and "Positive" distribution lists during the third quarter of 1958 :

\begin{tabular}{|c|c|c|}
\hline Month 1958 & Unclassified & Classified \\
\hline July & 842 & 7 \\
\hline August & 988 & 16 \\
\hline September & 857 & 16 \\
\hline
\end{tabular}


The following quantities of documents not on the "Standard" or "Positive" distribution lists were requisitioned and received during the third quarter of 1958:

Month 1958 July

August

September
Ordered

7
Received

11

10

7

On reports which were previously ordered, but not received, definite information was furnished promptly, such as:

$\begin{array}{lccc} & \text { July } & \text { August } & \text { September } \\ \text { "Denied or not available." } & 8 & 1 & 7 \\ \text { "Attempts will be made to obtain the report." } 4 & 5 & 8\end{array}$

Westinghouse APD remains of the opinion that considerable information developed for the naval pressurized water reactors and still classified would be of value to the Yankee Research and Development Program.

The type of information needed is that covering maintenance, operation, water chemistry, radiation, reactor physics and other experience and tests pertaining to pressurizer water reactors. The information released for the PWR Project is helpful but, at the present state of the art, additional information, particularly from plants with long experience records, can be most helpful and could reduce research and development costs by eliminating cuplication of effort.

Yankee Atomic Electric Company

The quantity of documents and replies to requests received by the Yankee Atomic Electric Company during the third quarter of 1958 has continued to show improvement. The availability of information applying to nuclear power reactors remains satisfactory.

Summaries of documents received as a result of requests, requested, and received under "Standard" distribution but not requested are:

Summary of Classified Documents Received - As of September 30, 1958

Total Documents Received

Total Documents Retained.

Total Documents Retumed 
Summary of Requested Unclassified Documents - As of September 30, 1958

Total Documents Requested

338

Documents Received and Retained

Documents Received and Returned (on Ioan)

Documents Not Yet Received (Include documents for which some notification was received i.e. not at TISE, no copies available, etc.)

Bocuments Denied

14

Summary of Unrequested Unclassified Reports Received on Standard Distribution As of September 30, 1958

Total Documents Received

617

Documents Retained

174

Documents Returned

443 
Section C - Abstracts of Trip Reports

Abstracts of trip reports written as a result of visits made by Westinghouse Atomic Power Department and Yankee Atomic Electric Company personnel to national laboratorles, installations of AEC contractors and privately owned facilities are contained in this section. Only those visits made for the purpose of furthering the progress of the YAEC Research and Development Program have been included.

To: Knolls Atomic Power Laboratory, Schenectady, New York (July 1-2, 1958) Visit made by:

\section{J. J. Iombardo - (1) APD}

The results of the post-irradiation examination of WCAP-1-2, 1-4, 2-3 and 2-6 process water capsules were obtained. Metho ds of cont inuing the cooperation between APD and KAPL personnel during the performance of the post-irradiation program were explored.

To: Argonne National Laboratory, Lemont, Illinois (July 2, 1958) Visit made by:

\section{A. Bournia - (1) APD}

Data were obtained on pressure drop runs in which air and water were used to simulate the steam voids in a two phase flow at atmospheric pressure. The problem of predicting pressure drops across sudden expansion and contraction of flow areas in a two phase flow system was discussed. The condition of fuel elements removed from the EBWR exposed to high and low heat fluxes was observed and reasons for the condition were given.

To: The Lummus Company, Neward, New Jersey (July 30-31, August 1, 1958) Visit made by:
C. D. Dishman - (1) APD
A. G. Thorp - APD

Removal of air from the primary loop section of the in-pile test loop was accomplished after several cycles of pressurizing and circulating loop water. Attempts were made to obtain flow data by operating the main flow pumps and recording the readings from the flow meter. A program was developed in order to obtain accurate flow data.

To: The Lummus Company, Newark, New Jersey (August. 19-20, 1958)

Visit made by:

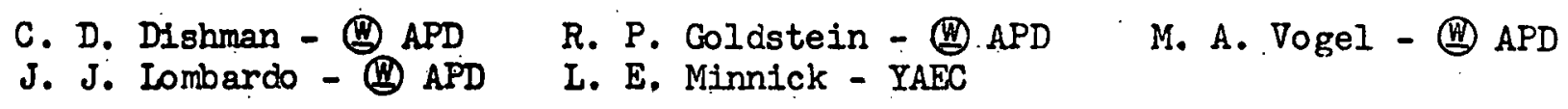




\section{Abstracts of Trip Reports (Continued)}

Loop operation flow data were established with various combinations of pump operation. Some instrument calibration and settings were made. Hydrostatic testing of the purification system was witnessed.

To: Westinghouse Atomic Equipment Department, Cheswick, Pa. (September 3, 1958) Vịsit made by:
E. Frisch - (IV) APD
G. Landau - (10) APD
I. Balog - (W) APD
P. B. Haga - (6) APD

The need for enlarging the inside diameter of the mechanism port in the reactor vessel head to accommodate the latch type control rod drive mechanism was presented. A delivery schedule and dimension requirements for machined lower mechanism housing adapters were discussed. Control rod.drive mechanism specifications and a detail drawing of the mechanism port were provided by (WT) APD personnel.

To: Bettis Plant, Pittsburgh, Pa.; PWR, Shippingport, Pa. (September 3, 1958)
W. E. Abbott - (W) APD
G. Reed - YAEC

Bettis Plant: The purpose of and results obtained from PWR flow measuring instruments and fuel and coolant thermocouples were discussed. Information was given on other instrumentation such as lncal boiling sonic detecturs, heat flux and coolant measuring devices, fuseable alloys to determine fuel assembly maximum temperatures and axial scanning flux wire thimhles.

PWR: Data obtained from PWR full power core instrumentation and experimental information instrumentation were discussed. Time, man power and computer analysis requirements to obtain core instrumentation data were reviewed.

To: The Lummus Company, Neward, New Jersey (September 3, 1958)

Visit made by:
G. L. Duke - (W) APD
A. G: Thorp - (1) APD
L. E. Minnick - YAEC

The price changes resulting from changes to in-pile test loop equipment were reviewed. The procedure for submittal of increases for approval - was agreed upon. A new date for the delivery of the test loop to the MTR was scheduled. The advisability of furnishing isometric drawings and photographs of the test loop to the MTR was discussed. A general discussion was held on the subject of (WV) APD personnel working at the MTR.

To: The Lummus Company, Neward, New Jersey (September 3-4, 1958) Visit made by:
C. D. Dishman - (10) APD 
Abstracts of Trip Reports (Continued).

Pump coast-down data for the in-pile test loop were obtained with all combinations of pump operation. Several loop components which require modifications were discussed. A program was established to incorporate the modifications prior to the operation test.

To: The Naval Reactor Testing Station, Scoville, Idaho (September 15, 16, \& 17,1958 )

Visit made by:
A: E. Voysey - (b) APD
W. J. Miller - YAEC

Operating experience with the SIW reactor was discussed with SIW personnel including primary system.long-lived activities, core instrumentation, bolling tests, and maintenance difficulties and their prevention. Information was obtained on industrial hygiene metho ds and operator training.

To: The Lummus Company, Newark, New Jersey (September 17, 18,\& 19, 1958) Visit made by :

C. D. Dishman - (6) APD R. P. Goldstein - (6) APD : I. E. Minnick - YaEC

Improper operation of the in-pile test loop three-way valve was observed during heating and pressurizing of the loop. An adjustment was made in pressurizer safety relief valve. Melting of the cast aluminum material surrounding the loop heater element occurred after three hours of operation of the loop heater. New heaters are to be provided using lower watt density heaters and aluminum-bronze cast material.

To: The Lummus Company, Newark, New Jersey (September 29-30, October 1, 1958) Visit made by:
J. J. Lumbardo - (W) ASD
A. Kricg $:=$ (4) $\Lambda P D$
C. D. Dishman - (9) APD.

The 120 hour operational test of the in-pile test loop was observed. During the test a complete check was made of the components and of the functional operation of the loop. From this check and previous negotiations, a IIst of items was presented to the Lummus Company for correction and action. 